\title{
"A LOT OF DIFFERENT STREAMS": QUESTIONING “JAZZ” AND COMPOSING BEYOND GENRE
}

BY

\section{JASMINE LOVELL-SMITH}

A thesis submitted to the Victoria University of Wellington

in fulfilment of the requirements for the degree of

Doctor of Musical Arts

Victoria University of Wellington

2021 


\section{ABSTRACT}

\section{"A Lot of Different Streams": Questioning “Jazz" and Composing Beyond Genre}

Many composers currently prominent in the jazz world draw upon multiple musical traditions or genres to create their work. The varied compositional activities of composers Nicole Mitchell, Tyshawn Sorey and Wayne Horvitz problematize attempts to classify their work as belonging to a single genre. Drawing on my interviews with these three composers and my analysis of selected works, I seek to understand how they conceptualize their compositional work and its relationship to the various musical traditions that have influenced them. Using Fabian Holt's genre framework and George E. Lewis's concept of the Afrological as critical tools, I propose that the work of these composers prioritizes spontaneity and agency, foregrounding process and transformation instead of a more fixed work concept, and claiming a mobility of practice that connects them strongly to the legacy of the AACM. I also use these concepts as ways to reflect on my own creative work developed throughout the DMA, and my relationship to the genre label of jazz.

The creative portfolio developed as part of this research incorporates influences from multiple streams of music-making, particularly the traditions of jazz, creative music and Western classical music. The submitted works include Cerulean Haze, for jazz octet and 5-piece chamber ensemble (13:00); Sanctuary, a suite in three movements for 11-piece ensemble (18:49); "Noche Oscura" for 10-piece ensemble (6:48); "Moorings (Titahi Bay)" for chordless jazz quartet (6:00); "Jimmy," "Nuevo Azul," "Neither Here nor There" and "Metamorphosis" for improvising quartet. These works explore extended jazz and modal harmonic language; strategies for extending songformderived compositional forms into larger, through-composed works; and varying degrees of notational specificity. The inclusion of improvisation is prioritized in each work. 


\section{ACKNOWLEDGEMENTS}

This research project would not have been possible without the help and support of many people. I would first like to thank my supervisors, Dave Wilson and John Psathas, for their generous and insightful guidance and mentorship. Thank you Dave for supporting the development of my scholarly voice, for challenging me to grow as a researcher and academic, and for asking the right questions. And thank you John for always being encouraging about my compositions, and for challenging me to dig deeper, and to make music that I love.

Many thanks are also due to composers Nicole Mitchell, Tyshawn Sorey and Wayne Horvitz for contributing their time and their voices to be interviewed for this project. It was a pleasure to meet you all, and I learned so much from our conversations.

I would also like to thank the musicians and friends who performed the works in this creative portfolio: the Noveltones, Stroma, the Jac, the CODE Quartet, and the Arthur Street Loft Orchestra.

Thanks also to Michael Norris and the NZSM Composition department (including my coworking companion Simon Eastwood), and to Inge van Rij for introducing me to the discourse of the work concept.

Thank you to RNZ Concert, SOUNZ, Thomas Voyce and Michael Sutherland for recording and documenting the works included in this portfolio. Thanks to the Wellington Jazz Festival for commissioning "Moorings (Titahi Bay)" and the Susan Rhind Award for commissioning Cerulean Haze. Thanks also to the Creative New Zealand Edwin Carr Foundation Scholarship and the Lankhuyzen/Whetu-Kairangi Masonic Trust, for supporting my residency at the Atlantic Center of the Arts with Nicole Mitchell.

Last (but certainly not least!) thank you to my family and friends for all of their support over the past three and a half years, especially Amelia, Roshan and Olivia. And the biggest thanks of all to my husband and fellow doctoral student Cristohper. Your love and support makes everything possible. Te amo! 


\section{CONTENTS}

ABSTRACT

ACKNOWLEDGEMENTS

II

CONTENTS

III

CHAPTER 1: CONTEXT AND METHODOLOGY

1

$\begin{array}{ll}\text { INTRODUCTION } & 1\end{array}$

PERSONAL CONTEXT

INTERVIEW METHODOLOGY

$\begin{array}{ll}\text { INTERPRETATION } & 6\end{array}$

$\begin{array}{ll}\text { STREAMS OF MUSIC-MAKING } & 7\end{array}$

$\begin{array}{ll}\text { QUESTIONING JAZZ } & 7\end{array}$

$\begin{array}{ll}\text { WESTERN CLASSICAL MUSIC AND NEW MUSIC } & 10\end{array}$

$\begin{array}{ll}\text { CREATIVE MUSIC } & 11\end{array}$

INTERSECTING STREAMS: PRECEDENTS TO THE WORK OF MITCHELL, SOREY AND HORVITZ 12

$\begin{array}{ll}\text { THIRD STREAM } & 13\end{array}$

The Association For THE AdVANCEMENT OF CREATIVE Musicians (AACM) 15

THE DOWNTOWN SCENE (OR DOWNTOWN 2) 17

$\begin{array}{lr}\text { STRUCTURE OF THE EXEGESIS } & 19\end{array}$

CHAPTER 2: COMPOSING BEYOND GENRE: TRANSCENDING, IGNORING, OR IN-

BETWEEN $\quad 21$

GENRE IN POPULAR AND ART MUSIC

THE "SYMBOLIC VIOLENCE" OF GENRE

$\begin{array}{ll}\text { FABIAN HOLT'S GENRE FRAMEWORK } & 24\end{array}$

$\begin{array}{ll}\text { NETWORKS } & 25\end{array}$

$\begin{array}{ll}\text { CONVENTIONS (CODES, VALUES AND PRACTICES) } & 26\end{array}$ 
MUSIC BETWEEN GENRES, AND “AESTHETIC DENSENESS” $\quad 27$

CONCLUSIONS: GENRE IN THE WORK OF SOREY, MITCHELL, AND HORVITZ 28

CHAPTER 3: DISCOURSES ABOUT JAZZ AND GENRE

$\begin{array}{ll}\text { DISCOURSES ABOUT JAZZ AND GENRE } & 31\end{array}$

$\begin{array}{ll}\text { AFROLOGICAL ASPECTS OF DISCOURSE } & 38\end{array}$

$\begin{array}{ll}\text { PERSONALITY } & 38\end{array}$

$\begin{array}{ll}\text { AGENCY } & 40\end{array}$

$\begin{array}{ll}\text { SOCIAL INSTRUMENTALITY } & 41\end{array}$

$\begin{array}{ll}\text { SPONTANEITY AND COLLECTIVITY } & 42\end{array}$

$\begin{array}{ll}\text { NETWORKS AND INFLUENCES } & 44\end{array}$

$\begin{array}{ll}\text { HEARING CONNECTIONS ACROSS GENRE BOUNDARIES } & 47\end{array}$

$\begin{array}{ll}\text { INFLUENCE ACROSS GENRE WORLDS } & 48\end{array}$

$\begin{array}{ll}\text { CONCLUSIONS } & 50\end{array}$

CHAPTER 4: ONTOLOGY AND FORM: WORKS IN PROCESS $\quad 52$

THE WORK CONCEPT IN JAZZ AND CREATIVE MUSIC

FORMING IMPROVISATION, IMPROVISING FORMS

ANALYSIS OF SELECTED WORKS: FORMS IN PrOCESS

WAYNE HORVITZ’S “BERLIN 1914”: “...CUT FROM THE SAME CLOTH...” 59

NICOLE MitCHELL’s “EgOES WAR”: “...COLLIDING DUALITIES...” 62

TYSHAWN SOREY’s THE INNER SPECTRUM OF VARIABLES: “ ...A HIGHLY FLEXIBLE SCORE...” 65

$\begin{array}{ll}\text { CONCLUSIONS: PROCESSUAL FORM } & 72\end{array}$

CHAPTER 5: BEYOND THE PAGE: REALIZING WORKS IN PERFORMANCE 76

BANDLEADING AS COMPOSITION: CHOOSING COLLABORATORS 76

ENSEMBLE DYNAMICS: COMPOSITIONAL STRATEGIES TO ALLOW FOR PERFORMER AGENCY 80

$\begin{array}{ll}\text { WAY OUT EAST } & 81\end{array}$

THE INNER SPECTRUM OF VARIABLES

$\begin{array}{ll}\text { MANDORLA AWAKENING } & 85\end{array}$ 
WRITING FOR NEW MUSIC AND WESTERN CLASSICAL ENSEMBLES: THE "COMPOSER" MODEL 88

$\begin{array}{ll}\text { FUNDING AND SYSTEMIC CONSTRAINTS } & 91\end{array}$

CONCLUSIONS: THE SPECTRUM OF VARIABLES 93

CHAPTER 6: REFLECTIONS ON THE CREATIVE PORTFOLIO 95

$\begin{array}{ll}\text { COMPOSITIONAL PROCESS } & 97\end{array}$

$\begin{array}{ll}\text { PORTFOLIO OVERVIEW } & 99\end{array}$

$\begin{array}{ll}\text { FINDING COMMUNITY AND COLLABORATORS } & 100\end{array}$

$\begin{array}{ll}\text { THE NOVELTONES } & 101\end{array}$

“METAMORPHOSIS" 103

$\begin{array}{ll}\text { Cerulean Haze } & 104\end{array}$

$\begin{array}{ll}\text { THE ARTHUR STREET LOFT ORCHESTRA } & 108\end{array}$

$\begin{array}{ll}\text { CONCLUSIONS } & 111\end{array}$

\begin{tabular}{lc} 
BIBLIOGRAPHY & 114 \\
\hline
\end{tabular}

APPENDIX A: INTERVIEW WITH TYSHAWN SOREY 122

$\begin{array}{ll}\text { SKYPE INTERVIEW, JUNE 2, } 2018 & 122\end{array}$

APPENDIX B: INTERVIEW WITH WAYNE HORVITZ 136

$\begin{array}{ll}\text { SKYPE INTERVIEW, SEPTEMBER 12, } 2018 & 136\end{array}$

APPENDIX C: $1^{\text {ST }}$ INTERVIEW WITH NICOLE MITCHELL 163

$\begin{array}{ll}\text { SKYPE INTERVIEW, SEPTEMBER 28, } 2018 & 163\end{array}$

APPENDIX D: 2 2D $^{\mathrm{NNTERVIEW} \mathrm{WITH} \mathrm{NICOLE} \mathrm{MITCHELL}} \quad 174$

IN-PERSON INTERVIEW, NEW SMYRNA BEACH, FL JULY 10, 2019 


\section{CHAPTER 1: CONTEXT AND METHODOLOGY}

\section{Introduction}

In this exegesis, I focus on the work and discourses of three currently active composer/improvisers, Nicole Mitchell (b. 1967), Tyshawn Sorey (b. 1980) and Wayne Horvitz (b. 1955), and upon the broader themes of musical genre, ontology, and Afrological musical traditions. Mitchell, Sorey and Horvitz are all well known within the jazz world, yet do not identify primarily (or in some cases at all) as jazz musicians. They each compose for a wide variety of ensemble formations ranging from improvising ensembles to orchestral and chamber ensembles, and their works are programmed in jazz festivals and in concert halls. They explore various points of the spectrum from composed to improvised music, showing a diversity and mobility that is not typical of jazz practice. These composers are not members of a single movement, generation or scene, and though they do share some common aspects of their musical lineages, they offer three distinct perspectives on contemporary music-making that is not constrained by preconceived ideas about musical genre.

This exegesis also reflects on my own compositional work created during the course of this doctorate. During the time that I have been researching, listening to and engaging in discourse with these three artists, I have also been composing and performing new music for a variety of ensemble formations, and navigating experiences in the art worlds of jazz and new music in Wellington, New Zealand. My discourse with Mitchell, Sorey and Horvitz has served as a catalyst for reflection upon my own aesthetics and musical values, and my relationship to the various musical traditions that have influenced me.

\section{Personal context}

In the years since I began my journey towards the elusive career of "jazz musician" in 2001 at Massey University in Wellington, New Zealand, my sense of my musical identity and of what kind of music I want to make has been gradually changing. Over the past nineteen years I have inhabited music scenes in Wellington; New York City; Middletown, Connecticut; and Morelia, Mexico. Along the way I have encountered a wide variety of jazz scenes and practices, and I have also participated in other genre worlds including free improvisation, creative music and new music. My 
sense of who I am as a musician has shifted from feeling uncomplicatedly like a jazz saxophonist and composer, to feeling less interest in some aspects of mainstream jazz practice and more of a desire to be a "composer" without the jazz qualifier.

It was this impulse that led me to pursue graduate studies in composition, initially in the Master of Arts program at Wesleyan University, where I worked with Anthony Braxton and Paula Matthusen, and currently in my doctoral studies in composition at the New Zealand School of Music-Te Kōkī. During my doctoral studies, I have focused on composing music that integrates composition and improvisation for ensembles that combine instrumentation commonly used in jazz with that more strongly associated with the Western classical music tradition. I chose to study with John Psathas - a classically-trained composer also influenced by jazz, rock and world music - with the goal of writing chamber and orchestral works. I sought to expand the compositional resources at my disposal in order to access a greater variety of instrumentations, harmonic possibilities, formal organizational strategies, and performance contexts for my music. At the same time, my love of improvisation, spontaneous collective creativity, and what Ted Gioia has called the "aesthetics of imperfection" (Gioia 1990, 56) endures, and I also sought to incorporate this as a central aspect in much of my music. I see many aspects of value in both jazz and Western classical music traditions (as well as in other musical traditions), and I see an opportunity for rich, meaningful and mutually beneficial collaborations across these musical worlds. My goal has been to write music that is not a self-conscious, uncomfortable hybrid, but rather a personal expression drawing upon any and all of my musical and life experiences as translated through sound.

This genesis of this research project was my interest in the various intersections between the traditions of jazz and Western classical music. After spending considerable time engaging with historical examples of the ongoing dialogue between these musical traditions, including the work of twentieth-century art music composers, the third stream, and works by composers from the Association for the Advancement of Creative Musicians (AACM), I concluded that it was important for me to engage with contemporary composers whose work transgressed these genre boundaries, and who incorporated improvisation as a central element in their work. I chose to focus on Nicole Mitchell, Tyshawn Sorey, and Wayne Horvitz because of my deep admiration for both their creative work and their career trajectories. I perceived of each of their careers as occupying this intersection between the worlds of jazz and Western classical music, a preconception that was 
challenged as I dug deeper into their work. While their music appealed to me aesthetically, I also found aspects of their work mysterious and opaque, which suggested to me that it would be a rich source of study and investigation.

In order to gain a deeper understanding of the works and perspectives of each of these composers, I chose to interview each composer, hoping to hear in their own words how they conceptualize their work, and how they think about their careers and place in the musical landscape. ${ }^{1}$ These three artists have received relatively little attention in scholarship thus far relative to the degrees of artistic success and critical acclaim they have attained. Because of this, the interviews that I have conducted contribute to filling the gap in scholarship on these composers, which I hope will stimulate further research on their work and serve as a resource for others also interested in the work of these artists.

\section{Interview methodology}

My approach to exploring the work of Sorey, Mitchell and Horvitz included conducting interviews with the composers, as well as analysing a selected work by each composer. Education researcher and academic Irving Seidman suggests that interviews should be conducted because of "an interest in understanding the experience of other people and the meaning they make of that experience" $(1991,3)$. It is this understanding of the composers' experience, specifically with reference to my selected works, that I hoped to gain through the interview process.

My choice of methodology was influenced by previous scholarship from a number of discursive streams, including ethnomusicology, musicology and philosophy. This included the jazz scholarship of Ingrid Monson (1996), Paul Berliner (1994) and Eric Porter (2002), and seminal writings on creative music by George E. Lewis (2008) and Graham Lock (1988). Fabian Holt's scholarship on genre in popular music was invaluable (2007), as was the recent work of Eric Lewis on the "work concept" (2019). I was also influenced by the musicological analysis of Ekkehard Jost (1974), Paul Steinbeck (2017), and Christopher Coady (2016). As well as these scholarly sources, I have also found inspiration in the tradition of musicians interviewing fellow

\footnotetext{
${ }^{1}$ For the idea of constructing my DMA research around a composer interview project, I am indebted to Rafael Piccolotto de Lima, whose dissertation I read at an early stage of my research (de Lima 2017).
} 
musicians, with examples including Arthur Taylor's Notes and Tones (Taylor [1977] 1993), as well as interviews by pianist Ethan Iverson on his Do the M@th blog and Jeremiah Cymerman's 5049 Podcast; and by self-reflective writings by musicians about their own practice, including John Zorn's Arcana series of essays by musicians (2000), Anthony Braxton's Tri-Axium Writings (1985), Wadada Leo Smith's Notes (8 Pieces) Source a New World Music: Creative Music (2015), and other published writings, often in the form of liner notes. I have chosen to draw influence from all of these discursive streams because, as a composer, performer, and scholar, I see them all as necessarily intertwined in my own life and work.

My selection of composer subjects was based on the subjective criteria of my interest in and affinity for their work. I made initial contact with each interview subject via email, and conducted my interviews over Skype (in addition to one follow-up interview with Nicole Mitchell conducted in person). I was previously acquainted with Tyshawn Sorey, having met him at several workshops and performances while I was living in New York City, and again in Banff in 2015. I met Nicole Mitchell for the first time during our initial Skype interview, and then met her in person in 2019 when I was selected to participate in a composition residency with her at the Atlantic Center for the Arts. I also met Wayne Horvitz for the first time during our Skype interview, and at the date of writing have not yet met him in person.

In preparation for undertaking the interviews, I investigated sources on interviewing in the social sciences (Seidman 1991), as well as some sources relating to journalistic interviewing (Obrecht 2011; Tynan 2011). These highlighted a number of practical concerns, including the need for informed consent (Seidman 1991, 48-60), the importance of agreeing on a structure and duration for the interviews in advance (Seidman 1991, 9-15) and the necessity of doing research to prepare for the interview (Obrecht 2011). My preliminary research also emphasized the necessity of considering the positionality of interviewer and participant with regards to how race, gender, class, age and any other power differentials play into the interview dynamic (Seidman 1991, 83-90). I have considerable differences with all of my composers in these aspects. In my case, as a 33-year-old (at the time) white woman from New Zealand wishing to interview two African American musicians, the aspect that struck me as potentially of most concern was race. This is due to the long history of writing and criticism about jazz and other Black American music 
being dominated by white American and European male writers, and often omitting the voices of the musicians themselves.

In my own research I have been particularly drawn to work that foregrounds the voices of musical artists, especially when it is written by fellow practising musicians, whether this be scholarly writing, interviews, or self-reflexive writings by the artists themselves. I agree with Ingrid Monson that “...the only ethical point of departure for work in jazz studies and ethnomusicology remains the documentation and interpretation of vernacular perspectives..." $(1996,6)$. I hope that my interviews can serve as a contribution to this discursive tradition and that, through speaking directly with the musicians, I am less likely to misinterpret their work. However, I acknowledge my own subjectivity, and that both the interview process and the process of analysing the material has been intrinsically subjective.

A considerable volume of published writing exists about these three artists, particularly journalistic writing in the form of interviews and reviews. In preparation for conducting the interviews, I did preliminary research: reading and listening to interviews, listening to their recorded works, and also reading reviews of their recordings. I conducted semi-structured interviews, in which I had a number of questions or topics prepared to discuss. These included the story of how each artist began composing; their creative processes; their relationship to jazz and genre; their approach to form and structure; composing for improvisers; performance contexts; artistic communities and influences.

Once the interviews began, I found it difficult to stick to my planned list of topics, and, for the most part, I chose to follow the flow of the conversation in order to include topics that were of most interest to the composers themselves. This resulted in three interviews with overlapping but not identical scopes. I transcribed the interviews, lightly editing them for clarity, and provided the transcripts to the composers so that they could offer any corrections or changes they deemed necessary. The complete interviews are included in Appendices A, B, C, and D, and I have drawn on the interviews throughout the body of my exegesis in my discussion of the work of these artists. 


\section{Interpretation}

At the interpretation stage, my reading stressed the importance of coming to the transcribed interview text with an open mind, rather than trying to make it fit a preconceived hypothesis (Seidman 1991, 110). Through multiple readings of the interviews, I extracted sections that I thought were most relevant to my research, identifying themes in each interview. I then crossreferenced the sections that had caught my interest, looking for common themes across the interviews. The themes that emerged at this stage included: early compositional experiences and education; compositional influences; relationship to jazz and genre; experiences writing for new music or chamber ensembles and orchestra; scenes and artistic communities; approaches to combining improvisation and composition; performance contexts; approaches to form and structure; hearing commonalities between music from different traditions; and ensemble dynamics. In some cases these themes emerged because I asked similar questions of the artists (for example, I began each of the three Skype interviews by asking each artist about how they got started with composing). In other cases, common themes appeared without me anticipating them, such as the importance of a "personal" sound or vocabulary (respectively) to Sorey and Horvitz, or the fact that all three composers mentioned the work of Charles Mingus as a musical influence, or that both Horvitz and Sorey were influenced by the polytonality of Béla Bartók.

My relationship with each interviewee and the conditions under which the interviews were conducted were varied, as was the amount of time each had available to spend in conversation, and the rate (and quantity) that each person spoke. This has led to diverse results, and I recognize that in my roles as interviewer, editor, and interpreter, I have substantially mediated the results. I do not claim to have a full understanding of these artists or to represent the totality of who they are. These are "partial truths," (Clifford 1986) and these artists are still living, working and evolving, as am I, so all of these ideas will be in flux - as Clifford writes, “CCultures' do not hold still for their portraits" $(1986,10)$. All of these interviewees have been provided with transcripts of their interviews and given the opportunity to make edits or corrections, and it is my hope that they will be content with the way they have been represented within the limitations of the project. 


\section{Streams of music-making}

The title of the exegesis comes from a quote by Tyshawn Sorey, in which he contextualized his varied compositional language as follows: " I always had a lot of different streams...in my writing that I would go to for inspiration" (Sorey, interview by Brian Pace 2018). This struck me as an apt metaphor not only for Sorey's work, but also for that of Mitchell and Horvitz.

The music discussed in this exegesis poses challenges to traditional generic categories such as "jazz" and "classical." However, somewhat ironically, it proves to be almost impossible to problematize these types of genre labels without simultaneously employing them, as became clear both during the interview process and in the course of writing this exegesis. Here, I lay the groundwork for some of the complexities involved in understanding the meanings of some of these terms, beginning with the genre label "jazz."

\section{Questioning jazz}

I don't consider myself a jazz musician; I don't consider myself any kind of musician. I consider myself a student of music. I'm a trans-idiomatic musician.

Tyshawn Sorey (Milkowski 2011)

I'm an American composer, not a jazz composer [...] My whole life, I've never thought of myself as a jazz composer. I've always been in this weird grey area where jazz musicians are the only people who don't consider me a jazz musician. Everybody else does.

Wayne Horvitz (McBride 2015)

I really don't think much about genre. There are different musical styles that swim in my veins, that I've been attracted to and absorb. They subconsciously influence my creativity. I consider myself to be a "creative musician," because with "creative" music people don't have a specific expectation and they can be open to receive what you bring.

Nicole Mitchell (Locks 2009) 
I became aware of the work of Tyshawn Sorey, Nicole Mitchell and Wayne Horvitz through their prominence and renown in the world of jazz. Yet, early on in my research, it became clear that, in discussing their work, I would not be able to use the word "jazz" unchallenged. Tyshawn Sorey is perhaps the most outspoken of the three in rejecting the "jazz" label being applied to his work. Wayne Horvitz also distances himself from it in a more measured, humorous way. And Mitchell, while not rejecting the term outright, prefers to refer to her music as "creative music." 2 The discourses of each of these artists relating to the word jazz will be further explored later in this exegesis, but for now, it suffices to say that, somehow, these artists are known both for being and for not being jazz musicians. As such, they are part of a long tradition of musicians associated with the jazz tradition who have rejected or expressed reservations about the genre label "jazz." So what is this word "jazz," and why is it so controversial?

Jazz is most commonly understood to be a music genre or style. Defined by Fabian Holt as "a constellation of styles connected by a sense of tradition," genre is the primary way in which our society sorts music into categories for marketing and performance $(2007,18)$. However, there is no consensus in the jazz world about where exactly the boundaries of the jazz genre lie. ${ }^{3}$ Throughout its history, jazz has been through a number of radical shifts and transformations, each one decried in turn as "not jazz" before eventually being included in (or excluded from) the jazz canon (DeVeaux 1991). Today's jazz world is a veritable mélange of sub-genres and fusions, with the various factions all drawing the boundaries of what they consider to be "jazz" in different places. ${ }^{4}$ So, if jazz cannot be pinned down as a genre with certain characteristics, what might it be instead?

At the centre of many discussions about jazz is the issue of jazz and race. Jazz is today generally understood as a music that sprung from primarily African American origins, and also

${ }^{2}$ Nicole Mitchell, interview by author, Skype, September 27, 2018.

${ }^{3}$ The 2012 volume Jazz/Not Jazz, edited by Dave Ake, Chares Hiroshi Garrett and Daniel Goldmark, makes an essential contribution to this discourse about the boundaries of jazz - the authors state in their introduction that "jazz possesses no essential characteristics" $(2012,5)$.

${ }^{4}$ One of the more influential of these factions is the neoclassical movement, which emerged in the 1980s and is often associated with Jazz at Lincoln Center and its director, Wynton Marsalis. This movement promoted the idea of jazz as "America's classical music," tending to focus on recreation of classic jazz repertoire and historical performance practice over the tradition of innovation and experimentation that had also characterized much of jazz practice (G. E. Lewis 2008, 441). For more on this see Radano (2009, 269-73). 
understood to be a "hybrid cultural practice, with African, European, Latin American, and North American cultural roots" (Porter 2002, xvii). In the words of George Lewis "African American culture remains central to the narrative of world jazz" (2016, xi). The music emerged around the beginning of the twentieth-century in the southern United States, largely from communities of the African diaspora, and the majority of the canonic figures in the music have been African American. However, the word jazz itself has been contentious for a number of the genre's notable figures, who felt that it was used as a way to define, pigeonhole, or limit their possibilities. Canonical artists, including Duke Ellington and Max Roach, rejected the term, on aesthetic or racial/political grounds, and contemporary artists including Nicholas Payton continue this tradition, rejecting “jazz" as an "oppressive colonialist slave term" applied by white critics to Black music (Lewis 2016, xiv). This gives weight to Lewis's description of jazz as “a race, gender and class-inflected social location within which sound and musical practice take on additional meanings" (2008, xliv). However, many artists worldwide still prefer to use "jazz" in lieu of any of the proposed alternatives. Jazz does not mean one thing, and there is no single or unified jazz community that agrees on what it is. It is a word that some people reject and others embrace, and it is associated with a plurality of traditions and current-day practices, some of which are also known by other names, and which have varying degrees of relationship to the African American roots of jazz (Lewis 2016, xx).

Other writers have argued that, rather than a musical style with specific musical characteristics, jazz is more akin to an approach or process. This argument is more in line with the personal stance on the meaning of the word from which I began my research. ${ }^{5}$ Others have highlighted the social or political dimensions of the interactions that take place in jazz ensembles, with Mark Laver describing how it is frequently deployed as a metaphor for freedom $(2014,538)$, and John Szwed defining it as "maximum individualism within the framework of spontaneous egalitarian interaction" (Lewis, George E. 2008, xi-xii). This brief overview demonstrates that "jazz" can mean many different things in different contexts, and this ambiguity around the meaning and significance of the word contributes to my ambivalence about using the term to describe both my

\footnotetext{
${ }^{5}$ Norman Meehan discusses "jazz as process" in his doctoral dissertation (Meehan 2015, 88-93), drawing on
} arguments by Christopher Small (1987), Olly Wilson (1974; 1983) and Ingrid Monson (2007). 
music and the music of Mitchell, Sorey and Horvitz. However, I believe it is still a useful term for referencing a musical tradition that, for now, has no other widely accepted name. ${ }^{6}$

\section{Western classical music and new music}

The next stream of music-making I will discuss is that of Western classical music. I have chosen this terminology in lieu of other equally imprecise terms such as "classical music" and "Western art music" to refer to the diverse tradition of European musical composition stretching back to before the Renaissance era. This tradition continues into the twenty-first century and has expanded throughout the world outside of Europe. It has been the traditional subject of study in musicological and academic contexts.

Also known in some circles as "serious," "fine" or "concert" music, Western classical music has traditionally been associated with high art, viewed as a pinnacle achievement of Western culture. It has often served as the normative standard against which jazz is judged, although in many ways the two traditions emphasize different musical values. Yet, while these two traditions are often posed as opposites, Western classical music is also one of jazz's musical ancestors: as pianist Ethan Iverson has argued, “'Jazz harmony' is 18th- and 19th-century European harmony plus black music (especially the blues) and the added note harmony of early $20^{\text {th }}$-century French and Russian composers" (2017).

Whereas the history of jazz is often told as a narrative centred around exceptional performers such as Louis Armstrong or Miles Davis, the history of Western classical music is usually told as a history of composers: Bach, Beethoven and Brahms (and many others). While improvisation was practised at certain periods in the history of Western classical music, it has generally been deemphasized in favour of a greater emphasis on composition and interpretation of pre-composed material.

${ }^{6}$ In "Foreword: Who is Jazz?" Lewis quotes Nicholas Payton choosing to call his music "Postmodern New Orleans Music" (xiii-xiv). Payton has also advocated for the term \#BAM, or Black American Music, on his blog (Payton 2014). The Art Ensemble of Chicago's motto was "Great Black Music." George Lewis describes Lester Bowie's understanding of this term as "historically emergent rather than ethnically essential," in that Bowie understood the white jazz composer Stan Kenton to be a member of the tradition of "Great Black Music" (Lewis, 2008, 449). 
The more recent history in this lineage is often known by the moniker of "new music," a term that arose in each of my interviews. This term seems to have been in use as early as the 1920s, as composer Henry Cowell founded a quarterly publication of this name in 1927, devoted to the publication of scores of "non-commercial works of artistic value" (Good and Nicholls 2001). Eric Drott describes the field of "post 1945 new music" as one in which new aesthetic proposals are constantly being made in opposition to those that preceded $(2013,15)$. In common usage it serves not only to describe contemporary or recent compositional activity from the Western classical tradition, but also describes a type of ensemble that focuses on performance of this type of repertoire (for example, the International Contemporary Ensemble, who have performed works by both Sorey and Mitchell).

\section{Creative music}

Another relevant term employed in this exegesis is "creative music." Nicole Mitchell employs this discourse to describe her music, and it is strongly associated with the Association for the Advancement of Creative Musicians (AACM), an artist-run collective organization formed in Chicago in the 1960s. ${ }^{7}$ The term is used to refer to original composition not limited by any genre definition. According to AACM member and scholar George Lewis, "Being a 'creative musician' in this sense is an act of perpetual becoming, an assertion of mobility that can take one anywhere at all, beyond the purview of genre or method" (2008, xxxv). This statement clarifies that creative music is not intended as a musical genre, but rather indicates a claiming of artistic agency on the part of the musician, and an unwillingness to subscribe to existing genre categories. In this sense, it has a similar function to terms like "avant-garde," "experimental" and "free improvisation," all of which have been proposed to provide alternatives to established ways of doing things. Yet, as Eric Drott argues, "any work aiming to declare its independence from a particular genre necessarily ratifies a latent connection with the latter through the very act of negation that it performs" (2013, 7). In the case of "creative music," it seems likely that the established way of doing things that the AACM composers wanted to distance themselves from was the genre label of jazz. However, although labels such as "creative music" present themselves as operating outside of genre and

\footnotetext{
${ }^{7}$ For more about the AACM, see G. E. Lewis (2008).
} 
style, in each of these cases, something of a tradition of music-making has solidified around each label, meaning that they function in a way analogous to genre. ${ }^{8}$

\section{Intersecting streams: precedents to the work of Mitchell, Sorey and Horvitz}

When undertaking this research project, I started from the assumption that the work of Mitchell, Sorey and Horvitz was situated at the intersection of the jazz and Western classical traditions. As such, in my preliminary reading and listening research, I attempted to gain a sense of the historical precedents for compositional work at the intersection of these two traditions. The musical traditions of jazz and Western classical music have been in dialogue, each one exerting influence on the other, since the early days of jazz. ${ }^{9}$ These areas of cross-pollination and intersection have included jazz-influenced concert music by both European and American composers, which primarily occurred in the 1920s, with prominent examples including Gershwin's Rhapsody in Blue, Ravel's Piano Concerto in G and Violin Sonata No. 2, and Aaron Copland's Music for the Theatre. (Ehle 1972; Fauser 2007). Music by Black classical composers including Florence Price, William Grant Still and the concert work "Yamekraw" by James P. Johnson provided other examples of the influence of blues, jazz and other African American forms on concert music (Coady 2016; Howland 2006).

Duke Ellington's concert works and suites are another often cited example of jazz that was influenced by concert music, as are some of Charles Mingus's early works such as his tone poem "The Chill of Death." The influence of classical music on jazz became more mainstream in the West Coast jazz scene of the 1950s. Colloquially known as "cool jazz," this music showed a marked influence from chamber music, with ensembles including the Modern Jazz Quartet exploring improvising using classical forms, and Gerry Mulligan and Jimmy Giuffre using counterpoint in their compositions. A more populist movement, "jazz with strings," can be traced in its origins back to Paul Whiteman's "symphonic jazz" in the 1930s, but some of the best-known

${ }^{8}$ Eric Drott argues something similar about post-1945 new music (2013), drawing on an argument by Jason Toynbee about free improvisation (Toynbee 2000).

${ }^{9}$ Liesa Karen Norman's DMA thesis provided a useful overview of some of these historical movements. (Norman 2002). 
examples date from the 1940s and 1950s including Charlie Parker with Strings (1946), and Frank Sinatra's Songs for Swingin' Lovers! (1956) (Howland 2012). Some more recent examples of music for jazz ensembles including strings or woodwinds include: John Scofield's Quiet (1996); Charlie Haden's American Dreams (2002); Wayne Shorter's Alegria (2003); Michael Brecker Quindectet's Wide Angles (2014); and Seamus Blake's Superconductor (2016). These albums could be seen in some ways as an extension of the "jazz with strings" movement, as the string and woodwind parts generally play a colouristic, accompaniment role, although the orchestrations on these albums tend to be more intricate and active than the "jazz with strings" of the 1940s and 1950s. ${ }^{10}$

While these examples demonstrate a longstanding interest in combining elements of the jazz and Western classical traditions among composers, three movements seem to provide more direct precedents for the work of Mitchell, Sorey and Horvitz. These include the third stream movement, the AACM, and the New York Downtown scene.

\section{Third stream}

The third stream was a musical genre that was named and codified by Gunther Schuller, a composer, performer and scholar who was active in both classical and jazz contexts, and who would become the movement's principal composer and proponent. Though he initially mentioned the term in 1957 in a lecture at Brandeis University (Schuller and Greenland 2013), Schuller's first written definition of third stream appeared in 1961, when he defined it as "a new genre of music located about halfway between jazz and classical music" $(1989,114)$. Schuller did not claim to be the inventor of this phenomenon but rather to be putting a name to something that had already been going on for some time, with historical precedents including the jazz-influenced music of Ravel, Debussy, and Milhaud (Schuller 2000). Schuller's earliest collaborator in this project was pianist and composer John Lewis, ${ }^{11}$ and other associated composers would include Jimmy Giuffre, William Russo and Andre Hodeir (Schuller 1989, 118).

${ }^{10}$ Several of the works from my album Yellow Red Blue (2016) featured string quartet in this type of accompaniment role.

${ }^{11}$ For an in-depth investigation into Lewis's body of work, see Coady (2016). 
The codification of the third stream genre proved quite controversial for several reasons. The first reason was that it was seen as an attempt to legitimize jazz and grant it more cultural capital through associating it with Western classical music (Gioia 1997, 297, 349; 1992, 158; Joyner 2000, 76). This was connected with the second reason, which had to do with race: some critics saw third stream as a European dilution which threatened the integrity of jazz as an African American art form (Baraka 1999, 228; Joyner 2000, 73). The third reason was that people felt that the combination of jazz and classical music resulted in a combination that was unsatisfactory according to the aesthetic criteria of both genres (Hentoff and Goldberg 1961, 45; Joyner 2000, 73). Nevertheless, third stream concerts did also receive positive reviews (M. Williams 1979, 299304; J. S. Wilson 1960), a number of innovative recordings of third stream works were released, and an educational wing of the movement was created with the establishment (by Schuller) of the Third Stream Department at the New England Conservatory in 1972, which has evolved into the current-day “Contemporary Improvisation” major (Blake 1976, 32).

By 1981 Schuller's definition of third stream had evolved to become inclusive enough "to embrace, at least potentially, all the world's ethnic, vernacular and folk music" (Schuller 1989, 120). At this point the definition ran the risk of being so all-encompassing that it was synonymous with other words like "fusion" or "hybrid," arguably becoming somewhat redundant. This updated definition of third stream has not been widely adopted. When used in a contemporary context, third stream tends to be used either to describe any jazz/classical hybrid (Blumenthal et al. 2001) or as reference to a historical style period and the music written by Schuller or one of his contemporaries during this time (Joyner 2000; Teachout 2000).

Much of the writing about third stream is devoted to explaining the definitions of the term or debating the validity of the concept, rather than discussion of the music itself (Hentoff and Goldberg 1961). Perhaps this disproportionate ratio of discourse to music was part of the downfall of the genre. The third stream never really took off, with the period of the most intense third stream activity ending around 1965 (Joyner 2000). The term is not very commonly used as a genre descriptor today. Posterity has judged third stream fairly harshly, as it has been given short shrift in (or all but written out of) some of the more recent jazz history texts (Gioia 1997; Shipton 2001). 
Joyner refers to third stream as a failure, and certainly the genre did not have wide commercial appeal. Paradoxically, while third stream never seems to have caught on, the practices of hybridization that Schuller was interested in when he formulated the idea of the third stream are more alive than ever. More and more composers are writing music that draws from multiple traditions, and more and more performers possess the necessary skills for moving between multiple and diverse music styles.

George Lewis has referred to third stream as a "performative amalgamation" of the two traditions $(2008,359)$, and has described the movement as having "failed to realize or support the complexity of black musical culture's independent development of a black experimentalism that, while in dialogue with white high culture was...strongly insistent upon the inclusion of the black vernacular, including the imperative of improvisation" $(2008,360)$.

Schuller's model of hybridization is only one of many, and the AACM and the New York Downtown scene also seem to provide clear precedents for the type of genre-fluid activity the work of Mitchell, Sorey and Horvitz exemplify. None of my interviewees has cited the third stream as an influence on their work, although music writer Adam Shatz argued (perhaps controversially) in a post on the London Review of Books blog that the music of Henry Threadgill, Wadada Leo Smith and Tyshawn Sorey could be considered third stream (Shatz 2016).

The Association for the Advancement of Creative Musicians (AACM)

An influence that all three of my interview subjects do share in common is that of the AACM. The organization was founded in Chicago in 1965 by Muhal Richard Abrams, Philip Cohran, Jodie Christian and Steve McCall to create a forum for developing and presenting the original compositions, or "creative music," of its members. Like the third stream composers, the AACM composers were active in breaking down barriers between the worlds of jazz and Western classical music. However, AACM member and commentator George Lewis sees important differences between the two movements, and has described the third stream approach to combining jazz and Western classical music as "culturally collagist rather than interpenetrative" (Lewis 2008, 340).

While the third stream movement enjoyed some of the infrastructure associated with Western classical music (for example, compositions were commissioned by Brandeis Festival of the Arts), 
the AACM operated instead with a grassroots, collectively organized model, self-funding independent performance opportunities for its African American members. The organization had a strong political aspect related to other African American movements of the time such as the Black Power movement (Lewis, George E. 2008, ix). Members John Shenoy Jackson and Muhal Richard Abrams wrote in a 1973 article that "the AACM intends to show how the disadvantaged can come together and determine their own strategies for political and economic freedom, thereby determining their own destinies" (Radano 1992, 86). Self-determination was a fundamental aim of the AACM, which manifested both aesthetically (in the artistic choices of the members and the ways in which they chose to define their music), and practically, in the way that organization produced and promoted the work of its own members.

There was a strong current of Afrocentricity in the organization (Radano 1992, 86), and Radano has described the members generally moving away from harmony (strongly associated with European music and associated cultural dominance), and towards melody and rhythm (1992, 90). However, many AACM members were also significantly influenced by music from the Western classical tradition, and the use of what Radano called the "abstract, non-tonal soundworld of modernism" $(1992,93)$ combined with jazz-derived materials could result in music that bore some similarities to the third stream.

A key aesthetic difference between the two movements was that the music of the AACM musicians incorporated the advances made in the intervening years in jazz, particularly those in improvisational practice instigated by "free jazz" musicians such as Ornette Coleman and Cecil Taylor, including non-harmonically determinate and collective approaches to improvisation with more temporal fluidity and less rigidity around instrumental roles.

It is impossible to generalize about the musical aesthetics of the AACM as a whole. An unnamed AACM member has said: "If you take all the sounds of the AACM musicians and put them together, that's the AACM sound, but I don't think anyone's heard that yet" (Lewis, George E. 2008, xxvi). The relationship of the genre label of jazz to the music of AACM members is complex; while many of the members had experience playing jazz before entering the organization, Lewis emphasizes in his history of the organization that the participants consciously chose to define their music as "creative music" rather than jazz, choosing "to articulate a mobility 
of practice that in relatively nonracialized circumstances would be seen as operating outside the frame of jazz" (2008, xxxv). For AACM members, "creative music" implied original composition, but it did not imply any specific genre affiliation (Lewis, George E. 2008, x). Despite this discursive strategy on the part of the AACM membership, much of the work of AACM members has been framed in critical discourse in light of its relationship to jazz, for example musicologist Ekkehard Jost's chapter on the organization in his monograph Free Jazz (1994). Prominent AACM members have also received a significant amount of coverage in jazz publications (with member Wadada Leo Smith notably winning "Jazz Artist of the Year" and "Jazz Album of the Year" in the 2017 DownBeat Critics Poll).

Some of the most well-known AACM members include Anthony Braxton, Henry Threadgill, Muhal Richard Abrams (1930-2017), George Lewis, and the members of the Art Ensemble of Chicago. Nicole Mitchell is also a key figure, and was the first woman president of the organization. Tyshawn Sorey has cited the AACM as an important influence on him, particularly in the collective's focus on self-determination, and in the examples of Black composers among its members (Guzelimian et al. 2017). He has also studied with AACM members Anthony Braxton (at Wesleyan University) and George Lewis (at Columbia University). Horvitz has mentioned the Art Ensemble of Chicago as an important musical influence. ${ }^{12}$ The organization remains active, with branches both in New York and Chicago.

\section{The Downtown scene (or Downtown 2)}

There have been multiple New York music scenes known by the moniker of Downtown, but the one most relevant to this research was based in Manhattan's Lower East Side during the 1980s and 1990s, and centred around venues including Tonic, the Knitting Factory and the Kitchen. Emerging in the wider cultural context of a breakdown in cultural hierarchies and ideas about high and low art that took place during the 1960s and 1970s (Dessen 2003, 166), the Downtown scene "drew together experimentally inclined musicians with varied backgrounds, in jazz and free improvisation, garage rock, blues, and classical composition, who were intent on the unlikely

\footnotetext{
${ }^{12}$ Wayne Horvitz, interview by author, Skype, September 12, 2018.
} 
project of bringing all these idioms into dialogue"13 (Barzel 2015, 2). George E. Lewis has described the music emerging from Downtown as "often timbrally and dynamically disjunctive, with rapid and frequent changes of mood and extremes of dynamics, extensive use of timbres reminiscent of rock, and strong interface with popular culture" (2002b, 235).

Saxophonist John Zorn was one of the principal instigators of this scene, and the Radical Jewish Culture movement (instigated by Zorn) was a notable current. Other associated artists included guitarist Fred Frith, harpist Zeena Parkins, guitarist Elliott Sharp, guitarist Bill Frisell and (most salient to this research) Wayne Horvitz. Lewis points out that the Downtown scene was generally coded as white, and Downtown artists were lauded for their genre mobility at a time when AACM artists were not. Though there was intersection between the Downtown scene and the members of the 1970s loft jazz scene (in which a number of AACM members participated) and the contemporaneous M-Base collective, writing about the Downtown scene has tended to downplay the influence of Black music on the downtown artists, instead generally portraying it as being in the lineage of academic experimental "classical" composition in journalism and musicology. ${ }^{14,15}$ Much of the work of Downtown artists is documented on John Zorn's Tzadik record label, and the discourses of Downtown musicians and other like-minded artists (including Mitchell, Sorey and Horvitz) are documented in the series of writings by musicians on music called Arcana, also edited by John Zorn (Zorn 2000).

The Downtown scene is still influential, although rising Manhattan rents have displaced many artists and venues from the Lower East Side. Venues including the Knitting Factory and Roulette have relocated to Brooklyn. A more recent downtown venue, the Stone, operated by John Zorn,

${ }^{13}$ George E. Lewis, drawing on the work of sociologist Samuel Gilmore (1987), writes that New York Western classical composition worlds were also often referred to by subdivisions of Uptown, Midtown and Downtown, with Downtown in that case referring to composers such as John Cage, Philip Glass, Philip Corner, Robert Ashley, LaMonte Young (and venues such as the Kitchen, and Roulette). George Lewis refers to this as Downtown I and to the Zorn-affiliated, post-1980 composers as Downtown II. Here I have chosen to refer simply to the Downtown scene, as within the jazz world this is likely to be understood as synonymous with Downtown II (Lewis 2008, 330).

${ }^{14}$ For further discussion of this see Dessen (2003).

${ }^{15}$ Lewis is uniquely positioned to comment on the relationship between these communities as he served as a nexus between them: in his role as curator of the Kitchen in the 1980s he programmed an early gig featuring John Zorn and a number of his collaborators, and Lewis can be heard on a number of recordings on the Tzadik label. 
was the principal home of this scene from 2005 to 2018, after which time the venue's programming was moved to its current location at the New School. Nicole Mitchell, Tyshawn Sorey and Wayne Horvitz have each presented their work at the Stone. The continued influence of the Downtown scene on the contemporary jazz scene is demonstrated through the critical acclaim accorded to a number of its members, and the greater fluidity between genre worlds of jazz, experimental, rock and many other genres that have occurred since the 1980s.

\section{Structure of the exegesis}

The chapters that follow draw on my interviews with the three composers as source material, while also incorporating material from other interviews and, in some cases, from the artists' own writings. Chapter 2 focuses on a discussion of musical genre. Here I outline the genre framework proposed by Fabian Holt, and introduce some of the complexities that the works and discourses of Mitchell, Sorey and Horvitz present to simplistic genre-based categorization. Chapter 3 further develops this discussion, drawing extensively on my interviews with the three composers in order to discuss their discourses about jazz and genre. Here, I introduce George E. Lewis's concept of Afrological sociomusical systems, proposing this concept as a framework through which to view the discourses of the three composers. I also discuss the networks the composers are part of, and the way they contextualize their work by referencing their musical influences.

In Chapter 4, I rely less on my interview materials, shifting my focus to analysis of a selected work by each composer: specifically, Horvitz's “Berlin 1914”; Mitchell's "Egoes War” and Sorey's The Inner Spectrum of Variables. I frame my analysis within the broader context of the discourses of ontology and musical form, as applied to the jazz and creative music traditions, with a particular focus on the scholarship of philosopher Eric Lewis. In Chapter 5, I discuss the practices involved in realizing the works of the three composers in performers. Here I return to drawing on my interviews with the three composers, in combination with the genre scholarship of Holt.

In Chapter 6, I change the focus to a discussion of my own creative portfolio developed during the process of this research. In this chapter I reflect on the creative process, and the experience of making music that exists within multiple genre worlds, drawing on my consideration of aesthetics, 
genre and streams of music-making in the work of these composers to critically reflect on my own work in its similarity and difference. 


\section{CHAPTER 2: COMPOSING BEYOND GENRE: TRANSCENDING, IGNORING, OR IN-BETWEEN}

I began my research into the music of Sorey, Mitchell and Horvitz assuming that their work represented a hybrid of jazz and Western classical music. However, as I continued my research, this type of $1+1=2$ formula began to seem like an increasingly inadequate way to describe it. The work of these composers is not of one well-established genre, nor a simple combination of two elements. Rather, their music references (or signifies on) the various traditions that have influenced them; not only jazz and Western classical music, but also the work of the AACM and the Downtown composers, rock and blues (Horvitz), new music (Sorey) and Malian music (Mitchell), among many others.

These composers traverse the boundaries between composition and improvisation, composer and performer, jazz and Western classical music, and popular music and art music. They each combine a range of approaches and strategies in the realization of their creative visions. While these artists are all prominent in the world of jazz, and fluent in its traditions, they do not necessarily identify as jazz musicians. They may also have visibility in the Western classical or new music worlds, but do not necessarily identify as "of" those worlds either. Describing themselves variously as a "creative musician," a "trans-idiomatic musician" and simply "an American composer" (see quotations in Chapter 1), Mitchell, Sorey, and Horvitz have carefully defined their own personal musical landscapes and canons of influence and tradition. Simply put, they conceptualize their work as existing outside of the bounds of musical genre. Yet, when their music makes its way out into the world, it (and they) must navigate the musical terrain of our contemporary world, which is largely organized according to genre categories.

Some of the recent activities of Mitchell, Sorey and Horvitz signal towards the various genre worlds they move between: Sorey has headlined at iconic jazz venue the Village Vanguard and has also presented new works at the Ojai Music Festival (a prominent new music festival). In 2019 he was Opera Philadelphia's composer in residence. Horvitz's recent releases include works for orchestra and string quartet, each featuring an improvising soloist (Those Who Remain, 2018), and a much less densely composed album for piano trio and electronics (The Snowghost Sessions, 2018). Mitchell's 2017 album Mandorla Awakening: Emerging Worlds was named Jazz Album of 
the Year by the New York Times, and she received a Champion of New Music award from the American Composers Forum in 2018.

Discussing the work of Sorey, Mitchell and Horvitz necessarily involves grappling with the issue of what language to use to describe or classify their work, and by extension, grappling with the concept of musical genre. The work of Mitchell, Sorey and Horvitz combines aspects of multiple musical traditions, presenting difficulties if one were to attempt to classify it under a singular genre label. In this chapter, I aim to reach a deeper understanding of the nature of the work of these three composers by considering it in relation to the framework for genre developed by Fabian Holt. This chapter takes as its underlying assumption that genres can be analysed for codes and other conventions, and are characterized by rules and principles (Holt 2007, 22-24; Fabbri 1981, 54-59). Holt argues that "there are genres of music and music between genres, but not music without genre" $(2007,2)$. Though the music of these composers may not be of a specific genre, it is clearly related to other music that has come before it. But what is the nature of this relationship, and how can that best be articulated?

Each of these three artists tends to avoid describing their own work using genre-based terminology. In Sorey's own words:

I've never really wanted to put things in categories because I felt that that would limit my overall perspective on what I think music should be... my music focuses on many different types of music-making, different types of ensemble behaviour, and my work also transcends generic boundaries. (MacArthur Foundation 2017)

So what does it mean to make work that "transcends" genre? What is the nature of these "generic boundaries" that the work of these composers ignores or transcends? Are they stylistic, aesthetic, procedural or social?

Though Holt defines genre as necessarily collective, he also argues that it is important to engage with music on an individual basis in order to understand its wider generic context (2007, 7). Perhaps, through examining this particular music, we can shed some light on the nature of genre and, particularly, of jazz. 


\section{Genre in popular and art music}

According to Jennifer C. Lena and Richard A Peterson, "Genre is a conceptual tool most often used to classify varieties of cultural products, particularly in the fields of visual art, popular culture, video games, film, literature, and music" (2008, 697). As Simon Frith writes, "generic labels are in fact amongst the critic's most essential tools" $(1999,90)$. Indeed, it is one of the principal ways that music, especially popular music, is described, marketed and organized for dissemination in the contemporary music landscape.

As mentioned in Chapter 1, jazz is commonly understood to be a musical genre, and it also occupies an ambiguous position somewhere between popular and art music. Scholarship around musical genre is currently more commonly associated with the study of popular music. In the Western classical tradition, genres have been traditionally thought of as dividing works into categories on the basis of form or instrumentation (for example, a symphony, an art song, or a string quartet). However, since the break with tradition enacted by high modernist composers in the 1950s, composers became "less concerned to exemplify genres than to make their own statement" (Samson 2001). Works of new music are generally not thought of as belonging to a genre, but instead as autonomous works of art (Drott 2013, 2-3, drawing on Dahlhaus and Adorno) with the discourse of the "work concept" (discussed further in Chapter 4) occupying a similar place in classical musicology to that of genre scholarship in popular music. ${ }^{16}$ However, as Eric Drott argues, terms such as "new music," "experimental," "modernist" and "post-modernist" ultimately function in a way very similar to genre labels such as "rock" or "jazz" (2013, 7-8).

\section{The "symbolic violence" of genre}

Since genre labels seem so useful, why then is there such a long tradition in (and beyond) jazz of artists objecting to generic classification of their work? While categorizing by genre involves grouping similar things together, it is also an approximation that "necessarily minimizes certain features and exaggerates others" (Drott 2013, 9). Therefore, generic categorization can seem inaccurate, or like an oversimplification that ignores unique features of the work.

\footnotetext{
${ }^{16}$ As Eric Lewis writes, "genre theory...is really just ontology with its hands dirty" $(2019,5)$.
} 
Also, genre labels are often based not so much on the music itself but on extramusical aspects. Historically, race has been a big factor in distinguishing between musical genres (Brackett 2005) and even today genre labels "are often imposed from without via acts of cultural segregation" (E. Lewis 2019, 140). Thus, seemingly neutral genre labels can instead function as "instrument[s] of symbolic violence, whose baleful effects may be seen in the sanctions that musicians incur when they stray from the norms promulgated by the genre with which they are affiliated or in the exclusions that result from the habitual identification of certain genres with certain social groups" (Drott 2013, 8).

Mitchell, Sorey and Horvitz are not eager to be categorized or labelled. However, it is worth interrogating the terms that Sorey, Mitchell and Horvitz do use to describe their music. Sorey uses "trans-idiomatic" after the saxophonist and composer Anthony Braxton, ${ }^{17}$ as meaning music that transcends idiom. ${ }^{18}$ Mitchell uses "creative music," a terminology commonly used within the AACM. ${ }^{19}$ And Horvitz's "American composer" is a much more general and less specific definition, claiming a national identity rather than a stylistic one, although perhaps also signalling towards the influence of Americana and blues on his music. Are these in some way genre terms themselves? Trans-idiomatic and creative music both seem to be, in different ways, words that actively distance themselves from genre categorization, as does "American composer," in a different sort of way, by virtue of its extreme generality.

\section{Fabian Holt's genre framework}

Fabian Holt, building on Franco Fabbri and other scholars of genre, proposes a genre framework that aims to bring "genre scholarship closer to musical practice and experience" (2007, 3). Holt defines musical genre as "a type of category that refers to a particular kind of music within a distinctive cultural web of production, circulation, and signification" (2007, 2), and as "a constellation of styles connected by a sense of tradition" $(2007,18)$. These definitions indicate

\footnotetext{
${ }^{17}$ Sorey worked with Anthony Braxton during his Masters study at Wesleyan University.

${ }^{18}$ Holt describes "idiom" being another word that is frequently used interchangeably with both genre and style.

19 George Lewis writes that "Being a "creative musician" in this sense is an act of perpetual becoming, an assertion of mobility that can take one anywhere at all, beyond the purview of genre or method" (2008, xxxv).
} 
that, for Holt, musical genres are characterized not only by the presence or absence of discrete musical elements, but by broader procedural, contextual and socially shaped aspects.

Holt's genre framework is divided into the following aspects: networks (social and discursive); conventions (codes, values and practices); mainstream dialectics; genre and the corporate music industry; and media and cultural practice. The aspects of most relevance to my study are conventions (codes, values and practices), networks, and (to a lesser degree) mainstream dialectics. While it would also be fascinating to apply Holt's last two categories to the work of these artists, that is beyond the scope of this research. I am less concerned with the dissemination and reception of their work, being more focused on how it is conceptualized and executed by the artists (conventions) and within the contexts of their communities of creative collaborators (networks), as well as on how that relates to the related genre worlds of jazz, Western classical music, new music, and creative music (mainstream dialectics). Holt also proposes a "poetics of music in between genres," which provides a useful way of interrogating/discussing music that cannot be easily categorized yet is related to existing categories. I will return to these poetics later in this chapter.

\section{Networks}

For Holt, networks in genre are "...the communicative relations between the many different agents that create and sustain a genre's identity" $(2007,20)$. This can be at the level of community or scene, whether local or international, and encompasses in-person communication and other types of discourse such as journalism, criticism, and online discussion. As previously mentioned, Mitchell, Sorey and Horvitz are all well-known in the world of jazz, yet also work beyond jazz's traditional boundaries. They also each have strong associations with local scenes or communities of like-minded musicians. Mitchell, who was based in Chicago for many years, is a long-time member and former president of the Association for the Advancement of Creative Musicians, and also identifies strongly with the wider Chicago Black Arts community. In Horvitz's early career, he was a member of the New York Downtown scene of the 1980s and 1990s, and he is now a key figure in the Seattle improvised and new music scenes. Sorey's career has been primarily based in New York, and he has worked extensively in both the New York avant-jazz scene, and the New York new music scene. Sorey also has connections to both the AACM and the New York 
Downtown scene - he worked with AACM luminaries Anthony Braxton and George E. Lewis during his graduate studies at Wesleyan University and Columbia University, and has also worked as a sideman with musicians associated with the Downtown scene such as Dave Douglas, John Zorn and Butch Morris (these Networks are further discussed in Chapter 3). Consideration of these various lineages and affinities, and the discourses and ideologies that are prevalent in each adds useful context that aids in understanding the musical works and perspectives of these three composers.

\section{Conventions (codes, values and practices)}

The codes, values, and practices that constitute Holt's category of genre "conventions" are particularly useful for my analysis of the genre-fluid work of Mitchell, Sorey and Horvitz. The jazz and Western classical traditions, as well as other genres or traditions the composers draw from, feature various conventions, whether related to musical content (codes), aesthetics (values) or process (practices). Examples of relevant codes in the work of these composers include their choices of instrumentation, the formal organization of their works, and their approaches to harmonic and rhythmic organization. Sorey's choice to employ a combined instrumentation of string trio (a code of Western classical music) and a piano trio with bass and drums (a code of jazz) on The Inner Spectrum of Variables suggests that this work will not fit neatly into categorizations of either jazz or Western classical music, and may even flow between genres. Horvitz's Gravitas Quartet and Mitchell's Mandorla Awakening ensemble similarly employ instrumentations that trouble straightforward genre categorization. Formal aspects of the works of these composers signify ${ }^{20}$ on codes of jazz, creative music, and Western classical music, whether in their use of cyclical forms and vamps (jazz), open or collectively improvised sections (creative music), or through-composed, teleological development (Western classical music).

The discourses of Mitchell, Sorey and Horvitz signal towards some of the values that they prioritize in their creative work. In their discourses, they emphasize spontaneity, collectivity and the importance of a "personal" sound or compositional vocabulary, all of which values are connected with the jazz tradition. (This is further discussed in Chapter 3.) Their works also

${ }^{20}$ For more on signifying as a practice common in Black music and other arts, see Monson (1996); Tomlinson (2002); Gates (1988). 
demonstrate practices associated with a variety of genre worlds. These include composing for their own ensembles (as is common in the worlds of jazz and creative music) and writing commissioned words for pre-existing ensembles (common in Western classical and new music). Their works include both complex, notated material (typical of Western classical and new music) and a variety of approaches to improvisation, from soloistic (more typical in jazz) to collective (common in creative music, and further discussed in Chapter 5).

\section{Music between genres, and "aesthetic denseness"}

Holt also proposes a "poetics of music between genres" that accounts for music that cannot be encompassed within a single category $(2007,158)$. In engaging with the work of Sorey, Mitchell and Horvitz, I have found myself puzzling over how to articulate how their music relates to genre categories both in their own conceptions and as the music lives in the world. The work of these composers does not fit neatly into any one genre category. However, thinking about it in relation to theories of genre points towards some of the ways they are seeking to transcend, ignore, subvert, or exist in between genre categories. I do not mean to argue that their work has been created in some way "in relation" to the idea of genre, but rather that thinking analytically about their work through the lens of Holt's genre framework illuminates their complex use of diverse codes, values, and practices that are associated with an entanglement of different genre categories.

For Holt, the concept of a poetics of music between genres "emphasizes the cross-generic and processual qualities of music to break the stasis that categories produce. There is a nomadic edge to the ethos of this poetics because it engages in movement and transformation" $(2007,159)$. I see this "nomadic edge" at work in the spirit of constant change and evolution that runs through the work of these composers. They are each, in their own ways, combining codes, values, and practices associated with genre worlds of jazz and Western classical music, as well as codes from other musical traditions, and their approaches to the combination of these and other materials are changing and evolving over time.

There is significant precedent for this exploration of the space between genres in the work of the AACM composers, and also artists from the Downtown scene. Of the AACM composers, Lewis writes that 'Being a 'creative musician' in this sense is an act of perpetual becoming, an 
assertion of mobility that can take one anywhere at all, beyond the purview of genre or method" (2008, xxxv). Lewis has also identified a shared proposal in the writings of AACM members Wadada Leo Smith and Anthony Braxton "that a new musical order will necessarily involve some degree of code-switching across traditions and genres" (2004a, 165). Eric Lewis has identified similar characteristics in the work of the Art Ensemble of Chicago, which he gives the name "aesthetic denseness." For him, aesthetic denseness describes "musical performances that positively invite consideration from numerous genre positions" (E. Lewis 2019, 8) a description that is equally well applied to the work of Mitchell, Sorey and Horvitz.

\section{Conclusions: genre in the work of Sorey, Mitchell, and Horvitz}

The work of Mitchell, Sorey and Horvitz challenges cultural hierarchies and destabilizes binary conceptions such as art music versus popular music, jazz versus classical music, and composer versus improviser, which divide understandings of musical landscapes. Their careers combine the model of the individual jazz composer/performer who performs original music, prioritizing improvisation and spontaneous collective creativity, with that of the classical composer who is commissioned, awarded grants, has a place in the academy and composes works for other people to perform.

The work of these composers lives in the space between genres, and their music is characterized by the fluidity with which they mix the conventions of various traditions. Holt proposes that "spaces between genres are as valid sites of inquiry as are genres themselves" (2007, 160). Following Holt, I argue that this is part of what is important about the work of these three composers. The contemporary musical landscape holds broad possibility for combination across genre lines, yet musical worlds remain remarkably segmented along genre lines, which are in many cases more socially determined than musically determined. While genre may be a useful concept for grouping like things together, articulating relationships and subdividing the musical world into navigable sub-sections, it can equally cause divisions between musical traditions and musicians who otherwise might share much in common. These divisions can also cause listeners not to encounter or to disregard as irrelevant certain music on the basis of aspects that are more social than musical. 
As Holt argues, "Discourse plays a major role in genre making. A genre category can only be established if the music has a name" $(2007,3)$. The discourses of these composers often tend towards denial or avoidance of genre associations, particularly with jazz, and this refusal to name the work actively resists it being categorized as part of a wider genre grouping. In so doing, these composers maintain aesthetic freedom and agency to constantly reinvent their creative practices, a stance which is in line with the artists of the AACM and the Downtown scene, and which facilitates some of the innovative and characteristic aspects of their work.

So, what relationship does the work of these composers bear to jazz? These three musicians are all well versed in jazz traditions, but have complex relationships with jazz as a category, partially because their music engages with much broader aesthetics than are typically included under the rubric of jazz. While Sorey and Horvitz do not identify with the jazz genre label, I believe that their work, as well as Mitchell's, nevertheless demonstrates varying degrees of codes, and, particularly of values and practices, that are congruent with the jazz tradition. As so many composers and musicians flow between genres today, it is crucial for people making music to consider that music that might not be immediately recognizable as "jazz" might nevertheless employ jazz values and jazz practices.

As for the definition of jazz itself, if jazz is understood as a fixed and codified genre, necessarily demonstrating fidelity to 1950s practice, featuring swing, cyclical forms and soloistic improvisation, then the music of these composers certainly does not have much to do with jazz. However, if jazz is understood to be a continuously evolving tradition of radicalism and innovation, that has been constantly in dialogue with and influenced by a variety of other traditions, then perhaps the work of these composers could comfortably be encompassed within this lineage after all. I suppose it all depends who is telling the story. 


\section{CHAPTER 3: DISCOURSES ABOUT JAZZ AND GENRE}

In his autobiography Beneath the Underdog, Charles Mingus includes a letter that he wrote to the music critic Nat Hentoff from Bellevue hospital. He had been listening to a recording of a Bartók string quartet, and he wrote, "Hearing artists like this reminds me of my original goal but a thing called 'jazz' took me far off the path and I don't know if I'll ever get back. I am a good composer with great possibilities and I made an easy success through jazz but it wasn't really success — jazz has too many strangling qualities for a composer" (Mingus [1971]2010, 280, emphasis mine).

Mingus is one of many composers generally known as a jazz musician, but whose output and creative impulses transcended the commonly conceived boundaries of the genre. In this letter, Mingus seems to feel restricted by the genre label of jazz. I imagine that Mitchell, Sorey and Horvitz might sympathize with this assessment. As mentioned in Chapter 1, each of these composers is simultaneously known for both being and not being jazz musicians. Each of these artists employs discourses that refute or complicate their categorization as jazz musicians. In doing so, they are in good company, along with Duke Ellington, Max Roach, Abbey Lincoln and Nicholas Payton, among others (Lewis, 2016, xii-xiv).

This chapter examines the discourses employed by Mitchell, Sorey and Horvitz about jazz, genre, and the musical lineages and traditions that influence them. In the first part of the chapter, I consider the discourses of these composers concerning the word jazz and the broader concept of musical genre. The second part of the chapter introduces George E. Lewis's concept of the Afrological and describes the relationship I perceive between the composers' discourses and this sociomusical system. In the third part of the chapter, I consider the networks that these composers are a part of, and the influences that they cite, as another way of situating their work in a broader social and historical context. In the fourth part of the chapter, I examine the discourses of the composers for evidence of how they conceptualize music across generic boundaries.

In undertaking this research, I wanted to understand how these composers conceive of their work and its relationship both to jazz and to the various other musical traditions that influence them. Throughout the chapter, I supplement my interview materials with other sources from previous interviews with these musicians. Each of these three artists is adept at articulating their 
perspective on genre issues. In most cases, their discourse about these topics has appeared in journalistic interviews, though each has also published some writing (of liner notes, as part of John Zorn's Arcana: Musicians on Music series (Mitchell 2017a; Sorey 2009; Horvitz 2009), and, in the case of Sorey, in his doctoral exegesis (Sorey 2017a)). I have occasionally drawn on this wider discourse in the discussion that follows, where it addresses topics not covered in our interviews. My selection of excerpts and my interpretations are, of course, my own.

\section{Discourses about jazz and genre}

In each of my conversations with these composers, we touched (whether directly or indirectly) on their relationship to the genre label "jazz." These composers are prominent in the world of jazz, yet both their work and their discourses complicate attempts to categorize them simply as jazz musicians. Each of the three composers has an individual and complex relationship with the word jazz. When I asked whether she identifies with the word jazz, Nicole Mitchell responded:

I completely understand the struggle that people have had with embracing the identity of being a jazz musician, because, if you look at a lot of our elder musicians and what they had to go through, and how they were being limited in what their possibilities are, just for being labelled as a jazz musician, and the lack of respect and opportunities that were presented to them for being labelled as a jazz musician, then, I mean, that's something that we have to always keep in mind. And yet, there's an amazing legacy that goes along with that word that I want to be connected to, that I feel that I am connected to. I mean, I don't want to disconnect from Sarah Vaughan and Ella Fitzgerald, and Charlie Parker. I mean, there's a direct relationship there with, you know, Duke Ellington, and Archie Shepp, and all these great musicians that have been put within that framework of being a jazz musician. Like [Charles] Mingus and [Thelonious] Monk, you know. So, while a lot of people may not want to take on that identity, and they may take on the label of being a creative musician or they might say 
"I just play music," some people say "I play Black music" you know, I identify with the word jazz, I don't squirm away from it. ${ }^{21}$

Here, Mitchell acknowledges jazz as a "race gender and class inflected social location" (George Lewis, 2008, xxxv) which has been used as a way of limiting possibilities and opportunities for African American musicians, and "a form of segregation imposed from the outside" (Eric Lewis, 2019 , 7). Viewed from this angle, the word "jazz" is not a neutral shorthand for a set of musical style characteristics but has implications in terms of social and artistic capital associated with the genre, social or racial groups who have traditionally played the music, and the working conditions they experience. In the words of Max Roach, "What 'jazz' means to me is the worst kind of working conditions, the worst in cultural prejudice... The term 'jazz' has come to mean the abuse and exploitation of black musicians..." (Max Roach, 1999, 307, quoted in Lewis, 2016, xiii).

Mitchell shows her awareness of the historical and real-world impact that being labelled as a jazz musician had (and can still have) in terms of the presentation, performance, funding and critical response to the work of performers and composers labelled as such. Jazz fits uneasily into constructions of high and low culture, sitting in an "all-too-fluid and uneasy location somewhere between the popular and classical realms" (Ake, Garrett, Goldmark, 2012, 4). Jazz seems to be too "popular" to be afforded the status (and financial support) given to art music, and too unpopular (at least post-1950) to flourish in the commercial marketplace without that support. And, as Mitchell would point out in our second conversation, cultural hierarchies are an illusion, but one that directly affects musicians' lives and earning potential. ${ }^{22}$

But, with these qualifications, Mitchell does still identify with the word jazz, acknowledging its power in referencing a legacy of African American musical innovators who form an important part of her artistic lineage. The word "jazz" still has relevance for her as a generally understood shorthand for acknowledging her connection with this musical tradition and group of significant musical influences. However, she also offers another way of framing her work:

\footnotetext{
${ }^{21}$ Nicole Mitchell, interview by author, Skype, September 28, 2018.

${ }^{22}$ Nicole Mitchell, interview by author, New Smyrna Beach, FL, July 10, 2019.
} 
I think for people, for audiences, it's easier for them to navigate my music understanding that I'm a creative musician, because then they're not going to have expectation of a certain kind of thing; whereas if you say you're a jazz musician there's all these expectations that may not be fulfilled (laughs).[...] when my album Mandorla Awakening was given the rank of the \#1 jazz album [of 2017, by the] New York Times, that was a real ironic moment, because a lot of people would be like "This isn't jazz. How are you going to say this is the number one jazz album, and it's not even jazz," you know. So, that's kind of a perfect example of what I'm trying to explain. ${ }^{23}$

While acknowledging that she does identify with the word jazz, Mitchell also chooses to identify as a "creative musician" because that label affords her more aesthetic freedom and agency, and allows her not to feel restricted by whatever expectations an audience might bring to a "jazz" performance. For audiences whose expectations of jazz are that it resembles 1950s practice, featuring swing rhythms and cyclical forms with soloistic improvisation for one of jazz's traditional ensemble formations such as saxophone, piano, bass and drums, Mandorla Awakening would be likely to trouble several of those expectations. Instead, the album features an ensemble that includes instruments not traditionally found in jazz such as shakuhachi, oud, shamisen, taiko, cello, flute, banjo and electronics. The album also includes non-metric time where swing rhythms do not feature, textural improvising, and compositional structures that do not follow the conventions of song form, which might also trouble jazz expectations - although groove, improvisation and spontaneous collective interaction are certainly in evidence.

In contrast, the term "creative music," widely adopted by the AACM musicians, is likely to provoke a less specific set of audience expectations - or what Mitchell referred to as "the expectation of surprise." 24 As Lewis writes, "Being a 'creative musician'... is an act of perpetual becoming, an assertion of mobility that can take one anywhere at all, beyond the purview of genre or method" (2008, xxxv). When asked about how genre operates in her work, Mitchell's response was similarly nuanced:

\footnotetext{
${ }^{23}$ Nicole Mitchell, interview by author, Skype, September 28, 2018.

${ }^{24}$ Nicole Mitchell, interview by author, New Smyrna Beach, FL, July 10, 2019.
} 
I don't really think about genre, in terms of creating music. But I do maintain an awareness of it, because I know that different circles might ask me to make music and have certain expectations. The most confusing thing for me is if a classical organization asks me to write something, but they're assuming it's going to be jazz [...] Because I do write through-composed music, and I do have a lot of aesthetics that I explore $[\ldots .$.$] So, the genre thing, I think, is dissolving more than it has in the past,$ because of the online way that we experience music, the fact that you can access music from all over the world, and from all different kinds of scenes and cultures, like, really easily. And so, I embrace a lot of genres, that's the way I deal with it. ${ }^{25}$

While Mitchell does not necessarily consider genre during the process of creation, she does acknowledge that genre affects how her music is received, and the expectations that various musical circles may bring to it. These expectations are manifest both in the responses of individual audience members and also at an institutional level, such as how a "classical organization" brings certain expectations to her work when they classify her as a "jazz" artist. As Eric Drott has argued, genre is a "dynamic ensemble of correlations" that "give rise to an array of assumptions, behaviors, and competences, which taken together orient the (individual) actions and (social) interactions of different 'art world' participants: composers, performers, publishers, audiences, critics, music industry personnel, arts administrators, and music scholars (among others)" (2013, 9). In Mitchell's case, a "classical organization," knowing her reputation as a jazz artist, may expect her to write something that meets their stylistic expectations of jazz, not realizing that fluency in the jazz idiom does not rule out fluency in other idioms, or that writing through-composed music and lead sheets are not mutually exclusive traits.

Mitchell also alludes to a cultural shift taking place, in which genre is declining in power or "dissolving" as a result in changes to how music is disseminated online. As Johnson describes, "Online platforms like YouTube, Spotify, Pandora, Bandcamp, and SoundCloud embody the new modes of musical engagement, giving relatively unfettered access to essentially infinite (kinds of) music while stripping away investments conventionally required of the consumer, be they financial, temporal, or cultural" $(2018,104)$. This has given rise to a contemporary discourse

${ }^{25}$ Nicole Mitchell, interview by author, New Smyrna Beach, FL, July 10, 2019. 
around the death of genre (Johnson 2018, 108), which Mitchell's statement seems broadly in line with. Yet, Johnson problematizes the death of genre discourse, pointing out that genre terms are still widely employed in online streaming and distribution "as adjectival descriptors on an unprecedented level of sophistication and numerousness," $(2018,107)$ and agrees with James that genre also "functions explicitly as metadata" (James 2017).

Mitchell's metaphorical description of her work "embracing" a lot of genres demonstrates the inclusive nature of her practice and aesthetics, an approach which is congruent with the legacy and discourses of the AACM composers. As George Lewis writes, the AACM musicians "often sought to place their work in dialogue with diasporic traditions and histories from both Africa and Europe," $(2008,361)$ challenging attempts to categorize them simply with the traditionally Black sphere of jazz, and instead claiming a broader sphere of aesthetic expression. As such, they would provide a model of "a new kind of musician who works across genres with fluidity, grace, discernment, and trenchancy," $(2008,512)$ a tradition that Mitchell's work seems to continue.

In a departure from Mitchell's position that embraces the term "jazz," with recognition of its limitations, Tyshawn Sorey has been outspoken in past interviews in rejecting the "jazz" label being applied to his work. In a 2011 interview he states:

My music is not classical, it is not jazz, it is not Western art music, and it is not Eastern art music. The music is not a style, in the way that we speak of what style "is." However, it is a unification of concepts derived from these musics and their respective philosophies[...]in addition to my life experience...("Interview: Tyshawn Sorey" 2011)

Here, Sorey anticipates and pre-empts incorrect categorizations of his work, distancing himself not only from jazz as a category, but from categorization itself. Like the AACM artists, he refuses to allow his work to be viewed only in the context of the jazz tradition, but claims a broader sphere of activity. In our interview, he elaborated further on the issue of style:

It didn't concern me what style anything was in, and for me, Mingus was kind of like that too. You know, where you have the blues, and you had all of these other types of music that are so embedded in his original work, and you can't really categorize it. 
And so, that was what was fascinating to me, because I was never interested in making a weird music per say, or I was never really interested in playing so-called jazz and that was it $[\ldots]$ There was something about the way that I've listened and the way that I grew up that sort of proposed that I learn as much from everything as I could, and putting that in a personal sort of vocabulary that I thought would make sense. ${ }^{26}$

Sorey's lack of concern about musical style echoes Mitchell's remark about not "really think[ing] about" genre when creating her work. It seems that, for both artists, genre is not a determining factor in the creative process, and transgressing generic boundaries is not itself an artistic goal, but a natural outcome of following their creative instincts. In citing Charles Mingus as a precedent to his approach to working in the space between genres, Sorey situates his work in a lineage of Black composers working within and beyond the jazz tradition. His use of the word "embedded" suggests mixing at a deep or fundamental level, making it difficult to discern the boundaries between the many styles that form part of his musical language. In describing his lack of interest in making "a weird music," Sorey clarifies that he is not seeking to shock or be innovative by transgressing genre boundaries, but rather to make a personal statement that is reflective of his many interests.

Wayne Horvitz is similarly dismissive of the issue of genre-based categorization of his work, and of the idea of mixing genres for the sake of appearing innovative or experimental:

If you go particularly to the so-called "Downtown scene" in the eighties, and we were supposed to be revolutionary because we were mixing genres - I didn't understand that at all, really. I mean, the Grateful Dead didn't say “Oh, we're going to mix genres." It was just sort of what was in the air. ${ }^{27}$

Like Sorey, Horvitz points out that, in the Downtown scene, the mixing of genres was not an aim in itself, but rather something that was occurring organically as a natural expression of the time and place. This perspective is supported by Dessen, who situates the Downtown scene as a

\footnotetext{
${ }^{26}$ Tyshawn Sorey, interview by author, Skype, June 2, 2018.

${ }^{27}$ Wayne Horvitz, interview by author, Skype, September 12, 2018.
} 
consequence and extension of the "broader breakdown in cultural hierarchies in America from the 1960 s through the 1970s" $(2003,166)$.

Horvitz continued by discussing being labelled as a jazz musician:

As for being pinned down...yeah, that's still a drag. I mean, I just wrote an orchestra piece for the Seattle Symphony, and I don't think there's a note of jazz language in it, but it's like "The jazz musician, writing an orchestra piece." I like to say that everybody calls me a jazz musician except jazz musicians, who say that I can't play jazz [...] And I don't think of myself as [a jazz musician]. I certainly am as influenced by non-jazz traditional American music as I am by jazz. That being said, I grew up listening to jazz as a kid, my dad was a big jazz fan. You know, so... I just don't [think] about it too much. But sure, it makes it hard. ${ }^{28}$

Similar to Mitchell, Horvitz references institutional discourses in talking about being branded by the Seattle Symphony as "the jazz musician writing an orchestra piece," implying that the discourse of this classical institution involves a jazz/classical binary conception in which anyone whose work involves improvisation is automatically on the "jazz" side. He points out that he is often lumped into the general category of "jazz musician," even when making music that does not have any obvious stylistic connection to the jazz tradition. While acknowledging that he grew up listening to jazz, Horvitz rejects the notion that it defines him, or is the predominant strand of his work. Horvitz's "I just don't [think] about it too much" echoes the other two artists in deemphasizing the issue. Yet it is clear that being categorized as a jazz musician affects the reception of his work in ways that can, at times, feel frustrating and inaccurate.

Each of these composers has their own relationship to the concepts of jazz and genre, whether embracing multiple genres, transcending genre, or just not thinking about it. Something they share in common is that they all employ discourse that decentres genre considerations, and their discourses complicate attempts to classify them simply as jazz musicians. They may accept the label with certain qualifications, disavow it completely, or jokingly sidestep the issue. But they repudiate attempts to situate them exclusively within the jazz tradition, problematizing

\footnotetext{
${ }^{28}$ Wayne Horvitz, interview by author, Skype, September 12, 2018.
} 
categorization of their work according to genre. In so doing, they invite listeners to hear their work in a broader musical context beyond the frames of what "jazz" might offer as a category.

\section{Afrological aspects of discourse}

While Mitchell, Sorey and Horvitz's work does not fit neatly into the jazz category, aspects of their discourse nevertheless emphasize values that are traditionally associated with the jazz genre. Many of these values are also prioritized in a broader Afrological "sociomusical belief system" (Lewis 2002b, 217) of improvisative musicality. George E. Lewis defines Afrological improvisation as characterized by the following elements: a prioritization of personality, both in terms of the personal narrative, of "telling your own story," and in terms of having a personal sound (241-243); a focus on collective, rather than individual music-making (234); a view of the importance of "social instrumentality" or resistance to oppression as part of music-making, (218219); an approach to spontaneity that includes rather than erases history and tradition (238); and a concept of freedom as emerging through discipline (238). Lewis's concept of the Afrological usefully articulates a through-line between the jazz tradition and the related traditions of creative music and improvised music, based on common musical values. While Lewis's article focuses on Afrological approaches to improvisation, here I extend his concept and apply it to the compositional practice of these three composer-improvisers.

\section{Personality}

The importance of personality, both in terms of personal narrative, or "telling your own story," and developing a personal sound, was a theme that was apparent in my interviews with these composers. Sorey's description of creating a "personal vocabulary" by combining aspects of all of the music that interests him (see quotation above) seems to be right in line with how Lewis describes Afrological sociomusical systems of improvisatory music-making as emphasising the personal. This "personal vocabulary" can be seen as a compositional equivalent to the personal sound to which jazz improvisers aspire.

Horvitz has similarly employed discourse that prioritizes the personal, as in this excerpt from a 2009 essay for Arcana about an organ solo by Garth Hudson (of the Band): 
Hudson is an enviable example of a musical stylist whose influences are myriad, yet whose own playing is utterly unique, or perhaps personal would be a better description. No other keyboard player in rock music has such a singular style, and it is interesting to note that few, if any, have tried to imitate him. (Horvitz 2009, 168, emphasis mine)

He employed a similar discourse in an interview which is excerpted on the Nonesuch website:

The fact that I have been placed in the camp of the "avant-garde," the "post-modern," or what have you is only a reflection of the conventional wisdom, and not any of my doing. If my work is innovative, it is only because it is personal. ("Wayne Horvitz" n.d., emphasis mine)

In our interview, after talking about how the New York Downtown scene became known for "genre breaking," he continued:

But I was like "who cares?" I mean, that wasn't what was exciting to me. What was exciting to me in New York was people's individual voice and the music... ${ }^{29}$

For Horvitz, it seems that a personal sound is something which he strives for in his own work, appreciates in the musicians he admires, and that he sees as a characteristic of innovative work.

Nicole Mitchell's discourse prioritizes the concept of "self-expression." While this initially seemed quite similar to "personal narrative," on further consideration perhaps the difference is that what is "expressed" might be something other than a narrative. Yet in the prioritization of the unique artistic voice of the individual creator, these concepts seem related. In our interview, Mitchell talks about improvisation enabling her to express her "full self," and her subsequent discovery of composition as a way to create ideal environments for her improvisation, so she could “express what I was trying to express." Mitchell's compositional practice here is framed as necessarily intertwined with her practice as an improviser, and both work together in aid of her "self-expression."

${ }^{29}$ Wayne Horvitz, interview by author, Skype, September 12, 2018. 
Narrative is an important part of Mitchell's creative process, and is oftentimes the catalyst for the work itself.

From the beginning, there's always a narrative underlying every piece of music that I write. And I've been writing poetry probably longer than I've been making music. And so, narrative, story, poetry, is directly related to the music, and in other situations it might be visual art, or, like with the Octavia Butler work, someone else's fiction. Or a philosophy or a concept, like with Mandorla Awakening. I don't think that there's ever a time that I'm making music, that it's just about the sound. ${ }^{30}$

For Mitchell, these narratives can range from the personal (e.g., she wrote the song "Cause and Effect" about one of her father's favourite catchphrases ${ }^{31}$ ), to the visionary global narrative of a better future that underpins Mandorla Awakening (discussed further in Chapter 4).

Agency

Lewis's framing of the Afrological also prioritizes agency. Improvising performers have the autonomy to make decisions for themselves about how, when and what to play, and there is a collective aspect to spontaneously co-creating the performance. This differs from Eurological modes of improvisation, which emphasise indeterminacy (as epitomized in Lewis's essay by the work of John Cage), where performers' actions are more explicitly guided by goals or rules (2002b, 239-41).

Mitchell and Sorey both employ discourses which invite their performers and collaborators to be themselves and contribute their own experiences to performances of their works, "reaffirming a role for the personality of the improviser-performers within the work" (G. E. Lewis 2002b, 237). In my second interview with Mitchell, she reflected on the group improvisation we had been doing while in residency at the Atlantic Center for the Arts, saying that she felt we had not been

\footnotetext{
${ }^{30}$ Nicole Mitchell, interview by author, Skype, September 28, 2018.

${ }^{31}$ Nicole Mitchell, interview by author, New Smyrna Beach, FL, July 10, 2019.
} 
successful at getting people to "bring their whole self" to our group improvisations, and elaborating on what was at stake:

But if people don't bring it, then everybody loses out. The person loses out if they don't bring it, because they're not being their whole self, and then the other people lose out because they didn't get the opportunity to be challenged and to learn more about themselves in navigating this thing that they're not used to, you know what I mean. ${ }^{32}$

Sorey describes a similar desire for his performers to be themselves and contribute to the performance of his music:

[I] started writing out things where open improvisation would be called for, to the point where I'm going to force the issue, where no licks can get played, but people really had to play from themselves (emphasis mine). ${ }^{33}$

Sorey describes his works as inviting or even requiring of performers the freedom and agency to bring their own voices and experience to the work, and to contribute to shaping it. This type of paradigm for performer participation, which prioritizes personality and agency for the performers, and allows them into co-creation of the work, is distinctly Afrological.

\section{Social instrumentality}

This prioritization of agency from the performers is a key element in another of the aspects of Afrological music-making that Lewis defines, which is social instrumentality. In my discussion with Nicole Mitchell, there was a natural flow between talking about interactions among improvisers and broader social dynamics. ${ }^{34}$ After the previous conversation about people bringing their "whole self" to an improvisation, she continued:

\footnotetext{
${ }^{32}$ Nicole Mitchell, interview by author, New Smyrna Beach, FL, July 10, 2019.

${ }^{33}$ Tyshawn Sorey, interview by author, Skype, June 22018.

${ }^{34}$ I did not discuss this with Sorey and Horvitz but it may also be relevant to their work.
} 
And, to me, that's a great metaphor for diversity, and how I feel that we should approach diversity... and to not expect people to, you know, get into this uniformity thing $[\ldots]$ and this idea of one idea being better than another one, and really holding onto that $^{35}$

Mitchell's discourse about each participant in her music bringing their "whole self," and how that creates diversity, clearly articulates a vision for social change that both operates within Mitchell's music and can extend far beyond it to the world at large. Mitchell elaborated on a similar discourse with respect to her album Mandorla Awakening:

So, the idea of overlapping is something I'm really interested in. I'm interested in it philosophically, like when I talk about Mandorla Awakening and this idea of why don't we find, like, the greatest wisdom from each culture and bring those together and overlap them in order to create a better reality, versus this idea that only European culture is the best and let's not listen to anybody else. Like, it's not getting us anywhere doing that (laughs). ${ }^{36}$

By bringing together musicians from different musical traditions (as on Mandorla Awakening) and allowing them to bring their whole selves, Mitchell creates a musical model of a wider social vision of peaceful coexistence, and learning from what each person or culture has to offer.

\section{Spontaneity and collectivity}

Lewis's concept of the Afrological is theorized in relation to improvisation or "real-time musicmaking," and, as such implicitly prioritizes spontaneity. In contrast with a Eurological approach to improvisation, which prioritizes "chance" and eliminates reference to history or known styles, the Afrological approach to spontaneity signifies on history and culture. The compositional work of these composers troubles binary oppositions often posed between improvisation and composition, as improvisation (or "spontaneous composition") is often an integral feature of their composed works. Sorey's discourse in particular emphasizes the way his compositions prioritize

\footnotetext{
${ }^{35}$ Nicole Mitchell, interview by author, New Smyrna Beach, FL, July 10, 2019.

${ }^{36}$ Nicole Mitchell, interview by author, New Smyrna Beach, FL, July 10, 2019.
} 
spontaneity, as in this retelling of a conversation he had with Claire Chase (former director of the International Contemporary Ensemble) about how he wanted to work with the ensemble:

I just want to make a singular music that involves all of us responding together, through improvisation or through playing written music, or whatever, because none of these things are separate to me, you know, composition and improvisation, I mean, they're never separate things. It's all composition, really, for me. ${ }^{37}$

This "singular music" Sorey seeks to make is a music that can exist one time only, created collectively, through real-time interaction, and based on values of spontaneity, presence and collectivity. Sorey's discourse reframes improvisation as spontaneous composition, a perspective also advanced by Charles Mingus. In his essay "What is a Jazz Composer?” Mingus argued compellingly that a jazz improviser was also a composer - a "spontaneous composer" rather than a "pencil composer."

Each jazz musician when he takes a horn in his hand [...] each soloist, that is, when he begins to ad lib on a given composition with a title and improvise a new creative melody, this man is taking the place of a composer. (Mingus 1972)

Like Mingus, Sorey sees the activities of composition and improvisation as one and the same, indicating not only that composition (for him) can be spontaneous, but that it can also be collective and participatory, something that he co-creates with his fellow improvising performers.

The discourses of these composers highlight the importance in their work of personality, agency, social instrumentality, spontaneity and collectivity, all values that connect them with the tradition that George Lewis calls Afrological (and also, arguably, with the genre conventions of jazz). These composer/improviser/performers do not fit neatly into any one category, troubling the composer/performer or composer/improviser binaries that are common in jazz and Western classical music discourses. Their music invites participants to bring themselves and their whole experience, and to participate as co-creators in its performance.

${ }^{37}$ Tyshawn Sorey, interview by author, Skype, June 2018. 
However, while the discourses of these composers emphasize some similar values, the large variety of their works and their constantly evolving perspectives makes it difficult to generalize about their compositional approaches and aesthetics. One of the features of Afrological sociomusical systems is that they do engage with multiple social and cultural influences (G. E. Lewis $2004 b, 10$ ). This is reflected in the discourse of these composers about their influences, who are not limited to the Afrological jazz and creative music traditions but also come from a variety of other musical traditions.

\section{Networks and influences}

In her essay "What was Feared Lost," Mitchell weaves together an extended and poetic description of her musical genealogy, tracing lines of influence and connection between artists within the field of jazz and creative music:

Heard about Trane seeking a map from Gilmore, and that Dee Alexander calls birdlines to Light Huff. Did Roscoe Mitchell flash a blueprint to Braxton or did Vijay's fingers flicker some from Geri Allen's silver sparks? Myra Melford strided to Erwin Helfer, and yeah, I thought someone saw Steve Coleman catch some micro-rhythmic vision from Threadgill. (Mitchell 2017a)

In this essay, Mitchell situates her work within multiple lineages, creating a rich tapestry of context that adds to an understanding of her music. In my interviews with the three composers, they similarly mentioned names of their musical influences and cited their associations with a variety of networks, scenes and communities. Discourse about networks and influences can serve as a means of contextualising the work of these composers without resorting to genre labels. The networks that have nurtured and sustained these creative artists inform audiences' and critics' understanding of their musicianship, and have influenced their approach to working in the space between musical genres. As mentioned in Chapter 2, some of the networks and influences that these composers share in common are the global jazz community, the AACM, and (particularly in the case of Horvitz and Sorey) the New York Downtown scene. ${ }^{38}$ These networks have themselves

\footnotetext{
${ }^{38}$ See Chapter 1 for more information about the AACM and the Downtown scene.
} 
been spaces where musical genres and styles collide and interact in atypical ways, crossing barriers of class, race, and musical training, incorporating practices from a variety of traditions.

Though Sorey and Horvitz do not identify as jazz musicians, they (along with Mitchell) name canonical jazz musicians as amongst their influences (such as Charles Mingus, who is namechecked by all three), as well as influences associated with free jazz or the jazz avant-garde, such as Cecil Taylor (Horvitz) and Archie Shepp (Mitchell). However, they equally named their own collaborators, as well as artists associated with a number of genre worlds including Western classical and new music, creative music, blues, rock, Wassoulou (a genre of Malian music), RnB and experimental electronica.

In my interview with Sorey I did not ask him directly about his influences, but throughout the conversation he mentioned the names of twentieth-century composers Morton Feldman, Hans Werner Henze, Steve Reich, Charles Wuorinen, and Béla Bartók, as well as contemporary jazz musicians Branford Marsalis and Kenny Garrett, and canonical jazz artists Charles Mingus and Thelonious Monk. He also mentioned key collaborators such as Cory Smythe, Thomas Morgan and Ben Gerstein as instrumental to his development. ${ }^{39}$

Horvitz mentioned jazz musicians Thelonious Monk and Duke Ellington, free jazz pianist Cecil Taylor, blues musicians Otis Spann and Jimi Hendrix, rock bands the Grateful Dead, The Band and the Beatles, AACM members the Art Ensemble of Chicago, along with Anthony Braxton and George Lewis, and twentieth-century composers Igor Stravinsky and Béla Bartók, combining and juxtaposing them in a stream of consciousness manner, as in this sentence: "I played in blues bands, I got interested in Jimmy Hendrix and the Grateful Dead, which led me to Stravinsky, which lead me to the Art Ensemble [of Chicago], and I got interested in improvised music."40 Horvitz also mentioned the names of a number of his collaborators from the Downtown and Seattle music scenes, such as Bill Frisell, John Zorn and Bobby Previte, among many others.

39 In his doctoral dissertation, Sorey offers the following list of influences: "Anthony Braxton, Alexander Scriabin, Roscoe Mitchell, Edward Kennedy "Duke" Ellington, Hale Smith, George Lewis, Arnold Schoenberg, Muhal Richard Abrams, John Coltrane, Wadada Leo Smith, Morton Feldman, Lawrence 'Butch' Morris, Toru Takemitsu, Jean Sibelius, Miles Davis, John Zorn, Harold Budd, and Steve Coleman” (Sorey 2017a, 1).

${ }^{40}$ Wayne Horvitz, interview by author, Skype, September 12, 2018. 
When I asked Mitchell about her influences, she named jazz and creative music flautists James Newton, Eric Dolphy and Hubert Laws, AACM composers Muhal Richard Abrams, George Lewis, Anthony Braxton, Wadada Leo Smith, Roscoe Mitchell, and women from the jazz and creative music traditions including Amina Claudine Myers, Geri Allen, and Maia and Shantah Nurullah (her collaborators in the ensemble Samana), as well as referencing new music composer Kaija Saariaho, Wassoulou singer and composer Oumou Sangaré and contemporary folk/electronica violinist/vocalist/producer Sudan Archives. ${ }^{41}$

There is a wide variety of lineages and networks represented in these discourses. The names Sorey mentioned in my interview were mainly drawn from the genre worlds of new music or twentieth-century Western classical music, and jazz and creative music. Horvitz's included jazz, free jazz and creative music, blues, rock and jam bands and twentieth-century classical composers. And Mitchell mentioned primarily influences from creative music, jazz, and world music, as well as experimental popular music.

This demonstrates the uniqueness of these composers' influences, of the "many different streams" that inform their music-making. While they share certain influences in common (all three composers mentioned Charles Mingus and Thelonious Monk, and both Sorey and Horvitz made mention of both Butch Morris and Béla Bartók), there are also streams of influence that don’t overlap. For example, Sorey named more influences from the sphere of new music. Horvitz emphasized blues and rock musicians as important influences on his musical development. And Mitchell mentioned influences from Malian music and experimental popular music, and emphasized women as influences. This diversity of influence clarifies that these three composers are not working only at the intersection of the jazz and Western classical or new music traditions, as in Schuller's model of the third stream as a 50/50 split between classical and jazz. Instead, these composers are working at the intersection of multiple streams of music-making, each one defining for themselves their own sphere of influence, interest and activity.

\footnotetext{
${ }^{41}$ A number of these influences are also mentioned in "What was Feared Lost," (Mitchell 2017a) along with many other influences extending beyond the sphere of music.
} 


\section{Hearing connections across genre boundaries}

It seems clear that genre categories inform the way many of us navigate the musical landscape, yet these artists are not bound by this type of thinking. Their discourses propose ways of listening that are not constrained by generic categorization. Genre is about grouping multiple aspects together, and serves as a way of simplifying things, making them predictable. But instead, these artists can hear relationships between harmonic approaches, orchestration or density, and conceptual relationships across musical categories in spite of differences in instrumentation, performance tradition, formal organization and numerous other aspects.

These composers use the names of musicians and composers who have influenced them as tools for talking about how they hear these relationships without genre labels. Horvitz spoke about a conceptual connection between the Art Ensemble of Chicago and Otis Spann, in their use of space:

And the Art Ensemble freed me from the Cecil Taylor thing, not that I wanted to leave it. But it freed me from the density thing that was always involved in that kind of free music. [...] And if you listen to Otis Spann, you'll hear the same thing...that there's a lot of space in his playing.

Here Horvitz speaks on hearing harmonic relationships between the music of Béla Bartók and Cecil Taylor:

I had played through [Bartók's] Mikrokosmos and that kind of stuff, and was influenced by that kind of polytonal sensibility. And I realized I heard that in Cecil Taylor too. There's so much, kind of, modes against modes in Cecil's playing. [...] And I heard those kinds of things that I heard in Bartók.

He expanded further on polytonality in relation to the Art Ensemble:

[The Art Ensemble] always kind of hinted at two harmonies at once. And what is that like? That's like the polytonality you find in Bartók, but it's almost like a conceptual polytonality too, they'll have different ideas going at the same time. 
Sorey also spoke of being inspired by the polytonality of Bartók, and writing early compositions with a lot of slash chords that drew on both polytonality and jazz composition as influences:

JLS: So this harmony that you were using with the slash chords... was this drawing on your studies of post-tonal theory at that time, or was it coming more from a perspective of an advanced contemporary jazz harmony?

TS: It kind of came from both. It came from both mediums, yeah. Because I was also very much interested in the music of Bartók. His music also was polytonal in its own nature. So I borrowed a lot from what Bartók did, but I also borrowed a lot from what Monk and all of these other people were doing, as well as a lot of the more advanced modern jazz composers or whatever coming up at around that time.

Sorey also describes attending his first new music performance while an undergraduate, and hearing how it connected with other music he was interested in:

That was the first time I've seen contemporary music being performed in a live setting. And it was at that point where I said, okay, this is something that I feel really close to. Because I appreciated it for what it was, and everything, and also just seeing how it connects a lot with improvisation and that kind of thing. So I was interested from the get-go to see about composing a kind of music that integrated these different principles in twentieth-century music... ${ }^{42}$

Sorey speaks to hearing connections between improvised music and new music, which suggested to him the potential for working at the intersection of these musical traditions.

\section{Influence across genre worlds}

Mitchell shows another way in which she ignores generic boundaries in her creative work, when she speaks about classical and new music influences on her writing. After first naming Kaija

\footnotetext{
${ }^{42}$ Tyshawn Sorey, interview by author, Skype, June 2, 2018.
} 
Saariaho as an influence, and then referencing AACM composers who have composed for new music contexts, she responds as follows:

There's always new influences that would influence my new music writing that might not be new music, you know what I mean. Like, listening to Oumou Sangaré, or I'm really interested in Sudan Archives, which is this really young producer, I guess, that's in Los Angeles now. ${ }^{43}$

Mitchell also speaks of her interest in "overlapping" and "colliding" and this seems to be an example of the ways in which the many traditions and circles she moves in can collide and overlap as part of her own creative practice.

This metaphor of overlapping is a useful one for visualizing the space in which each of these artists work. Horvitz talks about bringing a musical inspiration from one tradition into a different genre context in this discussion of a fully notated chamber work that he composed for the Seattle Chamber Players, which was named after Otis Spann:

But I made a really conscious effort not to try to make a piece for flute, clarinet, cello and violin that was trying to be bluesy, I thought that would be an extremely heinous idea. And so, I didn't write anything that sounded like Otis Spann's music. And what I was trying to convey is something I felt strongly about all along. You know, you can love Jimi Hendrix's music, but playing it with a string quartet may not be the best idea. But that doesn't mean that the spirit that Jimi Hendrix gives you about how it makes you feel about music can't be an inspiration. But it doesn't mean you have to use Jimi Hendrix's language to reflect that inspiration. ${ }^{44}$

In his choice not to write a "bluesy" piece for a chamber ensemble, Horvitz seems to imply the importance of considering context, community and process, not only musical content, when translating music from one tradition to another. What is idiomatic to one musical tradition (e.g. bent "bluesy" notes on electric guitar) may not translate well when applied to completely different

\footnotetext{
${ }^{43}$ Nicole Mitchell, interview by author, New Smyrna Beach, FL, July 10, 2019.

${ }^{44}$ Wayne Horvitz, interview by author, Skype, September 12, 2018.
} 
instrumentation, and musicians with different strengths and training. A transcription of an improvisation, re-read as notated material, will not have the same musical meaning when an accurate recreation is the goal, rather than a risky, improvised personal statement. He also implies that influence does not have to be direct or literal - it could equally be based on an emotional response, or a concept that sparks a new train of thought, rather than the literal application of blues language from one context to another. What makes sense in one tradition, with one way of making music, often does not immediately make the same kind of sense when transplanted to another community and approach to music-making.

The discourses of these composers around their influences show the ways in which they hear connections across genre boundaries, and see possibilities for combination and intersection of musical worlds that are usually viewed as being separate. They are able to hear music not as blocks of attached characteristics (e.g. saxophone equals jazz equals swing), but instead to imagine the infinite potential of intercombination and variation that becomes possible through working across genre boundaries.

\section{Conclusions}

Through their discourses and their creative work, Mitchell, Sorey and Horvitz problematize genre. When categorized as "jazz" musicians, Mitchell, Sorey and Horvitz either disavow these definitions, or often critical commentary or qualifiers. While there is a utility to using the genre label of jazz, there is also a detriment. Generic categorization serves to make music codifiable, predictable and formulaic, but these artists are not interested in working within existing templates. Instead, these artists define their own terms for engagement with their work, maintaining agency and mobility that enables them to express their own deeply personal perspectives.

Yet, while genre may not be important in their creative processes, it has real impacts as to how their work is received in the world. Genre labels can create expectations among audiences, presenters and other music industry players, potentially leading to misunderstandings. These expectations have complex histories that are intertwined with problematic power, racial and class dynamics. Genre labels are also oversimplifications, as they result in the application of a set of external criteria that seeks similarity and obscures difference (Drott 2013, 9). Yet, although the 
discourses of these artists decentre genre, these artists offer other ways of understanding their work within a broader context. Through naming their musical networks, influences, and collaborators, they invite listeners to hear their work as a confluence of multiple traditions that have influenced their practice.

With all of these qualifications, genre discourse is difficult to avoid, and even artists with deeply held reservations about genre labels may be forced to employ them due to the absence of clear alternatives (as happened occasionally during the course of my interviews). This line of thought leads me to ask the question, how can music be conceptualized and described without reference to genre? It seems as though thinking through the lens of genre eliminates many creative possibilities that then come back into play when this conceptual assumption is disregarded.

The discourses of Mitchell, Sorey and Horvitz suggest that they are able to hear connections across generic boundaries. So what might these artists be listening for? Perhaps they are listening for strategies for musical organization that could be taken from one context and applied to another, whether harmonic, rhythmic, formal, timbral, orchestrational, or behavioural. Perhaps they are listening for points of intersection between traditions that suggest unexpected pathways of connection and collaboration. And perhaps it might be more intuitive; they may be listening for a feeling, a spark of inspiration that leads them in a new direction, however unexpected or tangential the connection. Regardless of how they do it, this conceptual openness and imagining of out of the box possibilities leads to innovative work, work that can be seen as part of a tradition pioneered by artists such as Charles Mingus, the AACM members and the Downtown musicians. 


\section{CHAPTER 4: ONTOLOGY AND FORM: WORKS IN PROCESS}

This chapter considers the ontology of the works of Mitchell, Sorey and Horvitz, and the formal strategies they use for organizing their music. It also explores how questions of ontology and composers' formal strategies connect to the traditions of jazz and creative music. My discussion flows from two interrelated questions: What is a "work," in the practice of each of these composers? And how does form operate in the works of these composers? The diversity of compositional practice manifested in the works of each of these composers means that there must be a variety of answers to these questions. I will propose some answers in relation to selected works that are the focus of my analysis, suggesting that these composers, in different ways, each prioritize process as a structural principle of their works.

\section{The work concept in jazz and creative music}

The issue of the "work concept" is well-established and discussed in classical musicology, and has connotations of fixity, reproducibility and composerly authority. Something like its current usage dates from approximately the late eighteenth century, when changing ideas around the production of art led to a new understanding of music as an autonomous practice, the aim of which was creating enduring "works" of music (Goehr 1989, 55-56). Though the work concept has been questioned and problematized since the 1990s by scholars including Lydia Goehr, it is still a commonly accepted idea that underpins much musical discourse, including "musical analysis, history, intellectual property law, philosophy, criticism, journalism” (E. Lewis 2019, 15).

The work concept has also been applied to jazz, although the improvisatory and collaborative aspects of jazz practice and the hodgepodge nature of its traditional repertoire sit uneasily within this composer-centric framework. As Gabriel Solis points out, "It is problematic in the best of circumstances to suggest that a jazz performance, created through a dialogic, collaborative, improvisational process, might have a single author" (2004, 331). Scholarship on the work concept in jazz has tended to focus on the mainstream jazz practice of improvising over standards, with scholars variously considering jazz standards as works (Young and Matheson 2000); performances as works; recordings as works (Solis 2004); or whether jazz is a tradition without works (Kania 
2008; 2011). ${ }^{45}$ This scholarship has tended to make only peripheral mention of the issue of composition in a jazz or creative music context, or composing for improvisers. ${ }^{46}$

Eric Lewis's recent book Intents and Purposes (2019) fills this gap in previous scholarship, proposing a work concept developed to account for avant-garde jazz, creative music and improvised music, including original compositions. ${ }^{47,48}$ In Lewis's Afrological work concept (after George E. Lewis), works are continually in process, rather than fixed and unchanging as traditionally understood in Western classical music. Lewis emphasizes the centrality of performance in the jazz and creative music traditions, pointing out that, in these traditions, "the score, often merely a lead sheet, does not function as the sole source of all work-fixing properties" $(2019,49)$. Rather, works are shaped through their performances, including by the improvisatory contributions of performer improvisers.

Lewis questions binary oppositions often posed to exemplify the difference between Western classical music and jazz, such as composition vs. improvisation, pointing out that many musicians in jazz and creative music "move smoothly between these two musical practices" $(2019,64)$. He argues that, in musical discourse, jazz has often been seen as "a wholly opposed other or a poor stepchild to the European art music tradition" $(2019,10)$, and advocates for instead recognizing that "jazz might be a product of a hybrid basket of concerns, techniques, influences and motivations" (2019, 10-11). Lewis proposes that a work resulting from this type of hybrid practice and collective approach will be not "a fixed bit of the furniture of reality" but rather "a highly contextual and fluid identity" $(2019,15)$.

This is a useful frame through which to view the works of Mitchell, Sorey and Horvitz. Their works are indeed fluid and contextual. These composers, in their discourses and their works, question the composition/improvisation binary. And while aspects of their works are fixed and

${ }^{45}$ Each of these arguments is summarized in Kania 2011.

${ }^{46}$ While Kania does acknowledge that composers such as Duke Ellington composed music that more closely resembles classical composition, he argues that, due to Ellington's practice of continually revising his compositions, they do not achieve the "enduring entity" status of a musical work $(2011,397)$

${ }^{47}$ Lewis uses the word "jazz" as a shorthand to refer to all of this music, but I have chosen to differentiate between what I see as these distinct subsets of jazz-related music.

48 Another useful contribution to discourse on the work concept in jazz and creative music is Andrew Raffo Dewar's article on the work of Bill Dixon (2010). 
determinate, often using traditional Western notation to communicate their musical ideas at least some of the time ${ }^{49}$, it is clear that their works are not only located in the scores, but are also shaped by the improvisatory contributions of the improvising performers. Throughout this chapter, I have adopted Eric Lewis's concept of the work as "a highly contextual and fluid entity," in order to discuss the works of Mitchell, Sorey and Horvitz.

Historical precedent for the type of hybrid practice that Lewis mentions can be seen in the works of Duke Ellington. Katherine Williams' analysis of multiple versions of Diminuendo and Crescendo in Blue argues that the work combines classical compositional ideals (such as a clear harmonic direction and motivic development creating thematic unity) with characteristic swing elements (2012). Williams's analysis shows that the lines between what is composed and what is improvised in the work are sometimes blurred, with various aspects of the work sitting at different points on the "spectrum" from composition to improvisation $(2012,238) .{ }^{50}$

Most intriguingly, Williams's analysis highlights the flexibility and variability of the work's form, analysing four different recordings of the work over a 19-year period, and finding significant differences in the construction of each. Williams describes the work as "a combination of two short numbers from the band's repertoire, linked by an interlude of varying length and content" (2012, 230). On the 1937 recording, the interlude is a brief piano solo based around a descending riff, which fades to nothing, allowing an opportunity for the listener to turn the record over before Crescendo in Blue continues on the second side. A 1946 Carnegie Hall performance sees the piano interlude modulating and leading into a pre-existing Ellington composition entitled Transblucency, which is interposed in the middle of the two movements, and given the new title of Diminuendo in Blue/Transblucency/Crescendo in Blue (2012, 240). Recordings from 1953 and 1956 see a return to the piano interlude, now expanded into a multi-chorus solo for saxophonist Paul Gonsalves. The latter of these two recordings is notable in that this solo is dramatically extended, with a duration of 27 choruses $(2012,241)$.

${ }^{49}$ Some of the many exceptions to this include Mitchell's use of a mix of Western notation and graphic notation on Mandorla Awakening, and Sorey's and Horvitz's use of Conduction.

${ }^{50}$ The idea of a 'spectrum' between improvisation and composition comes from the work of Bruno Nettl (Nettl 1974) 
While Williams's article does not explicitly discuss Ellington's works in terms of ontology, she identifies many aspects of Ellington's composition and performance practice which are similar to the work concept that Eric Lewis proposes. As she states, "It is a common understanding that Ellington edited his compositions throughout his performing life" (2012, 239), making it clear that this work was treated as continually in process. These four recordings of Diminuendo and Crescendo in Blue show it to be a work of variable duration and tempo, with the option to include or exclude additional compositional material, and which could be expanded indefinitely to allow room for further improvisation $(2012,240)$. Though it is certainly a work that involves a high volume of predetermined and notated material, it is in other respects fluid and contextual.

\section{Forming improvisation, improvising forms}

The jazz tradition has generally not been known for its formal innovation, tending to focus less on composition than on improvisation, and less on form than on the content of improvised solos (Jost 1994, 17; Gioia 1997, 203). Jazz's most characteristic forms, 32-bar AABA song form and the 12bar blues, are not endemic to the jazz tradition, but have rather been adopted as jazz appropriated its repertoire from Tin Pan Alley, musicals, and the blues, which then became the basis for original jazz works. These characteristic forms are traditionally repeated cyclically, for an indeterminate length of time, and used as a basis for improvised solos, meaning that jazz performances have a characteristic, larger scale form of head, solos, head, or "theme, variations, theme" (Jost 1994, 39). There is an expediency to jazz's utilization of simple and repetitive forms, as they lend themselves well to being memorized and internalized by the improvising soloist. Original compositions in jazz have often been seen as "vehicles for improvisation" (Berliner 1994, 63), merely setting the scene for the improvised solos that are the focus of critical attention in jazz.

While the head, solos, head format is still widely used in mainstream jazz circles, parallel developments in formal organization have been taking place since at least as far back as Duke Ellington. Schuller describes Ellington's 1935 work Reminiscing in Tempo as “[bursting] the preset molds established for jazz once and for all (Schuller 1989, 75)," and Christopher Coady considers Ellington's work as a precursor to further "syncretic projects in venues outside the jazz

realm" by composers including Charles Mingus and John Lewis, along with other artists associated with West Coast jazz and the third stream (2016, 24-59). In an article by Schuller, written around 
the time he launched the third stream movement, he writes that "Jazz today, with its greatly enriched language, seems to feel the need for organization at a more extended level" $(1989,18)$. Schuller continues by stating that "the borrowing of a baroque form such as a fugue...very rarely produces the happiest results...Jazz, it seems to me, is strong and rich enough to find within its own domain forms much more indigenous to its own essential nature" $(1989,19)$.

Ekkehard Jost outlines many of the formal innovations from the more avant-garde spectrum in his book Free Jazz, including Charles Mingus's extended form compositions which incorporate both collective improvisation and open improvised sections of indeterminate length $(1994,39)$; Ornette Coleman's approach of playing "the music but not the background," in which composed themes would lead to improvisations of variable length without a pre-determined harmonic framework ${ }^{51}$ (1994, 44-65); Cecil Taylor's articulation of form through "register change, dynamic gradations, and variations in the rhythm, kinetic pace and instrumentation" $(1994,76)$; the "sound fields" approach of late Coltrane, in which a largely improvised work is formally structured by "systematic changes of modal levels" (1994, 87-89) and the "multi-facetted[sic]....musical conception" of the members of the AACM $(1994,168)$.

Composition is a central part of the ethos of the AACM. The organization evolved out of the a composer's workshop ensemble named the "experimental band" led by Muhal Richard Abrams (G. E. Lewis 2008, 55-83), and, according to Lewis, "The 'AACM model' stresses a composerimproviser orientation and the importance of asserting the agency, identity, and survival of the African-American artist" (2002b, 235). AACM members did not subscribe to binary oppositions between composition and improvisation, employing strategies that combined both aspects, and "often sought to place their work in dialogue with diasporic traditions and histories from both African and Europe" (G. E. Lewis 2008, 361). The AACM musicians claimed many of the "free jazz" musicians Jost writes about as artistic antecedents, but also drew from a wider aesthetic reference. Anthony Braxton writes that "By 1967 the AACM held composers' forums where every aspect of composition - from traditional to avant-garde techniques in western art music, to the complete tradition of trans-African music, were examined" $(1985,427)$.

${ }^{51}$ Eric Charry's article on Ornette Coleman's early Atlantic Recordings argues that this abandonment of form happened gradually over time in Coleman's work (Charry 1997). 
Likely due to the range of influences AACM musicians were drawing on, their works evince considerable formal diversity. The compositional practices of the AACM have sometimes corresponded with the jazz tradition, but also incorporated free jazz practices, such as collective improvisation, along with influences from Western classical and world musics. Jost identifies multi-thematic suites, and pieces based on what he calls "'group memory' improvisation," in which the group improvises around a predetermined theme which is never explicitly stated but only alluded to, as characteristic AACM forms $(1994,171) .{ }^{52}$ Lewis summarizes Art Ensemble member Roscoe Mitchell as "advancing a notion of composition as the creation of an environment" in a 1967 interview $(2008,150)$.

Composer/saxophonist Anthony Braxton's work combines a number of unique formal approaches, including its use of collage and layering strategies, which achieve temporal independence among subsets of his ensembles. ${ }^{53}$ He first pioneered these approaches in his "coordinate music" for his 1980s classic quartet with Marilyn Crispell (piano), Mark Dresser (bass) and Gerry Hemingway (drums), in which, as Braxton described it, "individual compositions can be put together like building blocks" (Lock 1988, 168), and has further developed them in his Ghost Trance music and other aspects of his TriCentric Music system (Dicker 2016).

Another unique aspect of Braxton's musical systems is his "language music," a system of sound categorization which was the basis of his seminal solo saxophone album For Alto (1969), and also operates as a conducted improvisation language that he has used in much of his subsequent work. ${ }^{54}$ Another key innovator in the field of conducted improvisation is Lawrence "Butch" Morris (1947-2013), a former colleague of Horvitz's from the New York Downtown scene, who developed a language of conducted improvisation which he named "Conduction." 55 Sean Sonderegger articulates the different emphases of these two systems by categorizing Braxton's language music as a "content-based conducted improvisation system" $(2014,44)$ and Morris's

52 The example Jost gives of group memory improvisation is Joseph Jarman's As If It Were the Seasons (1968).

${ }^{53}$ Both Sorey and Mitchell have cited Braxton's collage music as influential on their own work (Sorey 2017a, 6; Walls 2017).

${ }^{54}$ More information about Braxton's Language Music system can be found in (Wooley 2016).

55 Both Sorey and Horvitz had experiences collaborating with Morris and have utilized his Conduction cuing system in some of their own work. 
Conduction as a "structure and form based conducting language," indicating that Morris's system was differentiated from Braxton's and other systems by "its openness to the individual vocabularies of the participating musicians" (Sonderegger 2014, 59). These selective examples give some idea of the historical context within which the work of Mitchell, Sorey and Horvitz can be viewed.

\section{Analysis of Selected Works: Forms in Process}

In this part of the chapter, I explore form in the work of these composers, and the ways in which their forms allow space for improvisation. When composing for improvisers the work is, in a sense, purposefully "unfinished," and space is made for some kind of unknown quantity, contributed by the improvising performers. The works of Mitchell, Sorey and Horvitz are each quite different formally, but share in common a fluid and contextual aspect. There are aspects of their forms that are determinate, yet they also have inbuilt flexibility. The strategies they use to make space for improvisation in their works vary; improvisation can be soloistic, collective or conducted, over a given chord progression, a mode or drone, or harmonically open. The formal organization of their works serves as another clue to the works' ontologies, and to the musical traditions that have influenced these composers.

The work of these composers could all be considered what Andrew Raffo Dewar calls "post song-form jazz," or original composition that "[employs] a formal structure or style that is not based on cyclical harmonic structures or a theme and variations format" (2010). The analyses that follow are grounded in recordings of these works rather than scores for two reasons. First, from an analytical perspective, for music of this kind, I operate from the understanding that the score is not the definitive "text." Second, from a practical perspective, I did not have access to the scores, and decided to analyse the recordings alone. I focus on examples from the music of Mitchell, Sorey, and Horvitz that combine highly determinate aspects with fluid and contextual aspects, though these cases are by no means representative of all of the music of these composers.

I have questioned how to write about what I perceive, since my tendency as a composer/improviser is to want to discern what is improvised and what is composed. Yet, as Vijay Iyer has pointed out, "there's nothing inherent in musical improvisation that 'sounds' improvised. 
It's easier to identify things that 'sound composed': ensemble synchronies and unisons...." ( 2009, 173-74). It is, in general, these "ensemble synchronies" that I am listening for when I assert/assume that something is composed. But I also look for improvisation in contexts where it would make sense - where one solo voice is foregrounded (as in Gravitas Quartet), or where an ensemble texture seems to be one that would be most efficiently achieved via collectively improvising. In the case of Sorey, whose work perhaps presents the most difficulty in discerning between the two, I have relied on comparing two performances of the same work and looking for similarity (which indicates composition) and difference (which suggests the possibility of improvisation).

Wayne Horvitz's "Berlin 1914”. “...cut from the same cloth ...”

The Gravitas Quartet's instrumentation of piano, trumpet, bassoon and cello is not a conventional instrumental grouping in either classical or jazz practice. However, in general it seems to be coded more closely to Western classical music than to jazz (with cello and bassoon being particularly unusual in jazz contexts). The piece "Berlin 1914" appears on the ensemble's debut album Way Out East (Wayne Horvitz Gravitas Quartet 2006). All of the pieces of music on this album are credited to Horvitz, and they range between 2:42 and 10:25 in duration. The formal organization of these pieces ranges from more songform-derived structures to more through-composed (or possibly through-improvised) structures. Notable about this album is the fluidity with which improvised and composed material are integrated with one another. In an interview following the release of this album, Horvitz stated that "When I compose and when I improvise, it all comes out of the same cloth" (Gelfand, Alexander 2006, 31), and this consistency and integration of composed and improvised language is evident through the album.

Horvitz's "Berlin 1914" is largely based around a repeating, four-bar vamp in Eb Major in 3/4 time, and a melody that layers on top of variations of this vamp. Through varying the instrumentation and roles of foreground and accompaniment, subtle changes to the vamp's duration and harmony, layering of improvised and composed materials together, and an unexpected shift midway through the piece to a non-metrical and harmonically open cello improvisation, constant variety is maintained throughout the ten minutes with a small volume of composed materials. 
Formally, this piece seems to have a clear structure that also allows for wide open spaces for each of the improvised solos. The overall form could be generalized as in Table 1.

Table 1. "Berlin 1914” formal diagram

\begin{tabular}{|c|c|}
\hline Section/description & Time code \\
\hline Introduction & $0.00-0.29$ \\
\hline Theme statement 1 & $0.29-0.49$ \\
\hline Interlude/Vamp & $0.49-1.05$ \\
\hline Theme statement 2 & $1.05-1.20$ \\
\hline Piano solo over gradually evolving, collective interpretation of the vamp & $1.20-3.41$ \\
\hline Theme statement 3 & $3.41-3.58$ \\
\hline $\begin{array}{l}\text { Non-metrical cello solo over G drone, piano accompanies, trumpet and } \\
\text { bassoon join later. }\end{array}$ & $3.59-5.33$ \\
\hline Vamp re-enters behind cello solo, cello changes to pizz. & $5.33-6.41$ \\
\hline Trumpet solo over vamp & $6.41-8.20$ \\
\hline Theme statement 4 , trumpet improv. Played 7 times, gradual fade. & $8.20-10.07$ \\
\hline Trumpet improv & $10.07-10.14$ \\
\hline
\end{tabular}

There are three instrumental solos during the piece, and each one takes place in its own distinctive musical environment. First up after the opening theme is Horvitz's leisurely blues-inflected piano solo, which is based on the four-bar vamp that was first introduced at 0:49 in an interlude between the two initial statements of the theme. Here the vamp has been handed over to the rest of the quartet, who subtly vary it throughout the piano solo, creating a gradually evolving texture out of familiar materials. After another rendition of the theme, the ensemble pauses on the final note and the established pulse disappears. We find ourselves somewhere entirely new, in a tranquil, nonmetrical space, moored only by a droning $\mathrm{G}$ in the piano against which Lee, as soloist on cello, and Horvitz, her accompanist on piano, superimpose various modes and colours in a fluidly 
shifting dialogue. Miles on trumpet and Schoenbeck on bassoon join in with the drone and, unexpectedly, the piano vamp re-enters behind the cello improvisation, creating a dreamlike, blurred transition and a new, third musical space out of the overlap. We are here only briefly before the vamp takes over as the rest of the ensemble joins in, and Lee switches to pizzicato and completes her solo in this new environment, then seamlessly joins the vamp.

Ron Miles's trumpet solo takes over where Lee leaves off and carries through to the end of the piece. Still over the familiar four-chord vamp, he plays gently with subtle melodic friction, darting around the rest of the ensemble, then building to colourful extensions and strangled harmonic blurred pitches. The main melodic theme re-enters underneath the trumpet solo, and it is unclear whether the trumpet is accompanying the melody or the melody is accompanying the trumpet, as they engage in an evenly matched, unhurried dialogue. The theme repeats in a continuous loop, seven times, growing gradually softer dynamically in parallel to the trumpet solo, then dropping out as the trumpet finishes the piece alone with a breathy tremolo.

To me, the form of this piece seems like a relative of "theme-variations-theme" jazz form, but stretched, expanded, and disrupted. While the piece does open and close with a melodic theme, and contains improvisation in the intervening space, jazz formal expectations are subverted by the frequent returns to composed material throughout the work, the small variations to that material and variety of instrumentations, the use of collective improvisation, the layering of composed and improvised material, and the cello solo's departure from the harmonic and metrical framework of the piece, all of which demonstrate an elaborate and thoughtful formal organization.

It seems likely that the three solo sections are all of indeterminate length, allowing ample space for each soloist to infuse the work with their musical personalities, and to develop their own musical materials in dialogues with the environment Horvitz has created. There is an egalitarian dynamic in the way that ensemble roles of foreground and accompaniment are seamlessly handed around the ensemble, yet there are also moments where more traditional dynamics of solo versus accompaniment are maintained, such as in Horvitz's solo. However, even here, the microimprovisations in the collective accompaniment create an impression of collectivity and shared engagement. 
There is an apparent simplicity to this music, which is deceptive. While the composed material is repeated numerous times, there is always some kind of unexpected twist to subtly confound the listener's expectations - a 7- or 9-bar phrase, or a recapitulation of the theme that is longer than the exposition. Existing paradigms of soloist and accompaniment are maintained, but the lines are blurred, and roles are more fluid. The unconventional instrumentation of the ensemble frees the listener from genre-specific expectations of instrumentation before the listening experience even begins. The form of this piece invites listeners to meditate in a repetitive space, to be transported out of it and to return, and to see the familiar made new again. The works plays with memory and knowledge of the composed material, through the tiny variations and changes that happen throughout, yet it is also very much a work that exists from moment to moment, giving the sense that this space could continue indefinitely, for as long as the musicians are holding it, breathing it, shaping it together.

Nicole Mitchell's "Egoes War”: “...colliding dualities...”

Nicole Mitchell's Mandorla Awakening II: Emerging Worlds (2017b) was created for an ensemble of improviser/performers representing a diverse variety of musical lineages and traditions, including Chicago improvisers Renée Baker on violin, Tomeka Reid on cello and banjo, Jovia Armstrong on percussion, Alex Wing on guitar and oud, avery r. young on vocals, and Tatsu Aoki on bass, shamisen and taiko, the California-based Kojiro Umezaki on shakuhachi, and Mitchell on flute and electronics. The album was recorded live at the Museum of Contemporary Art in Chicago in 2015, and is based on an original Afrofuturist narrative written by Mitchell that asks the question "What is progress?" The variety of instruments, musical traditions, aesthetics and processes represented on the record seem to serve as a sonic representation of Mitchell's view of an imagined future society based around a union of nature and technology (Walls 2017; Mitchell 2017a, 234$35)$.

The album is made up of ten tracks with a collective duration of 75 minutes. In some cases the tracks run together continuously (e.g. "Sub-mission," "The Chalice," and "Dance of Many Hands"; "Shiny Divider" and "Mandorla Island"), and in other cases they appear as more detached, selfcontained pieces ("Egoes War"; "Listening Embrace"; "Forestwall Timewalk"; Staircase Struggle"; "Shiny Divider"). The distinctive sound of the ensemble, and the continuity in the 
approaches to time, ensemble playing, and combining composition and improvisation create a sense of cohesion and continuity, giving the album the effect of a multi-movement suite, with a total duration of 75 minutes.

The album received significant critical acclaim upon its release, including being ranked as the \#1 Jazz Album of 2017 by the New York Times (Pareles, Caramanica, and Russonello 2017). The work demonstrates the inclusiveness of Mitchell's aesthetic, which she has described as "blending the known, or the familiar, with the unknown" and encompassing "endless possibility" (Mitchell 2013). The imagined reality of Mandorla Awakening is brought to life with a highly distinctive palette of musical instruments from a range of cultures, both traditional and modern, and in a distinctive musical language that incorporates melody, groove, dissonance, noise, timbral exploration, atonality, temporal layering and independence. These are translated through the individual voices of eight improvisers, resulting in a complex and multi-faceted sonic experience.

It is a recording that has moments of dense, chaotic, tangled interwoven textures, and moments of coalescence and clarity. There is striking consonance and beauty, but also disruption, opposition and dissonance. It moves between abstract textures, noise, defined grooves, and melodies, often all at the same time. There is tremendous tension and opposition created between the different parts of the ensemble, which often seem to operate in a rhythmically independent but overlapping fashion. Some of the distinctive aspects of the ensemble interaction include: the use of heterophony or approximate unison; the layering of multiple meters,

"Egoes War" is the opening track of Mandorla Awakening. The piece begins with cymbal swells and foreboding bass-register electronics, creating an ominous, textural atmosphere. New electronic sounds appear, and multiple pulses emerge, are overlaid and dissolve, before the percussion coalesces into one consistent pulse. The bass enters strongly (2:06), setting up a groove which proves deceptively unpredictable, varying between 8-, 7- and 9-beat cycles. The guitar enters shortly thereafter with an assertive statement of the main melody (2:25), then diverges into an exuberant and noisy improvisation.

The melody is restated by flute and strings (3:49), but with a different character, now phrased slower and more rubato, floating independently over the bass and percussion. Meanwhile, the rhythm section gradually shifts to a new groove, arriving at a six-beat cycle, which can also be 
heard as a 3/4 meter. The guitar begins a melodic ostinato, implying a 4/4 meter over the 3/4 meter in the bass and percussion (4:25).

The flutes and strings continue to a new section of melodic material (4:30), and from this point on the lines between composition and improvisation become even more difficult to discern. While temporal independence between the two halves of the ensemble is maintained, there is alternating coalescence and divergence in the flutes and strings. At one moment (4:44), they unite in playing a set of pitches that almost becomes a melody, then disperse into separate flurries, explorations of density, and various sonic shapes. The guitar gradually diverges from the ostinato until it is improvising freely. The bass and drums have once again transitioned to a new groove (5:00), and maintain a steady pulse, until a disruptive moment sees them change abruptly to an up-tempo swing feel which is superimposed on top of the existing pulse $(5: 42)$. In the climactic moment of the work (5:59), the original pulse returns, and the rest of the ensemble improvises vigorously, briefly seeming to play together as a unified organism, with some parts locking in with the bass groove.

Towards the end of the track, the bass drops out abruptly (6:11), the density of the massed improvisation gradually disperses, and flutes and strings unite with the guitar to play a descending five-note melodic phrase, again with rubato phrasing (6:20). What begins as unison begins to diverge temporally, then splits to a two-part harmony. The percussion keeps up the consistent pulse, while the flutes and strings gradually slow and become softer, until they come to rest on a soft, sustained pitch, then cutting off at the same time as the percussion groove comes to a halt.

Ted Gioia has theorized the concepts of "blueprint" and "retrospective" form in relationship to jazz improvisation, comparing composition to a structure designed by an architect, whereas an improvisation is based more on spontaneous decision making, with its form only discerned in retrospect (1990). A work like Mandorla Awakening challenges this type of binary framework, seeming to dwell firmly in the overlap between these two states. The form of "Egoes War" highlights process, moving through a series of distinct episodes, with transitions occurring on multiple temporal planes. The interaction of these processes is quite unpredictable. There are so many variables involved in the realization of this work-both because of the inclusion of improvisation and graphic notated elements, and due to the strategy of layering temporally 
independent materials - that it is clear this work could never be played the same way twice. The performers contribute greatly to shaping the work, both through improvising, and through playing specified materials in personal, Afrological ways.

This is a music that is not overly concerned with harmony. Rather, it explores rhythm, density, the layering of multiple melodies, and creates friction through combining all of these things. The piece is moored most of the way through by a consistent pulse, but around this is evolution, friction, and chaotic change, as well as cooperation and cohesion. This is a piece that seems to contain multiple timelines at once, and the shifts that occur are sometimes synchronous, sometimes asynchronous. While the piece does use repetition, nothing ever happens the same way twice. Rather, there is a sense of constant change, tension and evolution.

Taken as a whole, Mandorla Awakening is united as a work by Mitchell's distinctive overarching creative vision. There are numerous fixed elements, such as groove, melodic and pitch materials, that interact in varied ways. Many of the musical ingredients are specified, but the precise way in which they all come together is left to spontaneous decision making, both collective and individual, which will necessarily result differently in each performance.

Tyshawn Sorey's The Inner Spectrum of Variables: “... a highly flexible score...”

Tyshawn Sorey's mammoth work, The Inner Spectrum of Variables (Sorey 2016b) was released as a double album with a duration of just under two hours, and is divided into several movements. The work was created for a combined ensemble of Sorey's longstanding piano trio with Cory Smythe on piano, Chris Tordini on bass, and Sorey on drum set, and a string trio of Chern Hwei Fung (violin), Kyle Armbrust (viola), and Rubin Kodheli (cello). In the album's liner notes, Sorey writes:

Variables is a highly flexible score that can be performed in a myriad of ways. The version heard on this recording employs conducted improvisation (the score gives a lexicon of cues for the conductor to use at any point during a given performance to enable real-time improvisation), but the work can also be realized with the performers following prescribed directives for improvisation or without any improvisation at all. (Sorey 2016a) 
This explanation makes clear that the work contains both a high degree of specificity and a variable or indeterminate aspect to its construction; it is an exemplary case of a composition exhibiting the contextual and fluid characteristics that Eric Lewis describes.

The listener can hardly help but wonder how the music is put together. In an interview, Sorey explained that it is not always easy for the listener to deduce what is composed and what is improvised, and intentionally so, naming as an example the viola solo at 3:30 in Movement IV, which many listeners assumed was improvised, but which is actually composed (Rentner 2017). Usefully, for the purpose of comparison, a live performance of the work from the Ojai Music Festival can be viewed on YouTube. This live performance has a considerably shorter duration of one hour seven minutes (Sorey 2017b). Here, I compare the two versions in broad strokes, looking for similarity and difference in order to understand more clearly which aspects of the work are variable.

\section{General overview}

The two performances of The Inner Spectrum of Variables have drastically different durations. Formally, many aspects of the piece are consistent between the performances and happen in the same (or a similar) sequence. However, in the live performance at the Ojai Music Festival, certain (possibly improvised) solos are omitted or added, some repetitions of thematic material are omitted, and one entire movement of the piece is not included (Reverie). ${ }^{56}$

Each movement has a distinctive character. Movement I is a solo piano feature, seemingly an improvised fantasia based on composed materials, with a duration of 3 minutes and 12 seconds. Performed by Cory Smythe in a lyrical, romantic style, evoking Impressionism and briefly quoting Beethoven, Movement I culminates in a repeated modal phrase in 7/4 that seems to act as a cue or bridge to the next movement. In the Ojai version, the same opening melodic materials are audible, but more obscured by harmonic diversions, before culminating in the same 7/4 modal phrase, here also slightly obfuscated.

${ }^{56}$ Movement $\mathrm{V}$ may also be omitted from the Ojai performance, but as it appears as a single continuous performance (Movement $\mathrm{V}+\mathrm{VI}+$ Reprise) on the album version, it is not entirely clear where this Movement ends. 
Movement II, is over twenty minutes long, with a structure resembling sonata form, and is influenced by multiple styles and periods of Western classical repertoire. Much of the movement sounds highly composed, and the ensemble largely functions as a chamber ensemble of strings (including arco double bass) and piano. A modal cello solo in the middle of the work and a viola sola over a rhythm section vamp are the only moments where Sorey appears on drums, both of which seem likely to contain improvisation. The Ojai version follows the same general structure, but omits repetitions and some of the thematic material towards the end of the movement, decreasing the movement's duration.

Movement III is the most variable of the movements. As a whole, Movement III seems to explore the juxtaposition of blocks of sound of dramatically different characters. The album version opens with a rhythmically intricate theme, initially performed by piano and drums, then joined by the rest of the ensemble, that is reminiscent of some of Sorey's early works, such as those on his 2011 album Oblique-1. ${ }^{57}$ The following sections of the work include slow-moving, Feldmanesque strings, a lyrical, ballad-like theme played by piano and then strings, and a riotous explosion of spontaneous group interaction. A return of the opening material from Movement I also features at approximately halfway through the work. The Ojai version differs significantly from the album version, first omitting the initial, rhythmically intricate theme, and then incorporating many aspects which have timbral or gestural similarities to the materials on the album version, but are not exact repetitions (likely employing conducted improvisation or other directed improvisation). However, the lyrical ballad-like melodic theme is a common element between both performances.

The subsequent movement, Reverie, is initially a reflective solo percussion spot, featuring spacious and melodic modal playing from Sorey on his extended percussion set up including various kinds of gongs. The rest of the ensemble gradually joins, providing accompanying textures in a harmonic drone space, a bed of sound with slow-moving strings and pizzicato bass and piano interjections, then gradually dropping out until sparse piano is all that remains, when out of the silence a solo viola melody emerges, heralding the transition to Movement IV. Reverie is entirely omitted from the Ojai performance.

${ }^{57}$ Although Oblique-I was recorded in 2011, the compositions featured on the recording date from 2002-2006. 
Movement IV foregrounds the influences of klezmer, cantorial music and Ethiopian jazz (Rentner 2017), exploring both rubato and groove-based time, and modal improvisation, and once again featuring the rhythm section. It opens with an extended viola solo, and also features an extended cello solo.

Movements V+VI + Reprise appear as a single continuous track on the album, creating some ambiguity about where one movement begins and another ends. The first section of the track begins with a series of static string textures using harmonics, out of which an ethereal melody gradually emerges. The next section of the track (perhaps Movement VI) features an undulating string ostinato which becomes entwined into a cumulatively thickening string texture. Finally, an extended piano solo finishes the piece, culminating with a return to the opening melodic material from Movement I.

\section{Close up: a moment of variability}

An example of variability between the two performances can be heard towards the end of Movement II. Emerging from a string ensemble passage in which the violin plays the theme, the piano plays alternating very low and high sonorities (16:04 on the album version). The note choice and extreme register creates an effect that is very harmonically ambiguous, but the ascending movement from $\mathrm{G} \#$ to $\mathrm{A}$ in the left hand of the piano effectively functions as a modulation into the next section of the piece (16:38-45), a fugue-like theme in the strings beginning in D minor (16:48). This theme culminates in a unison melody that implies a dominant-tonic resolution from B to the next section (18:38-52), in which the piano begins to play a repeating vamp establishing an E minor modal environment (18:54). Sorey joins here on drums and they play freely with the given materials, as would be typical in jazz practice over a vamp, while the viola solos above implying E Major. At the culmination of the viola solo, the piano plays a melodic cue over the same harmonic environment which ends the movement.

The Ojai version similarly moves from the violin melody to the section with alternating low and high sonorities on piano (11:52). This is clearly recognizable as the same musical gesture, and begins by employing the same pitches, but instead of continuing on to the fugue-like theme, the piano diverges into a brief duo with the violin (12:35), before moving directly into the closing 
E minor modal vamp section (13:14), over which, this time, the rhythm section plays more actively and viola again solos over the top,.

Here Sorey has found an alternate pathway through his own work which omits the fugue-like section of thematic material. The piano gesture with alternating low and high sonorities functions as a sonic signature that could be used to lead in many different directions. Sorey uses gestural, sonorous material as a way of modulating and transitioning between the very different musical worlds of the tightly composed thematic material in the strings, and the more fluidly interpreted vamp section. The affect achieved is a stylistic crossfade.

\section{Aesthetic range and ontological spectrum}

The most striking feature of The Inner Spectrum of Variables is the huge aesthetic range that it encompasses. If a listener randomly selected a few moments from either performance, they would likely have trouble imagining that they could all come from the same work, or be performed by the same group of musicians. The ensemble is alternately a string trio or quartet, a new music ensemble, a jazz trio, an improvising sextet, a duo of cello and drums, and almost every other combination imaginable; this is one of the ways Sorey both engages with multiple genre conventions and seeks to evade genre categorization. The aesthetic references are equally varied, sounding like classical music one moment, new music or klezmer in another, moving from tonal to modal to atonal, from metric time to rubato to large expanses in which time seems to stand still. There is also a huge spectrum of ensemble behaviour represented, which is discussed more fully in Chapter 5.

This is certainly a work that would defeat "jazz" genre expectations. Listeners who know Sorey's reputation as a jazz drummer would likely be surprised that the majority of the album does not include drums (in the video of the Ojai version Sorey can be seen conducting for the bulk of the performance). The division of the work into multiple, numbered movements is a naming convention that aligns it with the Western classical tradition, as does the inclusion of the string trio, a code of classical music. The musical material, especially Movements I and II, seem to make more overt reference to Western classical music than any of Sorey's previous works, and for much of the work the ensembles functions more like a chamber or new music ensemble than a jazz 
ensemble - in fact, Sorey is not heard on drums until 8:47 of Movement II, eleven minutes into the piece. Yet, intriguingly, he has connected the album with jazz, saying in an interview about the work: "Variability is something that is inherent in all of the music in this tradition that we're talking about, you know, in jazz and everything like that, where so many different things can happen in a given performance of a composition" (Rentner n.d., my emphasis). It is this quality of variability, of fluidity and change, that most characterizes this work, and also that connects it with Afrological traditions of music-making.

Though variability is a hallmark of the work, not all aspects of the work are equally variable. The individual movements (apart from Movement I and "Reverie") are substantial and contain multiple themes, all which are performed very similarly between the two versions. ${ }^{58}$ Some of these seem almost like sub-compositions within the larger work, with other, more variable types of material functioning to transition between and connect these sub-compositions (specifically sections that are gestural and harmonically ambiguous, vamps, and improvised solos over drones). Two examples of these sub-compositions are the opening of Movement III from the album version (0:00-1:45 in the album version) and the lyrical theme in Movement III (5:18 - 9:12 and 31:1032:44 on the album version; 22:32 - 25:06 and 42:30 - 43:58 in the Ojai version). These themes seem as though they could be stand-alone pieces with their own identities, and could almost be extracted and treated as "vehicles for improvisation," but have instead been woven into the larger fabric of the work.

So, the work itself seems to contain an ontological spectrum - some parts more fixed, some parts more fluid. Fluidity is evident in improvised solos, conducted improvisation, and the spontaneous interaction of the rhythm section. And the form is variable, as Sorey leads the musicians on new routes through the work in the radically shortened Ojai performance, omitting some sections and expanding or contracting others. The work is, as the title describes, a spectrum of variables that encompasses all of these possibilities, both in these and in many other future performances. I imagine the work as a maze, through which there are a variety of possible routes, yet with defined landmarks that will be achieved along the way, and with clear start and end points.

\footnotetext{
${ }^{58}$ With the exception of sections that are omitted entirely, likely due to time constraints.
} 
The Inner Spectrum of Variables is not formally typical of jazz, which is unsurprising given that many of the composers Sorey cites as influencing the work come from the traditions of Western classical and new music (Schoenberg, Bach, Brahms, Scriabin, Fred Lerdahl, Steve Reich, Morton Feldman) as well as the post-jazz Afrological tradition (Lawrence D. Butch Morris, Anthony Braxton) ("The Inner Spectrum of Variables" 2016b). ${ }^{59}$ Sorey is not reverting to the cyclical forms that are a code of jazz (except perhaps in the themes of Movement III), though he does use vamps (another code of jazz) and also gestures towards a code of classical music (Sonata form in Movement II).

As a large scale form, the work covers a tremendous scope, yet there are certain recurring aspects that serve to create a sense of cohesion and unity, in spite of the diversity of the musical material. The repetition of the melodic material from the start of Movement I, first in the middle of Movement III, and then at the end of piece (in both versions), serves to frame the work. There are some other elements that recur throughout the work and seem to act as sonic signatures, such as low double bass drones, often coupled with modal improvisation, string harmonics (especially harmonic glissandi), and musical gestures, such as a slow alternation between two sonorities. The distinctive instrumentation and the integration of a variety of musical practices are also elements that recur throughout the work.

And yet, perhaps asking how unity and coherence are achieved is the wrong question, as this may not be Sorey's goal. The form of this piece is vast, it is changeable, but above all it is variable. It never settles into a single style, identity, or organizational strategy as none of these would serve to encompass the complex questions that Sorey is exploring about composition and improvisation, about composerly authority and performer agency, and about so many different types of musical language. Sorey has developed a huge range of musical vocabularies, and he is interconnecting them all, treating them as materials that can all coexist, and giving them a different meaning collectively than they would have individually. There is an egalitarian impulse at work in asserting the right of all of these musical materials to inhabit the same space.

${ }^{59}$ Sorey also cites jazz musician Louis Armstrong and the difficult to categorize composer Harold Budd as influences on the work. 
Sorey has written of the importance of "spontaneous and preconceived structure, the unforeseen, and attention to affect" as elements of "the musical model that I continually strive to establish: one that is about life, experience and becoming" (2017a, 54). This description, while not specific to this work, encapsulates clearly the dual importance of construction and deconstruction, of the prearranged and the spontaneous, in Sorey's creative practice. This is a work its composer can diverge from and return to, can tear open to insert new material, and can find space within. The work is like a portrait of the inner workings of Sorey's mind, and of the many elements of his musical worlds.

\section{Conclusions: processual form}

In these analyses, I have not wanted to merely compare the works of these composers to various forms that I might be familiar with, but, also to take them for what they are, on their own terms. These works by Mitchell, Sorey and Horvitz are flexible and porous, able to be infused with the personalities and identities of the performers, while still retaining the unmistakable stamp of the composers who created them. These works clearly demonstrate the creative vision of their composers. They are characterized by specificity, attention to detail, and an overarching architecture, all of which qualities might be typically associated with the Western classical tradition. Yet, at the same time, these works are not entirely rigid or fixed, but will change, whether subtly or radically, from performance to performance.

All of these composers both take responsibility for shaping the work and communicating their ideas, whether through notation or other methods of composerly direction (such as conducted improvisation), and simultaneously provide space and flexibility for the input of the improvising performers, resulting in works that will vary with each performance. This variety of approaches to constructing a work implies a prioritization of process in the practice of each of these composers. They are each constantly dismantling or expanding their own habits, exploring a variety of ontological frameworks. These works demonstrate each composer's individual vision, craft and skill, as well as creating space for the agency and individual contributions of each performer/improviser. 
Formally, each piece seems to draw on different structuring principles. Horvitz's "Berlin 1914" seems to almost meditatively explore the colouristic potential of the different harmonic environments created in the piece. The organization of Mitchell's Mandorla Awakening is determined by the narrative and the conceptual underpinning of the work. And Sorey's The Inner Spectrum of Variables explores the passing of large expanses of time, as well as providing a living portrait of the spectrum of his musical interests.

These composers do not utilize the traditional cyclical forms that are a code of jazz, though there are moments in each of their works that seem somewhat related to this tradition. Their works do demonstrate values of spontaneity, agency, and making space for the personalities of the improvising performers, which are all values connected to the Afrological traditions of jazz and creative music. These composers' inclusion of varying types of improvisation connects their work to jazz and creative music practices.

The ways in which these composers combine improvised and composed material contribute to making the character of each work distinct. In Horvitz's "Berlin 1914," the improvisations have a sense of continuity, as if they flow out of the composition. Though each improviser contributes a unique voice, there is a sense of cohesion and overall consistency of language. In Mandorla Awakening, the solo spots for instrumentalists often bring a sense of chaos and rupture. And in The Inner Spectrum of Variables, it is as if these solos are spontaneously composed into the work, shaping it anew in each performance.

Beyond these compositions, these composers employ many other approaches to form in their work. For example, Sorey's 2009 album Koan features his guitar trio performing one-page "tunes" (Adler 2016) rather than the more extensively-notated works represented on recent albums such as Alloy (2014) and The Inner Spectrum of Variables (2016). And in his more recent "Autoschediasms" series of conducted improvisations, he creates expansive forms in real-time, directing a large ensemble of improvising performers through "visual gestures, textual directives, and autonomous prompts, relayed via the hands, baton (or several batons) and a whiteboard" (Pellegrinelli 2019). ${ }^{60}$ Horvitz's recent album Those Who Remain (2018) features two works in

${ }^{60}$ Sorey has not released a recording documenting his "Autoschediasms" yet, but various performances can be viewed on YouTube. 
which classically trained performers read notation and an improviser improvises, one for orchestra and improvising guitar, and one for string quartet and improvising clarinet. Horvitz has also explored conducted improvisation with the Royal Room Collective Music Ensemble (At the Reception, 2014). Mitchell's orchestral work Flight for Freedom (2011) features Mitchell as improvising flute soloist along with notated orchestral parts, while previous albums including Black Unstoppable (2007) see her Black Earth Ensemble playing compositions that bear more resemblance to jazz songform structures.

Andrew Kania argues that the work concept is a way to locate value in a musical tradition $(2011,394)$. This would seem to imply that composition is more highly valued in Western classical music, and improvisation is more highly valued in jazz. I would propose that creative music has an ontology that is a mixture of Western classical and jazz, in that composition and music as "Art" are valued, but spontaneity, personality, agency, and Afrocentricity are valued as well. It seems that there is no one ontology that can account for all the types of musical objects that can be created in the field of jazz and creative music. Rather, they exist on a spectrum, from those in which composition is more plentiful, central, or important to the work, to those where it is merely a "vehicle" for improvisation, to completely freely improvised performances. While Eric Lewis's Afrological work concept can encompass all of these, it seems to be an oversimplification to suggest that they are all, in some meaningful way, the same type of thing.

So, it seems that composing for improvisers is something of an ontological conundrum. Which aspects of the work are composed and which are improvised? Where does musical value or authority lie? Through their creative works, these composers each find their own ways of answering these questions. Whether Horvitz's continuous collective reworking of the same material to find new shades of meaning within, Sorey's construction of a work which is both elaborately planned and completely contingent upon what takes place in that musical moment, or Mitchell's simultaneously organized and chaotic approach to unleashing independent coexistence, each of these works is structured in a way that allows for the work to be reformed, reshaped in the now. These composers take a processual approach to form, constructing forms that are malleable, in fact improvising with form in their performances. These are forms that can be fluid rather than fixed, that can expand or contract to make space for an improvised utterance from a contributing 
performer. They are forms in which performers have agency to shape the piece, forms which can change to accommodate the feeling on the day, which can be reborn anew in each performance. 


\section{CHAPTER 5: BEYOND THE PAGE: REALIZING WORKS IN PERFORMANCE}

As Holt writes, "Music and genre cannot be perceived only in terms of 'content,' of what is played but also of how music is created, performed and received" $(2007,24)$. This chapter investigates the practices that are employed to realize the works of Mitchell, Sorey and Horvitz in performance, and their strategies for bridging the gap between the worlds of notated and improvised music, asking the questions: How are the works of these composers realized in performance? And what are the ways of interacting that this music asks or invites of the performers? The first part of the chapter explores bandleading and collaborating with improvisers as a part of the compositional practice of these composers. The second part of the chapter discusses the ways in which the selected works analysed in Chapter 4 transcend the improvisation/composition binary. The third part of the chapter considers some of the approaches these composers have taken to composing for pre-existing ensembles in new music or Western classical contexts. The fourth part of the chapter briefly addresses the funding and systemic constraints involved in the music scenes these musicians inhabit.

\section{Bandleading as composition: choosing collaborators}

Though Mitchell, Sorey and Horvitz each compose for a range of contexts, including traditionally "classical" contexts such as new music or chamber ensembles, a significant focus of their careers has been leading their own ensembles. In this respect, they are part of a long tradition of composer/bandleaders in the jazz and creative music traditions, including artists such as Duke Ellington, Charles Mingus, Ornette Coleman, AACM members, and New York Downtown improvisers. In fact, bandleading is typically the way that jazz and creative music composers are able to hear their works performed.

In Afrological music-making, where personal improvisational voice and performer agency are prioritized, the choice of collaborators is a significant creative decision, affecting the shape of the composer's works in performance. When creating ensembles to perform their musical works, Mitchell, Sorey and Horvitz give careful thought to the backgrounds, skills and individual creative 
voices of the musicians with whom they collaborate. This aspect of their practice connects them with the jazz and creative music traditions. Solis has argued that choosing sidemen and directing them in performance "should be seen as part of expressing an authorial voice in jazz" $(2004,337)$, and Sorey has expressed similar thoughts in relation to his own practice, saying "Deciding who you're going to work with is compositional" (Fancher 2020).

Mitchell, Sorey and Horvitz often choose to work with performers who are fluent in multiple musical traditions, affording them a greater range of possibilities for ensemble behaviour to utilize in the execution of their music. Precedent for this type of musical versatility can be seen in the AACM and the New York Downtown scene. Writing about Anthony Braxton's Creative Orchestra Music 1976, George Lewis states that "The hybridity evident in the Braxton session called for a new kind of musician, one whose mobility of reference encompassed many histories and perspectives" (2008, 340, emphasis mine). The collaborators of Mitchell, Sorey and Horvitz are just such a "new kind of musician," and are essential co-creators of this fluid and spontaneous music.

In the case of The Inner Spectrum of Variables, Sorey chose to feature his existing piano trio with Cory Smythe and Chris Tordini, along with a string trio he put together for the recording featuring Fung Chern Hwei (violin), Kyle Armbrust (viola), and Rubin Kodheli (cello). ${ }^{61}$ Pianist Cory Smythe's website describes him as working in "new, classical, and creative improvisatory music" (“CORY SMYTHE” n.d.). Smythe is a long-time collaborator of Sorey's and also featured on Sorey's 2007 debut That/Not. He is a member of the International Contemporary Ensemble and has collaborated with Anthony Braxton and Steve Lehman. Bassist Chris Tordini previously appeared on Sorey's Oblique-1 (2011), and collaborates with a wide variety of musicians in and beyond the New York jazz scene, including Becca Stevens, Ari Hoenig, Greg Osby, John Hollenbeck and Tigran Hamasyan ("Chris Tordini” n.d.). Sorey's existing practice working as a trio with Smythe and Tordini had led to the development of a number of strategies for interpreting his composed materials differently at every performance, and a dynamic in which each ensemble member is afforded a great deal of creative freedom and agency (Laskey 2014).

\footnotetext{
${ }^{61}$ Smythe, Tordini and Sorey featured as a trio on Sorey's 2014 release Alloy, and his 2017 release Verisimilitude
} 
For the string trio, Sorey assembled a group of New York-based players who had not previously worked together as an ensemble, but who are all experienced improvisers fluent in multiple musical idioms. Cellist Rubin Kodheli's website describes him as am improviser and composer, and a "genre-transcending creative rebel" who has worked with artists such as composer Philip Glass, AACM member Henry Threadgill, and jazz bassist Christian McBride ("Rubin Kodheli" n.d.). Violist Kyle Armbrust is a member of a number of prominent orchestras and new music ensembles including the International Contemporary Ensemble and the Argento ensemble, and he has also worked with jazz artist Herbie Hancock and popular musicians Lauren Hill, Sufjan Stevens and Sting ("Kyle Armbrust, Viola" n.d.). And violinist Fung Chern Hwei is a member of "progressive chamber music" ensemble Sirius Quartet, and has collaborated with Uri Caine, Bobby McFerrin, and Elliot Sharp ("Fung Chern Hwei” n.d.). Each of these three instrumentalists has experience working in both classical and jazz or creative music contexts, combining skills in interpreting written material, and in a variety of improvisational practices.

The personnel of Wayne Horvitz's Gravitas Quartet are Vancouver-based cellist Peggy Lee, New York-based bassoonist Sara Schoenbeck, and Colorado-based Trumpeter Ron Miles. Lee is a cellist, improviser and composer that works in improvised and creative music contexts and interdisciplinary collaborations, and has collaborated with Wadada Leo Smith and George Lewis ("Peggy Lee - Cellist Improviser and Composer" n.d.). Schoenbeck is a bassoonist "focusing on the intersection between extended technique and melody" who has performed with Wet Ink ensemble and collaborated with Anthony Braxton and Adam Rudolph ("Sara Schoenbeck Bassoon" n.d.). Trumpeter, cornetist and composer Ron Miles comes more directly from the world of jazz, and he has collaborated with Bill Frisell, Brian Blade, and Joshua Redman ("Ron Miles" n.d.).

Nicole Mitchell's Mandorla Awakening II: Emerging Worlds (2017) features an ensemble with a unique instrumentation formed for the purpose of the project. The line-up includes Mitchell on flute and electronics and a mixture of Mitchell's long-time collaborators, including Renee Baker on violin, Tomeka Reid on cello and banjo, JoVia Armstrong on percussion and Alex Wing on guitar and oud, as well as avery r. young on vocals, Tatsu Aoki on bass, shamisen and taiko, and Kojiro Umezaki on shakuhachi. 
The backgrounds and fields of expertise of these musicians are varied. Renee Baker is a classically trained violinist who first collaborated with Mitchell in her ensemble Black Earth Strings, and who is also an AACM member and composer ("Renee Baker - Composer" n.d.; Waterman 2008, 5). Cellist and composer Tomeka Reid is another long-time collaborator of Mitchell's and AACM member, who has also worked with Anthony Braxton, Roscoe Mitchell, and Mike Reed. On this recording, Reid also features on banjo ("Tomeka Reid" n.d.). Percussionist, composer and producer JoVia Armstrong has previously collaborated with Mitchell on Afrika Rising (2002), and also performs with Chicago ensembles the JC Brooks Band and Musique Noire ("JoVia Armstrong" n.d.). Alex Wing is a guitarist, bassist, oudist and creative musician who has also recorded with David Boykin and Avreeayl Ra (“Alex Wing” n.d.). Chicago "artist scholar and poet" avery r. young features on vocals on several of the tracks ("Avery r. Young" n.d.). Tatsu Aoki plays jazz bass, shamisen and taiko, and is a "prolific composer and performer of traditional and experimental music forms" (Tatsu Aoki n.d.). Kojiro Umezaki is a shakuhachi player and composer who "explore[s] global and hybrid practices in music." He has performed and recorded extensively with the Silkroad Ensemble since 2001 ("Kojiro Umezaki" n.d.).

The ensemble Mitchell assembled for this recording represents diverse ranges of instrumentation and of musical traditions, with the participants contributing expertise in Western classical music, jazz, creative music (perhaps the dominant strain with so much representation from the AACM membership), traditional Japanese music, Arab and Turkish music, electronic music, and popular music. In putting together this ensemble, Mitchell has indicated that she considered combining "different musical languages...the African-American expression and Japanese expression," as well as "colliding ancient and urban [styles]" (Walls 2017). She also gave thought to racial and gender diversity within the ensemble, mentioning in an interview that "half the band is black women![...]The gender balance has been important to me, too" (Walls 2017). It seems this ensemble was assembled not only for the sonic possibilities it affords, but also as a community that represents Mitchell's vision of collaboration which underpins the album.

In each of these three cases, the composers specifically formed ensembles with an intent to explore something new musically. The composers' knowledge of the musical fluencies of the personnel of the ensembles influenced the shape of their compositions. These performers are 
essential collaborators in realizing these works, contributing their unique musical personalities and voices as improvisers in service of the larger vision of their composers. Although these ensembles emphasize distinct priorities and are formed with divergent aims, it is notable that there are some common networks and lineages between some of these collaborators. Several of these musicians have collaborated with Anthony Braxton (Mitchell, Schoenbeck, Smythe, Reid, Sorey). Mitchell, Reid and Schoenbeck have all performed together, and Sorey, Smythe and Tordini have each performed with Mitchell. Sorey has also played with Lee and conducted a project in which Schoenbeck performed. They seem to form part of a larger network of genre-fluid performers that contribute to enabling this type of cross-genre collaboration in music today.

Composing for improvisers involves negotiating a balance between control and non-control, specificity and ambiguity, preplanning and spontaneity. Vijay Iyer writes that "Where performers need scripts, improvisers need stimuli and constraints. Composing for improvisers becomes a kind of architecture: the construction of spaces that frame, enable, and contextualize human action, without overspecifying these actions" (2007). Mitchell has expressed similar priorities around the music for Mandorla Awakening, saying "I wanted to make music that didn't constrict the musicians, but allowed them to be who they are. And at the same time, I wanted to guide the piece and shape it" (Walls 2017, emphasis mine). Having discussed choices of collaborators with musically multiplicitous ${ }^{62}$ backgrounds, I turn now to the strategies used by the three composers to guide and shape musicians, while still allowing them the agency to "be who they are."

\section{Ensemble dynamics: compositional strategies to allow for performer agency}

Composers employ various strategies to allow for agency of performers, and these strategies vary by genre. Some of the practices that differentiate musical genres including relationship to notation, division of labour and roles of various instruments, approaches to time and rhythm, and relationship to improvisation. In jazz, notation (when used) is often a kind of shorthand, based on which performers elaborate their own parts. There is typically a distinction between the roles of

62 Ethnomusicologist Mark Slobin has theorized "musical multiplicity" as "multiple-source, multiple-leveled music-making" $(2007,108)$. The term has also been employed by ethnomusicologist Amanda Scherbenske in her research about New York improviser-composers who belong to similar networks and employ similar practices to the musicians I am discussing here (2014). 
rhythm section instruments (bass, drums, and chordal instruments), which provide the consistent rhythmic foundation that is traditional in jazz, and the role of the melodic instruments, which play melodies and improvise in a soloistic fashion. After the advent of free jazz these conventions started to be subverted more frequently, with inclusion of more diverse approaches to improvisation, including "free" and collective improvisation, and more variable and expressive rhythmic approaches (Jost 1994).

Western classical and new music practices typically involve much greater notational specificity, with assigned parts and clearly defined expectations for each instrument. Rhythm tends to be used as a fluid and expressive element, with more use of rubato (Zimmerli 2016). When improvisation is emphasized, there may be more clearly defined systems that prioritize the composer's intent rather than performer agency (G. E. Lewis 2002b, 239-41).

\section{Way Out East}

In Horvitz's liner notes to his album Way Out East (2006) he writes that he had been searching for an ensemble that could "bridge the gap" between through-composed chamber music and his lifelong love of small group improvisation (Wayne Horvitz Gravitas Quartet 2006). The gap that Horvitz describes, between interpretation of notated material and improvisation, is one of practice. In Lee, Schoenbeck and Miles he found the potential to realize such a band. Horvitz became acquainted with Lee and Schoenbeck through performing with them at Time Flies, an improvisation festival in Vancouver following Derek Bailey's "Company" model. ${ }^{63} \mathrm{He}$ was acquainted with Miles through the jazz world. Horvitz emphasized in our interview that the material for the Gravitas Quartet was written "for the musicians in the band" rather than for a general piano, trumpet, cello and bassoon instrumentation. He spoke of the possibilities afforded by each musician's unique strengths:

After a while you start to know what's going to work for whom. I mean, Ron was perfectly capable of making all sorts of interesting noises, as were Sara and Peggy. And Peggy and Sarah were perfectly capable of taking very beautiful, melodic type

${ }^{63}$ Derek Bailey formed Company in 1976 as a collective of improvisers that performed in "semi-ad-hoc" groupings. This later developed into an annual event called Company Week (Bailey [1980]1993, 133-39). 
solos, but Ron was always going to be the king when it came to a certain kind of changes $[. .$.$] particularly if there was anything that hinted at jazz or swing, he was just$ going to kill it. And you know, both Sara and Peggy were just so gorgeous, in the more inside stuff. Sara's a master of sound, but Peggy's sonic language is just...particularly mind-blowing. And her ability to mix up something that was very traditional with something that was very sonic, kind of all in the same breath [...]so, I couldn't have picked a better band. ${ }^{64}$

The varied strengths and fluencies afforded by the different band members contributed to the band's ability to move between different improvisational practices. These include the soloistic, harmonically and rhythmically grounded improvisation that is traditional in jazz, or more timbral, harmonically open and collective improvisation more common in free jazz or creative music contexts.

The instrumentation of the Gravitas Quartet is non-standard, and it is particularly notable that it does not include the traditional rhythm section instruments of bass and drums. Cello and bassoon in particular are little-used instruments in jazz, and as such have no clearly defined instrumental role. Horvitz described the inclusion of these instruments as "a stroke of genius" due to the large range of both, and their ability to cover basslines as well as play melodies. ${ }^{65}$ This fluidity around instrumental roles creates a collaborative and egalitarian feel to the Gravitas Quartet's music, as the four musical voices of the band members take turns moving from foreground to background, melody to accompaniment. In the absence of a traditional rhythm section, each member is jointly responsible for the group time construct, which runs the gamut from collectively felt swing or straight-eighth grooves, to more fluid, rubato executions. This is not music that foregrounds personal virtuosity, but rather a music in which the individual voices of the improvising musicians intertwine to create a new, collective entity, a sound that is truly interdependent.

Horvitz also spoke of the members' strengths in interpreting notated material, as is common in Western classical contexts, and that sometimes they would collectively arrange his compositions in rehearsals, a practice that is common in the jazz world (Berliner 1994, 64). His

\footnotetext{
${ }^{64}$ Wayne Horvitz, interview by author, Skype, September 12, 2018.

${ }^{65}$ Wayne Horvitz, interview by author, Skype, September 12, 2018.
} 
choice to refer to the Gravitas Quartet as a "band" seems significant in that later in the conversation he emphasized his appreciation for bands, "groups that are larger than the sum of their parts," naming the Band, the Beatles, and the Art Ensemble of Chicago as examples of this type of musical collective. ${ }^{66}$ The Gravitas Quartet, though created by Horvitz for the purpose of realizing his vision, feels like such a unit. There is a collective spirit to their music, a give and take, with each distinctive musical voice contributing to form a uniquely satisfying whole.

\section{The Inner Spectrum of Variables}

The double-trio instrumentation Sorey employs on The Inner Spectrum of Variables suggests that this work would be in the tradition of previous jazz-plus-strings collaborations, such as Jim Hall's "Piece for Guitar and Strings," (J. Lewis, Schuller, and Hall 1960) or John Lewis's "Sketch" and "Conversations" (The Modern Jazz Quartet 1966). Sorey referenced this history in an interview:

Too much of a lot of the music I've listened to [for similar double ensembles] would often have the jazz group in the foreground, and the classical ensemble in the background... But what I wanted to do was something a little bit different from that, where the string trio and the piano trio sort of interact together. And not only interact just together as two trios, but also as three duos... or have all of these different sort of relationships going on within the music. (Rentner n.d., edited for clarity)

The "jazz in the foreground, classical in the background" tendency Sorey mentions has been described as the "concerto-grosso format," by David Joyner, who attributes its prevalence in jazz/classical collaborations to the difficulty of getting classical players, particularly string players, to swing $(2000,83)$. In choosing to collaborate with string players that have prior experience with jazz and improvisation and are able to improvise and play over a groove, Sorey created the necessary conditions to subvert this typical distribution of labour. Smythe's and Tordini's high degree of skill in interpreting notated material (and, in Tordini's case, in playing with a bow) are also essential ingredients in achieving this versatility.

${ }^{66}$ Wayne Horvitz, interview by author, Skype, September 12, 2018. 
An examination of some of the instrumental combinations Sorey uses in the work demonstrates that he has certainly achieved his goal of moving beyond segregated classical and jazz ensembles. The piece explores several textures including strings both as a trio and as a quartet (with double bass), the strings with piano (as a chamber ensemble), the jazz trio alone and also providing accompaniment while a string player improvises, the entire ensemble improvising together, and many separate sub-combinations, such as cello, double bass and drums in "Movement II" (8:48, album version). Overall, Sorey creates an integrated and egalitarian relationship between the two trios - in fact, treating them as one large ensemble that affords many possible sub-combinations of instruments, and a wide spectrum of musical references and stylistic fluencies.

Another strategy Sorey uses for subverting the bifurcation of the work into jazz and classical elements is incorporating conducted improvisation into the work. Sorey's approach to conducted improvisation is informed by the work of Lawrence "Butch" Morris (1947-2013) and Anthony Braxton, both of whom are acknowledged in the album's liner notes (The Inner Spectrum of Variables 2016a). The most well-known proponent of conducted improvisation, Morris developed a trademarked system called Conduction, which he described as "a bridge... between notation and improvisation" (Morris 2017, 39). The system uses a lexicon of pre-determined hand gestures to direct ensembles in improvisation in real-time. Morris originally developed Conduction as a way to "make notation more flexible," using it to spontaneously arrange composed materials, but eventually came to focus on using Conduction alone to generate musical works in real-time in collaboration with ensembles of improvisers (Morris 2017, 34-35). Sorey worked as a sideman with Morris between 2003 and 2008. In an essay in memoriam of Morris after his death, Sorey wrote: "That Butch was able to create a trans-idiomatic music, simultaneously embracing and altering a wide range of musical traditions, led me to the understanding that music is a direct language that can be communicated and developed with anyone, from anywhere, at any time" (Sorey 2014), a legacy which Sorey continues to explore in his work as whole.

Sorey has also worked extensively with Braxton, and completed his Master of Arts in composition under Braxton's guidance at Wesleyan University from 2009 to 2011. During this time he had the opportunity to conduct Braxton's ensemble, and was encouraged by him in 
spontaneously altering the structure of Braxton's works in performance, an experience which he said "gave me the opportunity to grow as a spontaneous composer" (Sorey, quoted in Adler 2016).

The video of the live performance of The Inner Spectrum of Variables provides valuable insights into how this process of spontaneous composition manifests in this performance (Sorey 2017b). At various points in the performance Sorey can be seen conducting the ensemble with a baton, adding orchestral colour or metric time on his extended percussion set, and cueing the ensemble with various hand signals. One example of a particularly fluid transition occurs from 35:45, where Sorey can initially be seen providing a conducted pulse but then begins to move the baton in a wavy, horizontal line (35:56), seemingly depicting a musical gesture, to which the strings respond with a texture of overlapping undulating lines. Once this is established, Sorey stops conducting and nods along while the strings maintain this texture until he cues a piano entry at 36:20. It is as though, in one fluid movement, Sorey has ushered the ensemble into a new mode of interaction. Watching this, I find myself envying this fluidity to move on and off the page at will, and to think of and execute compositional ideas in real-time with an ensemble.

\section{Mandorla Awakening}

Like the Gravitas Quartet, the ensemble that performs Mandorla Awakening employs a nonstandard instrumentation. However, the Mandorla Awakening encompasses an even broader range of musical languages, traditions and aesthetics. As well as featuring instruments that are traditionally associated with Western classical music, such as flute, violin and cello, and with jazz, such as electric guitar, bass and drums, the ensemble also includes shakuhachi, taiko, shamisen, oud, banjo and live electronics. The musicians featured come from various musical backgrounds, with the most predominant strand represented being the Chicago-based creative music tradition associated with the AACM. Other musical traditions represented in the ensemble include classical music, traditional Japanese music, Arab and Turkish music, experimental electronic music and interdisciplinary arts performance. ${ }^{67}$

${ }^{67}$ A number of the musicians perform on multiple instruments, which is another factor in expanding the sonic possibilities of the group. Multi-instrumentalism is a hallmark of practice in the AACM (Jost 1994, 169). 
In our interview, Mitchell shared the importance of flexibility in her practice:

When you are in the AACM you learn how to approach having different unusual configurations of instrumentation and how you can make music with any situation. [...] And that's a really encouraging kind of skill to attain, once you feel comfortable with whatever happens and the unpredictable, because that's how life is. And it helps you to be able to adjust, and I like creating challenges for myself. ${ }^{68}$

Rather than defaulting to conventional ensemble configurations, Mitchell seeks to be adaptable to a wide range of musical contexts. This approach is pragmatic and empowering, and shows a willingness to question traditional assumptions about what is essential or necessary to create music. Perhaps the fact that Mitchell's instrument is a non-standard instrument in jazz contexts may have contributed to her ability to think outside the box with respect to instrumentation. Mitchell's choice to work with instrumentation and musicians from multiple traditions is directly connected to the conceptual underpinning of the work, and is another way of enacting the model for diversity that her narrative explores.

Mitchell's flexible approach is further demonstrated in the variety of strategies she employs for communicating her ideas to musicians. While some of Mitchell's previous works make extensive use of Western notation (such as her 2011 orchestral work Flight for Freedom, which features an improvising flute part and fully notated orchestra parts ${ }^{69}$ ), this project saw her take a different approach. As she describes it:

I had gotten to a place where I had been over-composing a lot, I can get very intricate in my writing. I really wanted to get back to the improvisation. I wanted to make music that didn't constrict the musicians, but allowed them to be who they are. And at the same time, I wanted to guide the piece and shape it. The scores for this piece are mostly graphic: a mixture of [traditional] notation and graphic symbols. And I wrote everything by hand - I didn't use a computer at all, in terms of [composing] the music. (Walls 2017)

\footnotetext{
${ }^{68}$ Nicole Mitchell, interview by author, Skype, September 28, 2018.

${ }^{69}$ Nicole Mitchell, interview by author, Skype, September 28, 2018.
} 
Mitchell's choice to use a mix of traditional and graphic notation can be seen as yet another plane of the work in which she explores the collision of contrasts: in this case, contrasting notation styles, each with strengths in conveying different types of information. Her choice to limit the quantity of notation and make room for improvisation indicates that, rather than tightly controlling the musical result, she wished to prioritize giving space and agency to the individual performers, allowing their musical personalities to be expressed. It seems likely that this strategy was developed while keeping in mind the skillsets of the performers on this recording. Perhaps the deprioritization of Western notation also served as a way to better harness the skills of the improvisers who are fluent in traditions other than jazz and Western classical musics.

The approaches to time and rhythm on this album are varied. As discussed in Chapter 4, there is considerable use of rhythmic independence between two halves of the ensemble. Often one half of the ensemble plays a groove or metric time, while the other simultaneously plays rubato, a practice that calls to mind Anthony Braxton's work with collage music (Lock 1988, 203-6). ${ }^{70}$ Mitchell also employs rhythmic heterophony, in which multiple performers play the same phrase, but in their own time and in their own way, creating an overlapping effect. These divergent rhythmic aspects of the work seem connected to the traditions of free jazz and creative music. Yet other aspects of the rhythmic approach are more traditional, such as the unified, groove-based approach of the drums and bass, which connects this piece with common practices in the jazz tradition. With the exception of the bass and drums rhythm section unit, the unusual instrumentation of the ensemble makes it difficult to anticipate or predict the allocation of instrumental roles.

In curating their own ensembles and developing works that correspond to the strengths and backgrounds of each musician, each of these composers is taking an Afrological approach to composition. Their ensembles employ elements of jazz practice, such as the use of groove-based time, particularly in the rhythm section, and soloistic improvisation. They also employ free and collective approaches to improvisation, and more fluid rhythmic expression, as in free jazz and creative music practice. The practices of these three ensembles show varying degrees of influence from the Western classical tradition. Mandorla Awakening shows the least influence, seeming to

\footnotetext{
${ }^{70}$ Mitchell has cited Braxton's use of "democracy and shifting between configurations" as an influence on Mandorla Awakening (Walls 2017).
} 
draw more on jazz and creative music practice, as well as the individual backgrounds of the improvisers (for example, inflections on the shakuhachi), whereas the The Inner Spectrum of Variables seems to feature most evidence of ensemble behaviour in the tradition of Western classical music, such as chamber ensemble-type rubato phrasing and following a conductor. The Gravitas Quartet sits somewhere in between, combining notated and improvised material in more equal measure.

\section{Writing for new music and Western classical ensembles: the "composer" model}

As well as composing for their own ensembles, Mitchell, Sorey and Horvitz also compose for preexisting new music or Western classical ensembles. In these contexts they do not have the same freedom to make individual decisions about personnel, and must navigate existing conventions around notation, using or not using improvisation, and rehearsal protocol. Each of the three composers has had varying experiences and developed a range of approaches to this type of collaboration.

In our interview, Horvitz discussed his recent recording Those Who Remain (Horvitz 2018). The album features a composition of the same name for orchestra and improvising soloist, performed by the Seattle Symphony and Bill Frisell, and These Hills of Glory, a work for string quartet and improvising soloist, featuring clarinettist Beth Fleenor. The parts for orchestra and string quartet are fully notated. As Horvitz describes it:

My feeling is that I've got these people who've spent their whole life learning to interpret notation - I'm going to take full advantage of that, you know what I mean? And so, these pieces are conservative in the sense that they're not really breaking any boundaries, it's just that the concerto aspect of it is improvised. ${ }^{71}$

This strategy of allowing improvisers and classically trained musicians to each "do what they do best" is about creating a situation in which all participants are able to work within their "comfort zone.” By combining practitioners from different genres or communities within a single piece,

\footnotetext{
${ }^{71}$ Wayne Horvitz, interview by author, Skype, September 12, 2018.
} 
Horvitz draws on multiple traditions. There is a sense of pragmatism to this approach, and also perhaps an empathy and consideration for the experience of the players. He emphasizes the importance of knowing your players and knowing the context.

Tyshawn Sorey has a long working relationship with the International Contemporary Ensemble, and I asked him about early challenges when composing for this ensemble:

One of the things that was a little tricky for me at first was asking them to improvise (laughs). You know, that's something I've never done before. I believed in the idea of getting them to improvise, but I was afraid that they wouldn't want to do it. [. . .] But then, of course they were open to doing it, and so it led to some interesting musicmaking at that point. And then, in fact, one of the first things I said to [International Contemporary Ensemble director] Claire Chase, upon meeting her at ICElab, was: "Listen, some of my music has improvisation in it, but I'm not concerned with the idea of improvisation versus composition, or jazz versus new music, or jazz versus classical - I'm not interested in any of that. I just want to make a singular music that involves all of us responding together, through improvisation or through playing written music, or whatever, because none of these things are separate to me, you know, composition and improvisation, I mean, they're never separate things. It's all composition, really, for me.

Sorey's commentary shows a sense of riskiness that came with asking a new music ensemble to improvise, perhaps due to transgressing the bounds of typical practice in that context, and the importance of the performers' openness to taking that risk. Sorey's comments about improvisation and composition being "all composition...for me" show his commitment to the idea of composition as an activity that can be both collective and spontaneous.

When I asked Mitchell about challenges posed by writing for classical contexts, she described her first "really scary" experience at a reading for the American Composers Orchestra, in which she was sitting and listening and felt powerless to fix what was going on:

I felt like...they were playing the right notes, but[...]the kind of detail that you have to write to get $[\ldots]$ the way of approaching the phrasing, and even the time, is so hard, 
you know what I mean. And this idea of working with an improvised ensemble, and the kind of connection you have with them, and the gesturing and the communication and, like, stuff that really the written music can't fully do. ${ }^{72}$

Here Mitchell speaks to differing practices around notation and rehearsal protocol between the genre worlds of jazz and creative music and Western classical music. When working with an ensemble of improvising musicians, the composer/bandleader often works and plays directly with the musicians, and some important aspects of musical communication are not encompassed in the written music but occur through discussion, or "gesturing and communication." The compositional material that is brought into rehearsal may be in some ways unfinished, and intentionally so, so that performers can put their own stamp on it, or approaches to the material can be workshopped in rehearsal. In contrast, when writing for orchestra, all of the compositional decisions must be made in advance. Rehearsals are led by the conductor and focus on executing what is on the page. Thus, when watching the rehearsal and hearing that the music was not as she wished, Mitchell felt unable to fix it, as it was already too late.

And the other part is the performance practice of new music ensembles really not being as invested in rehearsal as improvising groups, because of the structure, the hierarchical structure of money, and how much it costs, per minute (laughs), for rehearsal. So, how do you actually have the time to make a breakthrough if people don't have time to actually learn something new, it's like you have to give them something they're already familiar with in order to do it well, but then how do you break anything? You know what I mean, so that's the challenge. ${ }^{73}$

These commentaries demonstrate the differences between practice in these different genre worlds, including the degree of notational specificity required, whether improvisation is typically included in performance, expected rehearsal procedures and the way information is transmitted from composer to performers. Transitioning from self-directed, bandleader/composer activities into

\footnotetext{
72 Nicole Mitchell, interview by author, New Smyrna Beach, FL, July 10, 2019.

${ }^{73}$ Nicole Mitchell, interview by author, New Smyrna Beach, FL, July 10, 2019.
} 
more of a classical composer role can involve a change in protocol which may necessitate adaptation or finding new strategies for communication.

\section{Funding and systemic constraints}

Considering differences in practice between genre worlds leads me to wonder how inequalities in funding, infrastructure and cultural capital or status afforded to different musical traditions affect musicians working between genres. As Holt has argued, "[Genre] is a major force in...cultural hierarchies, and decisions about...funding” (2007, 3). Jazz and creative music have historically enjoyed less philanthropic and grant support than Western classical music. Lewis has written on the paucity of funding support for jazz and creative music during the 1970s, at which time the NEA and the Guggenheim Foundation were among the first to offer funding support to jazz musicians, and the Pulitzer Prize "was completely closed to jazz-classified improvisers; no black composer had ever won the award" (2008, 400).

Thankfully, some changes have been seen with regard to the Pulitzer, which has since been awarded to Black composers working in and across several different genre worlds, including Wynton Marsalis (1997), Ornette Coleman (2007), Henry Threadgill (2016), Kendrick Lamar (2018) and Anthony Davis (2020). Some new grants and awards have emerged in the intervening years which have supported artists in the fields of jazz and creative music, including the Doris Duke performing artist awards and the MacArthur Fellows Program. This development seems likely to be related to jazz's changing position in in the cultural hierarchy, as it moves further towards the status of "art music." Yet, it is unclear how much progress has been made as a whole in reaching some kind of economic parity in this historically underfunded artistic sphere.

Nicole Mitchell, Tyshawn Sorey and Wayne Horvitz work at the intersection of multiple genre worlds, including those of Western classical music and jazz, and they also work both inside and outside of this kind of institutional support. They have each been the recipient of grants and awards. Sorey's work has been supported by the Jerome Foundation, The Shifting Foundation, the Van Lier Fellowship, and he was a 2017 MacArthur Fellow and a 2018 United States Artists Fellow. He also received a Doris Duke Impact Award (2015). Nicole Mitchell has been a recipient of the Herb Alpert Award (2011), the Chicago 3Arts Award (2011) and the Doris Duke Performing Artist 
Award (2012). Horvitz has received the Doris Duke Performing Artist Award (2016) MAP Grants and the NEA Masterpiece Award.

Each of these composers has each been commissioned by prominent ensembles and presenters: for Sorey, these include the Los Angeles Philharmonic, the JACK Quartet, Alarm Will Sound and tenor Lawrence Brownlee with Opera Philadelphia in Partnership with Carnegie Hall. Mitchell has been commissioned by the French Ministry of Culture, the Art Institute of Chicago, the Stone and the International Contemporary Ensemble. Horvitz has been commissioned by the NEA, Meet the Composer, the Kronos Quartet, Seattle Chamber Players, Brooklyn Academy of Music and Earshot Jazz.

Yet, these composers also continue to self-produce their own work. While I did not specifically ask these composers about their income streams or financial limitations on their work, some of their comments indicated that they may be impacted by the interaction between genre and constraints of infrastructure and funding. In my interview with Sorey, he mentioned that he decided to create a situation for himself to compose for strings with The Inner Spectrum of Variables because nobody was commissioning him to write for strings. ${ }^{74}$ In another interview, when asked why he chose to compose for string trio rather than for string quartet, his first (laughing) response was "budget" (Rentner 2017). Horvitz mentioned in our interview that it took him two years to raise the money to record Those Who Remain with the Seattle Symphony. ${ }^{75}$ Mitchell also commented on the differing economies and rates of pay between art worlds of new music and creative music, as in her comments above about "how much it costs, per minute" to rehearse in new music contexts. In her essay "What Was Feared Lost," she writes on the economic constraints of creative music, which she describes as existing "inside a margin's margin [...] jazz in a margin of classical (minus) creative music in the margin of jazz" (Mitchell 2017a, 232).

This is a complex topic, and an in-depth investigation of it is beyond the scope of this exegesis. However, more research is certainly needed into the political economies of jazz, creative music

\footnotetext{
74 Tyshawn Sorey, interview by author, Skype, June 2, 2018.

${ }^{75}$ Wayne Horvitz, interview by author, Skype, September 12, 2018.
} 
and other music between genres, as well as into how race and gender intersect with these various genre worlds.

\section{Conclusions: the spectrum of variables}

The range of ensemble formations, musical aesthetics, and practices employed by each of these composers is one of the most striking aspects of their musical careers. These composers move between bandleading and commissioned compositional work, between notation and improvisation, and between metric and non-metric rhythmic approaches, disregarding differences in practice that have traditionally divided musical worlds. Their professional activities seem to exist between the art worlds of jazz and new music, sometimes resembling the model of the "classical" composer, who receives funding support and is commissioned to write for orchestras or new music ensemble, and sometimes resembling the model of the composer/performer/bandleader, as is typical in the jazz and creative music traditions. Yet within each composer's body of work, individual works do not fit neatly into these two categories, but instead draw freely from multiple streams of musicmaking.

These composers approach communicating their music to their musicians in a range of ways, from notation-heavy scores to more collectively devised works. Their work allows for many different types of ensemble behaviour, again highlighting process. Collaboration with musicians who share their musical fluencies, and who also bring their own unique skills and competencies, is an essential part of the creative practice of all of these musicians. The backgrounds of the musicians they work with vary widely, ranging from conservatory-trained musicians to jazz and creative music improvisers, as well as musicians fluent in any number of musical traditions. They allow space for spontaneity and for elements of the music to be uncontrolled through the use of open improvisation or conducted improvisation. They incorporate both soloistic and collective improvisation into their works. Aspects of the works may be co-created with performers, allowing them agency, yet the composers still find ways to exert their guiding visions.

Their strategies for communicating ideas vary depending on the skillsets of the performers. Sometimes they choose collaborators precisely because of their fluency with multiple musical traditions; sometimes they compartmentalize musicians more according to their training or skillset; 
and sometimes they ask their performers to do something out of their comfort zones, which can be challenging, but also can lead to growth and discovery. Employing ideals of flexibility, spontaneity, collectivity, and a belief that they can make music with anyone, the different processes of these composers allow them to forge new pathways of connection between genre worlds which are often separate. 


\section{CHAPTER 6: REFLECTIONS ON THE CREATIVE PORTFOLIO}

As I near the completion of my doctoral project, I have been reflecting on the relationship of my research to my creative work developed during the same time period. My primary goal in pursuing this doctorate was to expand my resources as a composer. Specifically, I wanted to gain experience in writing for traditionally "classical" instrumentations such as chamber ensembles and orchestra, and to explore combined ensembles made up of improvising and non-improvising performers. I wanted to get beyond many of my compositional defaults, which are those that are common in jazz practice: the "head-solos-head" structural convention, the use of cyclical forms for improvising, the tendency to compose in four- and eight-bar phrases, and rigidly defined instrumental roles of rhythm section and soloist. I wanted to expand my harmonic concept, and write longer, more elaborately notated and organized works. All this was with a view towards establishing myself as a composer in the art music realm, avoiding the limiting description of "jazz" composer, and recovering the agency of being a composer with looser ties to a specific genre.

I chose to focus my research on engaging with the music and discourses of Mitchell, Sorey and Horvitz because I am inspired by the ways they traverse genre boundaries in their work. While I am a fan of the work of these composers, I have (for the most part) not directly sought to emulate specific musical-technical aspects of their work. Instead, I have followed my own musical instincts in search of a personal sound that similarly is not constrained by generic boundaries. However, there are some instances in which I have drawn direct influence from the works of the three composers. On "Egoes War," Nicole Mitchell superimposes non-metrical rubato melodies over a metrical groove in the rhythm section. I took inspiration from this concept in the opening of Movement III of Sanctuary ("Inevitable"), in which I superimpose a rubato melodic line over a metric ostinato in the rhythm section. While this temporal independence is a more central feature of "Egoes War," here I have used it only briefly, creating a sense of tension and suspended animation until, on a cue, the melody snaps into time with the rhythm section below.

In my analysis of the Inner Spectrum of Variables I was struck by Sorey's juxtaposition of tightly composed materials with free and collective improvisation, often over a mode or drone. This influenced my choice to insert the loosely composed "Interlude" as a transition between Movements I and II of Sanctuary, within which the bass and rhythm section improvise while the 
horns play a rubato, asynchronous modal melody over a drone. Although the musical materials I have used differ from Sorey's, his work taught me that it is possible to juxtapose these very different types of musical material effectively within the same work.

Horvitz's Gravitas Quartet provided a different sort of inspiration and influence early on, serving as a useful example of subversion of traditional paradigms of instrumentation in jazz, instead combining musicians skilled in both improvising and executing composed material into a chamber-ensemble-like band that could flow freely between these two states. This example inspired me to think of local musicians I knew who could move between these different modes of music-making, and to form a new ensemble, the Noveltones (discussed further below). This experiment in using non-typical instrumentation both created new challenges and opened up new musical possibilities, and is an area that I plan to explore further.

These examples demonstrate that my engagement with the work of these composers has been mostly conceptual. Throughout this project, I have been in a process of dialogue with their ideas and their work, using the insight gained from this dialogue to reflect on who I am and what I want to be doing as a composer, in its similarity and difference. My analysis of their work has led me to think more deeply about process, especially the relationship between composed and improvised approaches, and the possible reasons for choosing either of these approaches in a given situation. Through researching the contexts for the works and discourses of the three composers, particularly the AACM and the Downtown scene, I have gained a deeper understanding of the precedents for their work. I have also learned more about my own aesthetic orientations and biases, and gained a deeper understanding of my relationship to jazz, genre, and the broader tradition of Afrological music-making.

My own history of music-making also combines many different streams. I studied classical music in childhood; I developed an interest in singer-songwriters, alternative rock and jazz saxophone performance in high school; and my undergraduate education focused on canonic 1950s jazz practice. I changed my focus to jazz composition, and came to love the music of Wayne Shorter and 1960s-era jazz in general. I had a mind-opening experience at the Banff Jazz Workshop in 2008 under the directorship of Dave Douglas, where I was exposed to contemporary artists from the New York jazz scene for the first time. I lived in New York from 2010 to 2012, where I attended 
numerous gigs and received an education in contemporary jazz practice, including exposure to creative music and more avant-garde forms of jazz. I played with like-minded musicians, forming my first consistent band and recording my debut album. During my years at Wesleyan University in 2012-2014, I learned about the music of Anthony Braxton and post-Cageian American composers. I lived in Morelia, Mexico from 2014 to 2016, spending my time learning Spanish, teaching the saxophone, auditing a composition workshop with Hebert Vázquez and performing as part of the city's very small jazz scene. And, for the last three and a half years at the New Zealand School of Music, I have been working towards a doctorate as part of the composition department and reconnecting with the jazz, improvised and new music scenes of New Zealand.

On reflection, this project seems to me to have been my attempt to find a way of combining all of these different streams of music-making, of integrating them into my compositional language and of making them make sense together. It is no easy task. I see all of these various genre worlds as both overlapping and representing distinct approaches. While many of the aspects that divide these genre worlds seem arbitrary and more based on social aspects than intrinsic musical difference, other aspects of the value systems that underpin them seem incompatible and directly opposed to one another. It is not immediately clear how to reconcile the idea of the work as located in the musical score versus being collaboratively realized in performance, the idea of authority belonging to the composer rather than being shared amongst performers, or the idea of a work as fixed and permanent versus fluid and in process. I have struggled with where to position my work in relation to dialectics of innovation versus tradition, complexity versus accessibility, intellect versus intuition, specificity versus fluidity, and preplanning versus spontaneity. This portfolio of works demonstrates some of the spectrum of solutions that I have so far found to these conundrums.

\section{Compositional process}

This DMA project was designed to push me beyond my compositional comfort zone and grow my work in some new directions. This necessitated making changes to my process of composing. The compositional process I had developed over the preceding years was a fairly intuitive one in which I would find an opening melodic phrase, a chord progression, a vamp or ostinato, or sometimes a poem, and intuitively develop it into a song-form-like melody. While sometimes this process 
would be long and drawn out, at other times I would complete a composition in a single sitting. I would typically notate these melodies in jazz lead-sheet style, and then realize them in performance with an ensemble of jazz musicians, experiencing a particular magic when their contributions brought my ideas to life in unexpected ways. Though I had also written some larger, more elaborately arranged works and some chamber music over the preceding years, I had not become comfortable writing for these types of forces.

Although composing for improvisers is an important part of my compositional practice, I have spent most of the last three and a half years focusing on composition as the act of writing notes on the page. As I progressed further through the doctorate, I realized that I was not exploring as many modes of improvisation as the composers I was reflecting on, and that their exploration of different points along the spectrum from improvised to composed was one of the key aspects that drew me to their work. There were several factors that played into my primary focus on composition-asnotation during this doctorate. These included my preconceived ideas about what it meant to study towards a doctorate in composition, in the classical composition department of a university; the input of my supervisor John Psathas, who works extensively with notation (though also collaborates with improvisers) and often encouraged me to more specifically notate my musical ideas; and the strengths and comfort zones of the community of musicians who would perform my works.

The works in this portfolio occupy a variety of points on the ontological spectrum from fixity to fluidity, and include some larger-scale projects than I had previously attempted; specifically, Cerulean Haze and Sanctuary. I learned through this experience that composing notation-heavy music for large ensembles requires an investment of large amounts of time and focused attention, and involves delayed gratification. I worked intensively on the compositions of this portfolio with my supervisor John Psathas, and his input challenged me to develop my work in new ways. Rather than merely riding the first wave of inspiration until it ran out, as I might do when writing a piece for improvisers, I learned to develop my ideas more extensively, experimenting with new harmonic pathways and rhythmic variations. I followed these ideas down many musical dead-ends, eventually discovering solutions that I could not have arrived at by a flash of inspiration, but that needed this longer process of work and consideration to develop. I learned to think more about the feeling of the passage of time, and the emotional trajectory of my works, listening to where the 
music needed to go rather than superimposing a structural idea at the outset. I began to think more about orchestration; where before, many of my musical ideas were melodies that could be inhabited by any instrument, now I was writing parts with more specific timbres in mind. I focused in detail on each individual instrument's role, finding that development can occur on many levels of the work.

Making music in these new ways was often challenging and uncomfortable, and I spent much of this process getting stuck and then unstuck, as I struggled to integrate these new approaches with my existing creative practice. Though I wanted to expand my compositional language, I missed the flow and comfort of my habitual approaches to composing, and the sense of endless possibility I felt when realizing my loose frameworks for improvisation in performance. Becoming more specific and prescriptive about my musical ideas opened up new possibilities for how my music could sound, yet closed off many possible pathways through the material that could have been chosen by improvisers in performance. In the later stages of my doctorate, I began to crave more space, ambiguity and openness in my works, having gained the perspective that even if I now possessed the skills to notate a highly specific part for each instrument, it would not always make the music better to do so. In future work after this doctorate, I plan to explore improvisational dynamics as a more central feature of my works.

\section{Portfolio overview}

The creative portfolio developed as part of this research combines the genre conventions of jazz with those not typically employed as part of that genre world. The works included here explore varying degrees of notational specificity, and the inclusion of improvisation is prioritized in each work. Several of these works were realized in my capacity as composer/bandleader. These include "Jimmy," "Nuevo Azul," "Neither Here nor There" and "Metamorphosis," which were written for my improvising chamber quartet, the Noveltones (soprano saxophone, bass clarinet, violin and double bass); and "Noche Oscura" and Sanctuary (a suite in three movements), which were written for composers' collective the Arthur Street Loft Orchestra (trumpet, soprano saxophone, alto saxophone/bass clarinet, tenor saxophone, baritone saxophone/ bassoon, piano, guitar, bass and drums, along with flute on Sanctuary). 
Two of the works were commissioned for existing ensembles: "Moorings (Titahi Bay)" was commissioned by the 2019 Wellington Jazz Festival and premiered by the Montreal-based CODE quartet (alto saxophone, trumpet, bass and drums); and Cerulean Haze was commissioned in 2018 with the support of a Susan Rhind Award for local ensembles Stroma and the Jac (flute, clarinet, violin, cello, vibraphone, trumpet, alto saxophone, tenor saxophone, trombone, guitar, piano, bass and drums).

\section{Finding community and collaborators}

As a composer who usually writes for improvisers coming from an Afrological tradition, I enjoy writing for specific performers, with the expectation that they will bring their personalities as improvisers to the works and make them their own. The works in my portfolio have been influenced and shaped by the community of musicians that have performed them. When I began this doctorate, I had just returned to Wellington, New Zealand (the city where I completed my undergraduate degree and began my career as a jazz musician) after seven years based in the United States and Mexico. I embarked upon a process of reacquainting myself with the New Zealand jazz and improvised music scenes, and began to get to know the New Zealand new music community. I participated in this community in my capacity as a doctoral candidate at the New Zealand School of Music through attendance at composers' workshops, through auditing undergraduate orchestration classes, and through informal social gatherings with other graduate student colleagues from the composition department. I also attended new music concerts, both inside and outside the university.

I often felt out of place in these new music contexts, as it was hard for me to relate my creative work and approach to composition to the discourses and values that were prevalent in the new music world. I experienced feelings of disorientation and immobilization as I struggled with knowing how to do something that both appealed to my sensibilities and would be valued within the sphere of new music. I often felt that, within these contexts, my music was not intellectual, complex, or theoretical enough. It was too pretty, too soft, too subtle, too feminine. It was also too tuneful, too songlike, too formally obvious. It is hard to pin down where these ideas came from as, for the most part, they were not based on any comments that were specifically directed at me; rather, I extrapolated them from the prevailing discourses, or from casual conversations after 
concerts about what people liked and did not like. I struggled with the belief that, to be successful in this context (to receive a composition degree from a "classical" composition department) I need to become a different kind of composer.

I also re-engaged with the local jazz and improvised music scenes through attendance at gigs and jam sessions, and by participating as a saxophonist, composer and bandleader. The interconnected jazz and improvised music scenes had changed considerably in the years that I had been overseas. I was familiar with a number of musicians on the scene, but other musicians had left Wellington or changed careers, a new generation of younger musicians had emerged, old performance venues had closed and new ones had opened, and these and other factors had led to some significant aesthetic shifts in the orientation of the scene. Specifically, the jazz scene seemed to have an increased focus on straight-ahead, repertory jazz, and I noticed a growing divide between the jazz scene and the small and dedicated improvised and experimental music scene. I collaborated with musicians from both of these scenes, finding my most like-minded collaborators at the intersection of the two.

\section{The Noveltones}

In 2018, I formed a quartet with the instrumentation of soprano saxophone, violin, bass clarinet and double bass. The impetus for the group came from my desire to create an improvising ensemble with a chamber-music influenced instrumentation, inspired both by Wayne Horvitz's Gravitas Quartet, and by Jimmy Giuffre's works for drummerless ensembles. Like Horvitz, I wanted to bridge the gap between chamber music and improvisation (Wayne Horvitz Gravitas Quartet 2006), and, like Jimmy Giuffre, I wanted to escape "the insistent pounding of the rhythm section" (Giuffre 1955).

When considering possible ensemble members, my starting point was thinking of improvisers that played instruments less commonly used in jazz. I knew of violinist Tristan Carter as I had seen him perform both freely-improvised solo violin and as part of local jazz group the Troubles. Reedist Blair Latham was an excellent bass clarinettist and was fluent in both straight-ahead and experimental jazz idioms. Bassist Nick Tipping's jazz proficiency and background in classical music completed the ensemble. 
When compared with a typical jazz quartet instrumentation, the most apparent differences were the lack of drums or a chordal instrument, such as piano or guitar. My challenge was to figure out how the ensemble could sound complete without fulfilling these genre conventions of instrumentation. In my first piece for the ensemble, "Jimmy" (after Jimmy Giuffre), I experimented with treating each of the four instruments, including double bass, as a melody instrument, and creating a contrapuntal exchange between them. In our first rehearsal, I was struck by the clarity and transparency of the ensemble texture, and the ease with which all members of the band could be heard.

This contrapuntal strategy was effective for the composed, thematic sections of the piece, but I needed to give more thought to how to navigate the solo section. "Jimmy" is structured with a typical jazz formal organization of "head, solos, head," though the melodic phrases do not always conform to typical four- or eight-bar groupings. I experimented with composing some contrapuntal accompaniment lines in the solo section, but for the second soloist (violin) I initially provided only the chord changes in standard jazz fashion. This resulted in the ensemble texture dropping back to two players: the double bass walking the changes, and the violin improvising as a soloist. To solve this sudden drop-off in the ensemble texture, I looked for a strategy to involve the other two quartet members as accompanists. The solution I arrived at was to provide suggested pitches for each instrument, and an appendix page of suggested rhythmic phrases, which could be cued by band members to spontaneously create rhythmically unified accompaniments to improvised solos.

The two other early works for this ensemble were "Nuevo Azul" ("New Blue"), which explores more varied approaches to time, incorporating rubato, collectively felt metric time and metric modulation; and "Neither Here nor There," which developed out of experiments with harmony. The ensemble developed a repertoire of these and other works (including compositions by other band members, and older compositions of mine which I arranged for the ensemble), and performed in a variety of contexts, ranging from local experimental venue the Pyramid Club, to a jazz club, a bookstore, a photography gallery, and a refugee centre, as well as in concerts presented by Chamber Music New Zealand and recorded by SOUNZ, both organizations which support primarily Western classical and new music. 
This ensemble has largely stayed close to standard jazz performance practice, but the unique instrumentation and the varied backgrounds of the improvisers also offer the possibility of going in some different directions aesthetically, including towards chamber music, or free improvisation.

\section{"Metamorphosis"}

Recently, the Noveltones had a change of personnel and began working with bassist Tom Callwood, who is very comfortable in freely improvised contexts. A more recent sketch for this instrumentation, "Metamorphosis," is included here as an indication of a new direction for the ensemble. I wrote the piece as an experiment in the morning before a rehearsal, so that we could explore a new way of making music together. I had been feeling dissatisfied with the formal similarity of everything that I had written thus far for the ensemble, and the fact that I was using strategies for notation and arranging that were similar to what I would use with a typical jazz ensemble. My consideration of the processual, performer-dependent and collaborative approaches demonstrated in particular by Mitchell and Sorey led me to the desire to explore a less prescriptive approach to composing for the Noveltones, one which would invite the performers to interact more with the work.

The composed material is handwritten and fits on a single page. Due to the brevity of the work and my unfixed idea of how it should be interpreted, I was unsure if this composition would be interesting or substantial enough to engage the ensemble, or contained enough material to make for a complete performance. In rehearsal, we experimented with many different ways of playing the piece, and I discovered that, in fact, I had provided more than enough composed material. The band members were very engaged in the rehearsal process and contributed a number of suggestions about how we could realize the work in performance. In fact, they seemed to feel much freer to interact with the piece than they had with the longer, more fully orchestrated compositions I had previously brought to the band, suggesting that my use of less prescriptive notation, as might be more conventional in free jazz or creative music genre worlds, provided the performers with a sense of greater agency to contribute to shaping the work. My somewhat arbitrary decisions about the spacing of the notes seemed actually to convey a significant amount of information about rhythm and pacing, and also allowed space for a variety of interpretations. This piece signalled a 
new world of possibility, helping me to see that, sometimes, less really is more when it comes to notation - that less specificity can equal more agency, if you have the right musicians on the job.

\section{Cerulean Haze}

In 2018, my second year of doctoral study, I had the opportunity to compose a work that facilitated a collaboration between two local ensembles from different genre worlds: new music ensemble Stroma, and contemporary jazz octet the Jac. These two ensembles had met to discuss the prospect of collaborating, but had not yet found any suitable repertoire for their combined instrumentation, so when I expressed an interest in writing a piece for them, it was warmly received.

The Jac has a fixed instrumentation of trumpet, alto saxophone, tenor saxophone, trombone, piano, guitar, bass, and drums. Stroma has a variable instrumentation depending on the needs of the work, so I elected to compose for an instrumentation of violin, cello, flute, clarinet and vibraphone. I included the vibraphone because of its tradition of use in jazz and third stream contexts, as a bridge between the genre worlds.

I had written music that combined a jazz ensemble and a classical ensemble before, for jazz quintet and string quartet, on my album Yellow Red Blue (2016). In that instance, I had composed and recorded the music for jazz quintet first, then composed and recorded additional parts for string quartet afterwards. Though I was reasonably happy with the results of this, I was also very aware that the relationship between the two ensembles was one of soloist and accompaniment: I could have removed the string quartet and it would still have sounded like a complete piece of music. The two ensembles were never in the same room, so were not required to find a way of navigating time together and playing as a combined ensemble. This experience created a desire within me to compose for a double ensemble in which the jazz and classical ensembles were more intertwined, avoiding the "concerto-grosso format" (Joyner), and this is what I attempted to achieve with Cerulean Haze. I sought to vary the roles of foreground and accompaniment between the ensembles, and to explore a variety of sub-combinations from within the combined instrumentation, as well as featuring the massed double ensemble at climactic moments.

I also wanted to create a work that played to the strengths of the performers. Though I knew several individual members of the Jac and was familiar with their playing, I also spent time 
familiarizing myself with the recorded work of the Jac to get a sense of their personality as a group. The ensemble was initially formed in 2010 to play repertoire of the San Francisco Jazz Collective, but has for several years focused on performing original compositions by its members. Based on their prior recordings, I could tell that they were comfortable playing in odd time signatures and with executing substantial amounts of complex notated material, as well as improvising over jazz chord changes.

It was important to me to feature the Jac members as improvisers, and I chose to feature improvisation in multiple sections of the piece (in a foregrounded and backgrounded way), and to create a distinctive environment for each improvised solo (rather than just having one solo section that looped indefinitely). The improvised elements of Cerulean Haze include a guitar solo, a twosaxophone improvised duo, and more incidental improvisation including an alto saxophone flourish at the end of the introduction, improvised responses in the trumpet to composed ensemble figures, and brief solo spots for other band members over a vamp at the end of the piece. Aspects of the rhythm section parts are also improvised based on provided chords symbols and/or text instructions.

I had attended several concerts by Stroma, and I knew that they had varying personnel made up of experienced musicians, many of whom were members of the New Zealand Symphony Orchestra, and performed a wide cross-section of new music repertoire. As such, I saw them as being more chameleon-like as an ensemble, and less fixed in their musical identity than the Jac. Although I did consider incorporating an improvised or aleatoric aspect into their parts, I decided against this and in favour of relying on traditional Western notation, choosing to stick to more of a "comfort zone" approach in the vein of Wayne Horvitz.

The genesis of the piece was from a modal-ish melody over a $\mathrm{C}$ drone, which starts minor and becomes major at the close of the melody. The harmony of the piece is generally modal and jazzbased. I used an intuitive approach to harmonizing the work - though I had experimented with some alternative approaches to pitch organization in my first year of doctoral study, it felt awkward and stilted to me to do so, so instead I focused on expanding my harmonic palette in a more intuitive way. 
I did not have a clear idea of an overarching form for the piece upon beginning to compose it. The eventual form is all derived from the songform-esque melody that was the initial impetus for the work (letters B-D in the score). With a duration of thirteen minutes, this was also one of the longest pieces I have composed, and as such necessitated coming up with strategies for formal organization and managing the trajectory of the work in a more extensive way than I had previously done (see Table 2). Managing the flow of energy in the piece meant devoting more attention to instrumentation, and to the development of the ensemble texture and within each individual part as a whole, than I had done previously. Throughout the process of working on this piece, my supervisor John Psathas kept challenging me to further develop and be more specific about my musical ideas. I realized that, in my typical practice of writing lead-sheets to perform with a small group, I relied a lot on the members of the rhythm section to develop the rhythmic underpinning and manage the energy and flow of my compositions. In this work I took more ownership of that aspect, composing gradually accumulating ostinati in the vibraphone and guitar, and managing the rhythmic and harmonic journey over the whole span of the piece. I did still choose to incorporate improvisation in the drum part, but gave more specific instructions about how the dynamic progression and development should unfold throughout the work than I had done in the past.

Table 2. Formal Map of Cerulean Haze

\begin{tabular}{|l|c|c|}
\hline Section/description & Timecode & Rehearsal \\
\hline $\begin{array}{l}\text { Introduction }- \text { Harmony abstracted from the main melodic } \\
\text { theme. Conducted rubato, composed to sound improvised. }\end{array}$ & $0.00-2: 31$ & Start \\
\hline $\begin{array}{l}\text { Opening melody foreshadowed on cello. Transition from rubato } \\
\text { to establish groove in 5/4 time signature. }\end{array}$ & $2: 31-3: 35$ & A \\
\hline $\begin{array}{l}\text { Main theme: A, A }{ }^{1}, \mathrm{~B}, \mathrm{C} \\
\text { Mostly performed by Stroma, members of the Jac gradually } \\
\text { creep in and take over towards the end. }\end{array}$ & $3: 35-4: 09$ & $\mathrm{~B}, \mathrm{C}, \mathrm{D}$ \\
\hline
\end{tabular}




\begin{tabular}{|l|c|c|}
\hline $\begin{array}{l}\text { Main theme again, variation. Mostly performed by The Jac with } \\
\text { added winds and vibes. Incidental trumpet improv in gaps of } \\
\text { melody. Culminates in full double-ensemble texture. }\end{array}$ & 5:41-7:23, F, G \\
\hline $\begin{array}{l}\text { First solo section. Guitar solo over alternating two chord vamp. } \\
\text { Texture drops back to just vibes accompaniment. More } \\
\text { instruments gradually creep in - rhythm section and long held } \\
\text { notes. }\end{array}$ & H, I, J, K \\
\hline $\begin{array}{l}\text { Guitar solo continues, more active accompaniment including } \\
\text { melodic fragments. Rhythm section part evolves towards metric } \\
\text { modulation. }\end{array}$ & $9: 16-9: 42$ & $\mathrm{~L}$ \\
\hline $\begin{array}{l}\text { Two saxophone duo improvisation over 9/8 time signature. } \\
\text { Drums play with sticks, fuller and more active texture. }\end{array}$ & $9: 42-10: 56$ & $\mathrm{M}, \mathrm{N}, \mathrm{O}, \mathrm{P}$ \\
\hline $\begin{array}{l}\text { Tutti section - like a shout chorus, with ensemble hits (drums } \\
\text { solo in the gaps). }\end{array}$ & $10: 56-11: 14$ \\
\hline $\begin{array}{l}\text { Partial recapitulation of main theme by double ensemble in 15/8. } \\
\text { gradually drops out one by one. }\end{array}$ & $11: 14-11: 40$ & $\mathrm{Q}$ \\
\hline
\end{tabular}

The rehearsal process was conducted according to Stroma's usual practices, tightly scheduled and with clear time allotments for each work on the programme, and was directed by the conductor. The execution of each individual part generally went smoothly, but the main difficulty that needed to be negotiated in rehearsal was that of synchronizing the two ensembles and their dissimilar rhythmic conceptions of pulse. The premiere of the work went well, and it was a strange feeling to watch from the audience, feeling absolutely hyper-engaged, with such intimate knowledge of where every individual note should go throughout the entire piece. 
This collaboration was a rewarding experience and I felt positive about the outcome of the work in performance. When listening back, one of the things I notice about the performance is subtle differences in the phrasing between the two ensembles. The rehearsal time allocated, though sufficient to achieve a generally accurate rendition of the piece, was not enough for the combined ensemble to develop its own ensemble identity and collective time concept (because of, as Nicole

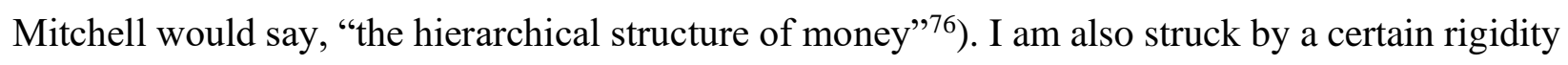
in the piece that I think is a result of my extensive use of notation. Although the piece does contain improvisation, the durations of the improvised sections and the accompanying ensemble textures are quite strictly controlled. There were valid reasons for my choice of this notation-heavy strategy, as I was confident that it would be comfortable for all of the musicians to engage with and was the safest approach to achieving a coherent performance. However, I also think it would have been fascinating to explore a more fluid, interactive approach to a work involving improvisation with this combined ensemble. I wonder what would have happened if I had left the solo sections more open and given the rhythm section and soloists more freedom, or if I had explored strategies for getting the classical ensemble to improvise. I imagine that all of these aspects would have made the work more challenging to rehearse, and might have resulted in a less tidy and consistent result, yet perhaps might have also imbued the piece with a different, more spontaneous spirit.

\section{The Arthur Street Loft Orchestra}

In 2018, my friend and fellow saxophonist and composer Jake Baxendale began to curate a composers' collective concert series called the Arthur Street Loft Orchestra, and invited me to colead a band with him. We formed a ten-piece (sometimes eleven-piece) chamber jazz ensemble, with personnel drawn from our combined associates on the Wellington jazz scene. The instrumentation of the ensemble is: trumpet, soprano saxophone, alto saxophone/bass clarinet, tenor saxophone, baritone saxophone/bass clarinet, piano, guitar, bass, drums, with the eleventh and occasional member on flute. Many of the members of the ensemble play mostly straight-ahead and contemporary jazz, while a few have more experimental-leaning tastes. I wrote several new works for this ensemble, including the rubato ballad "Noche Oscura" (included in this portfolio), before composing the larger work also submitted here, Sanctuary. These works were performed in

\footnotetext{
${ }^{76}$ Nicole Mitchell, interview by author, New Smyrna Beach, FL, July 10, 2019.
} 
a number of concerts during 2018 and 2019, providing me with the opportunity to workshop and revise my compositions through multiple performances. I found it challenging to effectively orchestrate my works for this little-but-big band, which fell between my predetermined ideas of a jazz combo and a big band. My attempts to make it sound like a big band did not quite work as there weren't enough instruments, and I needed to learn to carefully manage instrumental weighting, register and dynamics to achieve the variety of instrumental colour and range of intensity that I desired.

In our second year of working with the band, Jake and I set ourselves the assignment of writing a suite each for the ensemble, to be premiered during the 2019 Wellington Jazz Festival. The starting point for my suite was the piece that would became Movement II, "Strangely Familiar," a melancholic theme mostly based around the B Aeolian mode, with a time signature alternating between 5/4 and 4/4. I planned to write two more movements that were thematically connected to this, but underestimated the difficulty of this task, and ended up writing two other pieces that felt totally separate. We performed these at the festival, but I did not feel that I had achieved the composition of a suite and so chose to recompose the other movements from scratch, this time prioritizing thematic connectedness between the movements. I also considerably reworked "Strangely Familiar." While I was happy with the general outline of the work, I struggled with the orchestration. My initial arrangement included too many countermelodies at once in the cumulative sections, and overuse of loud, tutti passages, resulting in the music became very thick and heavy feeling. I went through three or four arrangements, some of which were workshopped in performance. Paying attention to register and weighting of instruments proved crucial, as did carving out space to create more of a sense of clarity in the ensemble.

Composing "Optimism" (Movement I) and "Inevitable" (Movement III) felt like solving a complex puzzle, as I worked to find ways of transforming and recycling the materials from "Strangely Familiar." "Optimism" is in a major key, with a time signature of 9/8, and is more harmonically active and mobile than the other movements. Much of my work on this piece was in navigating a harmonic trajectory through the work. My starting point for "Inevitable" was a reworking of the bassline from "Strangely Familiar." This time it was in the darker, Phrygian mode, played with an up-tempo 4/4 swing feel. I envisaged this movement as a harmonically simple, groove-oriented piece that would facilitate spontaneous interaction between the rhythm section 
and soloist (inspired by "Time of the Barracudas" from The Individualism of Gil Evans, 1964). While these did remain important aspects of the work, I also needed to find a way of transitioning between the final movements. The melodic materials I composed for this transition section became another key element of the work, and were developed throughout the piece.

In the process of composing "Inevitable" it felt as though I arrived at a new place compositionally. This movement is the only one of the three movements that uses an up-tempo, 4/4 swing feel, a genre convention of jazz, and features an extended baritone saxophone solo and rhythmic horn accompaniments which also connect it with the jazz tradition. Yet, it is also in this movement that I departed furthest from the "head-solos-head" formal convention of jazz. Though the baritone sax solo does occur over a cyclical, harmonic structure, there is a continuous trajectory of development throughout the work that means it never returns to its starting point.

"Interlude" was a last-minute addition to the work, sitting between "Optimism" and "Strangely Familiar." It consists of a scale melody abstracted from "Strangely Familiar" that is played by the horns additively and then subtractively, in a free, unsynchronized manner, while the bass improvises. The impetus for the inclusion of this movement was my sense that a different transition was needed between "Optimism" and "Strangely Familiar," as well as my desire to include a more spontaneous, free-flowing and collectively generated texture as part of this largely tightly controlled work.

In seeking to create thematic connectedness between the movements of the suite, I was buying into a value system that prioritizes "organic unity" in composition. This was a constraint I imposed on myself with regard to this specific work, although perhaps also a values system that had been present in some of the broader discourses of the composition department. Ironically, while working on completing the other movements of the suite, I was reading about the value system that prioritizes "organic unity" as representing a specific strand of ideology from German classical musicology, and starting to question this paradigm, and whether this really was or should be my end goal (Gabbard 1995, 12; K. Williams 2012, 228; Cooke 2003, 160; Monson 1996, 4). Creating thematic connectedness was a way of proving to myself that this composition was worthy of analysis when viewed through the imagined lens of academic composition. It has been a relief to 
discover the literature that challenges this and other internalized judgements of my own practice that come from evaluating jazz from the perspective of Western classical music.

\section{Conclusions}

In undertaking this doctoral project, I wanted to expand my resources as a composer, and to compose music that combined the traditions of jazz and Western classical music, partly as a way of escaping association with overly limiting interpretations of jazz as a genre. There have been many points throughout this doctorate where I questioned whether or not I was achieving these creative goals. It is somewhat ironic that, although the initial impulse for this project was intended to give me a feeling of greater aesthetic agency, there were times during this process where the effect was quite opposite. My creative work developed its own momentum which did not always feel related to my research, and I worried about how well I was fitting into the new "jazz/classical" or "genre-fluid" category that I had established for myself. Now, at the close of my project, I find that I have complicated my initial desire to frame my work at the intersection of these two traditions, instead seeing it as representing many different streams. This understanding leads me to feel more agency to freely combine materials according to my own aesthetic principles, in a way that feels personal, without so much anxiety about categorization.

Practically speaking, this process has challenged me to expand what I do as a composer. I have written for new instrumental configurations, and added to my repertoire of strategies for developing and structuring my works. I have developed my awareness of trajectory, instrumentation, intensity and flow. I have thought more deeply about dynamics of interaction and improvisation within ensembles, and have many more ideas in mind to explore in future work. I have also valued the opportunity to reflect deeply on the differences in music practice and aesthetics between each of these distinct yet interconnected musical worlds.

When I reflect on why I set myself this goal of studying "classical" composition, I conclude that I wanted to distance myself from the more formulaic aspects of the jazz tradition. I not only wanted to gain new approaches to organizing harmony, a greater knowledge of instrumentation and orchestration, and an understanding of how to formally structure extended works of music, but I thought that being a "composer" without the jazz qualifier would lead to an increased sense 
of possibility, agency, and aesthetic freedom. However, I have eventually concluded that there is no such thing as being just a "composer." To put it differently, there is no way of being an artist that is not considered in relation to other artists. As much as artists may dislike categories, other people will still try to categorize us. Attempting to be a "classical" or "new music" composer seems to mean trying to fit into another kind of box, being evaluated against different criteria, rather than avoiding evaluation and comparison. What I have valued most from the process of this doctorate has been gaining a framework with which to critique these various value systems, which leads me to the conclusion that, in fact, I do not need to buy into them at all.

Throughout this process, I have sought to gain a deeper understanding of my relationship to jazz and genre, as well as the relationships the three composers share to these concepts. When I began my research, I saw genre as necessarily tied to identifiable musical characteristics, but through this process, I have become much more interested in the processual and ideological aspects of genre. When thinking analytically about a given work of music, it seems to me that it cannot only be understood based on how it sounds, but also needs to be understood based on the values it demonstrates, the practices that were employed in its realization, and based on its connection to other musical traditions that have gone before.

Ultimately, my consideration of the different aesthetic values and social practices represented in these different streams of music-making leads me to feel more secure in my identity as a musician who participates in an Afrological tradition of music-making - and, in certain regards, as a jazz musician. There are many aspects of jazz values and practices that resonate with me, and inform my creative practice. These include spontaneity, collectivity, the "aesthetics of imperfection" (Gioia 1990), process, reinvention, fluidity and the celebration of the unique voices of improvisers. I also claim many musicians from this lineage as among my foremost musical influences. While I have not actively sought to distance myself from the word jazz, I also have not wanted my practice to be constrained by more restrictive interpretations of the "jazz tradition," however it may be defined. Usually the jazz label has felt like a useful descriptor for explaining where I am coming from musically. The label has only felt like a limitation when others apply it to me, particularly in new music contexts, within which I have felt that my work is seen as less valid because of the idea that it was created within a genre box or template. 
However, engaging more deeply with the social realities experienced by those labelled as jazz musicians also causes me to question my feelings about the jazz genre label - it has certainly been used as "an instrument of symbolic violence" (Drott 2013,9) to reductively label the work of many innovative musicians, and to limit their access to cultural capital, acknowledgement and recognition. George Lewis has written on the "one drop rule of jazz," and the "putative jazz label" (2008, xli; 2002, 119-20) - in other words, the tendency to view the work of any African American improver/composer as jazz, particularly if said musician is playing an instrument associated with the tradition. Sorey elaborates upon this point in his doctoral dissertation: "While the nature of my performance practice is trans-idiomatic and is not limited by cultural or stylistic boundaries, my music is almost always thought of as 'jazz,' even when it does not resemble it as such, given the simple fact that I am an African-American improvising behind a drum set" (2017a, 51). This tradition of oversimplification and misinterpretation of the work of Black artists makes the achievements of Sorey and Mitchell in boundary erosion even more noteworthy, and I wish to acknowledge that, in my search for genre mobility, as a white artist I am privileged not to have to contend with these essentialist categorizations of my work.

Whether or not the music I have made has transcended the jazz genre label, I have experimented throughout this process with participating in multiple genre worlds, which has led me to consider why this is not a more common practice for composers and other musical artists. In many ways, there are barriers to multiple-genre participation and experimentation. Some barriers are merely pragmatic, such as not knowing the people, the social rituals, or the musical systems that govern these art worlds. Other barriers are more ideological or philosophical, such as differing concepts of virtuosity between jazz and Western classical music, or the aforementioned prioritization of "organic unity" in the Western classical tradition. Still others are legacies of racism and classism, such as the hierarchies of culture that rank Western art music above jazz. Yet, in their work and discourses, Mitchell, Sorey and Horvitz provide inspiring examples of what is possible when making music that draws from a lot of different streams.

Now, when it seems to be time for me to reach some kind of a conclusion, I find this discussion is still very much in process. My future work will be composed and it will be improvised, but in what proportion I do not know, and it will be many other things as well. I feel that I have merely scratched the surface of what is possible. 


\section{BIBLIOGRAPHY}

Adler, David R. 2016. “Tyshawn Sorey: The Maestro.” JazzTimes, November 25, 2016. https://jazztimes.com/features/profiles/tyshawn-sorey-the-maestro/.

Ake, David Andrew, Charles Hiroshi Garrett, and Daniel Goldmark, eds. 2012. Jazz/Not Jazz: The Music and Its Boundaries. Berkeley: University of California Press.

“Alex Wing.” n.d. New Music USA. Accessed August 6, 2020. https://www.newmusicusa.org/profile/alexwing/.

“Avery r. Young.” n.d. Accessed August 6, 2020. https://www.averyryoung.com.

Bailey, Derek. [1980]1993. Improvisation: Its Nature and Practice in Music. New York: Da Capo Press.

Baraka, Amiri. 1999. Blues People: Negro Music in White America. 1st Quill ed. New York: William Morrow.

Barzel, Tamar. 2015. New York Noise: Radical Jewish Music and the Downtown Scene. Ethnomusicology Multimedia. Bloomington; Indianapolis: Indiana University Press.

Berliner, Paul. 1994. Thinking in Jazz: The Infinite Art of Improvisation. Chicago Studies in Ethnomusicology. Chicago: University of Chicago Press.

Blake, Ran. 1976. “Teaching Third Stream.” Music Educators Journal 63 (4): 32.

Blumenthal, Bob, Bill Shoemaker, Gunther Schuller, and Brad Mehldau. 2001. "New World Symphonies: A Survey of Modern Third Stream.” JazzTimes 31 (1).

Brackett, David. 2005. "Questions of Genre in Black Popular Music.” Black Music Research Journal 25 (1/2): 73-92.

Braxton, Anthony. 1985. Tri-Axium Writings, Vol. 1. Synthesis Music.

Brian Pace. 2018. The Pace Report: "The Composing Educator" The Tyshawn Sorey Interview. YouTube Video. https://www.youtube.com/watch?v=tivHLrcFi2M.

Charry, Eric. 1997. "Freedom and Form in Ornette Coleman's Early Atlantic Recordings." Edited by Edward Berger, David Cayer, Henry Martin, and Dan Morgenstern. Annual Review of Jazz Studies 9: 261-94.

“Chris Tordini." n.d. Newvelle Records. Accessed August 12, 2020. https://www.newvellerecords.com/pages/chris-tordini.

Clifford, James. 1986. "Introduction: Partial Truths." In Writing Culture: The Poetics and Politics of Ethnography, edited by James Clifford and G. E. Marcus, 1-26. Berkeley and Los Angeles, CA: University of California Press. https://lcst3789.files.wordpress.com/2012/01/clifford-writing-culture.pdf.

Coady, Christopher. 2016. John Lewis and the Challenge of "Real” Black Music. Jazz Perspectives. Ann Arbor: University of Michigan Press.

Cooke, Mervyn. 2003. "Jazz among the Classics, and the Case of Duke Ellington." In The Cambridge Companion to Jazz, edited by Mervyn Cooke and David Horn, 1st ed., 15374. Cambridge University Press. https://doi.org/10.1017/CCOL9780521663205.011. 
Dessen, Michael. 2003. "Decolonizing Art Music: Scenes from the Late Twentieth-Century United States.” PhD, San Diego: University of California.

DeVeaux, Scott. 1991. "Constructing the Jazz Tradition: Jazz Historiography." Black American Literature Forum 25 (3): 525. https://doi.org/10.2307/3041812.

Dewar, Andrew Raffo. 2010. "Searching for the Center of a Sound: Bill Dixon's Webern, the Unaccompanied Solo, and Compositional Ontology in Post-Songform Jazz." Jazz Perspectives 4 (1): 59-87. https://doi.org/10.1080/17494061003694162.

Dicker, Erica. 2016. "Ghost Trance Music: Event Space.” Edited by Nate Wooley. Sound American 16 (The Anthony Braxton Issue). http://archive.soundamerican.org/sa_archive/sa16/sa16-ghost-trance-music.html.

Drott, E. 2013. "The End(s) of Genre.” Journal of Music Theory 57 (1): 1-45. https://doi.org/10.1215/00222909-2017097.

Ehle, Robert C. 1972. "Jazz Classics or Classical Jazz: The Story of Third Stream Jazz." American Music Teacher 22 (1): 22-31.

Fabbri, Franco. 1981. "A Theory of Musical Genres: Two Applications." In Popular Music Perspectives, edited by D. Horn and P. Tagg, 52-81. Göteborg and Exeter: International Association for the Study of Popular Music,.

Fancher, Lou. 2020. "Tyshawn Sorey Keeps His Ears and Imagination Open." San Francisco Classical Voice, January 11, 2020, sec. Previews. https://www.sfcv.org/eventscalendar/artist-spotlight/tyshawn-sorey-keeps-his-ears-and-imagination-open.

Fauser, A. 2007. "Aaron Copland, Nadia Boulanger, and the Making of an 'American' Composer." The Musical Quarterly 89 (4): 524-54. https://doi.org/10.1093/musqtl/gdm005.

Frith, Simon. 1999. Performing Rites: On the Value of Popular Music. 1. Harvard Univ. Press pb. ed., 3. print. Cambridge, Mass.: Harvard Univ. Press.

"Fung Chern Hwei." n.d. Fung Chern Hwei. Accessed August 6, 2020. https://chernhwei.webs.com/.

Gabbard, Krin, ed. 1995. Jazz among the Discourses. Durham: Duke University Press.

Gates, Henry Louis. 1988. The Signifying Monkey: A Theory of Afro-American Literary Criticism. New York: Oxford University Press.

Gelfand, Alexander. 2006. “The Edge: Improvising Order.” JAZZIZ, December 2006.

Gilmore, Samuel. 1987. "Coordination and Convention: The Organization of the Concert World.” Symbolic Interaction 10 (2): 209-27. https://doi.org/10.1525/si.1987.10.2.209.

Gioia, Ted. 1990. The Imperfect Art: Reflections on Jazz and Modern Culture. Reprint. New York: Oxford Univ. Press.

—. 1992. West Coast Jazz: Modern Jazz in California, 1945-1960. New York: Oxford University Press.

—. 1997. The History of Jazz. New York: Oxford University Press.

Giuffre, Jimmy. 1955. Liner Notes to Tangents in Jazz. LP. Capitol Records. 
Goehr, Lydia. 1989. "Being True to the Work." The Journal of Aesthetics and Art Criticism 47 (1): 55. https://doi.org/10.2307/431993.

Good, Emily, and David Nicholls. 2001. New Music. Oxford University Press. https://www.oxfordmusiconline.com/grovemusic/view/10.1093/gmo/9781561592630.001 .0001/omo-9781561592630-e-0000042372.

Guzelimian, Ara, Muhal Richard Abrams, Claire Chase, George Lewis, Roscoe Mitchell, and Tyshawn Sorey. 2017. AACM Talks and Afterword, Friday. YouTube Video. Ojai Music Festival 2017. https://www.youtube.com/watch?v=MbS0XhO8KmY.

Hentoff, Nat, and Joe Goldberg. 1961. "The Third Stream: Is It Killing Jazz?” Hi-Fi/Stereo Review 7 (1): 44-47.

Holt, Fabian. 2007. Genre in Popular Music. Chicago: University of Chicago Press.

Horvitz, Wayne. 2009. “The Shape I'm In.” In Arcana IV: Musicians on Music, edited by John Zorn, 166-70. New York: Hips Road : Distributed to the trade by D.A.P./Distributed Art Publishers.

. 2018. Those Who Remain. CD. National Sawdust.

Howland, John. 2006. "Jazz Rhapsodies in Black and White: James P. Johnson's 'Yamekraw." American Music 24 (4): 445. https://doi.org/10.2307/25046051.

. 2012. "Jazz with Strings: Between Jazz and the Great American Songbook." In Jazz/Not Jazz: The Music and Its Boundaries, edited by David Andrew Ake, Charles Hiroshi Garrett, and Daniel Goldmark, 111-47. Berkeley: University of California Press.

"Interview: Tyshawn Sorey." 2011. Ars Nova Workshop. 2011. https://web.archive.org/web/20131219021956/www.arsnovaworkshop.com/blog/intervie w-tyshawn-sorey.

Iyer, Vijay. 2007. "Navigation through Form: Composing for Improvisers." American Composers Orchestra (blog). March 2007. https://www.americancomposers.org/iyer_essay_new.htm.

—. 2009. "Improvisation: Terms and Conditions." In Arcana IV: Musicians on Music, edited by John Zorn, 171-75. New York: Hips Road : Distributed to the trade by D.A.P./Distributed Art Publishers.

James, Robin. 2017. “Songs of Myself." Real Life, no. May. https://reallifemag.com/songs-ofmyself/.

Johnson, Thomas. 2018. "Analyzing Genre in Post-Millenial Popular Music.” CUNY Academic Works. https://academicworks.cuny.edu/gc_etds/2884.

Jost, Ekkehard. 1994. Free Jazz. 1st Da Capo Press pbk. ed. New York: Da Capo Press.

“JoVia Armstrong." n.d. JoVia Armstrong. Accessed August 6, 2020. https://www.joviaarmstrong.com.

Joyner, David. 2000. “Analyzing Third Stream.” Contemporary Music Review 19 (1): 63-87. https://doi.org/10.1080/07494460000640141. 
Kania, Andrew. 2008. "Works, Recordings, Performances: Classical, Rock, Jazz.” In Recorded Music: Philosophical and Critical Reflections, edited by Mine Doğantan, 3-21. London: Middlesex University Press.

. 2011. "All Play and No Work: An works in of Jazz." The Journal of Aesthetics and Art Criticism 69 (4): 391-403. https://doi.org/10.1111/j.1540-6245.2011.01483.x.

"Kojiro Umezaki." n.d. Accessed August 6, 2020. https://kojiroumezaki.com/.

"Kyle Armbrust, Viola." n.d. International Contemporary Ensemble. Accessed August 6, 2020. https://www.iceorg.org/kyle-armbrust.

Laskey, Kevin. 2014. “On Musical Multiplicity: Tyshawn Sorey Speaks | Jazz Speaks.” Blog. Jazz Speaks (blog). October 14, 2014. https://www.jazzspeaks.org/tyshawn-sorey-speakson-musical-multiplicity/.

Laver, Mark. 2014. "Freedom of Choice: Jazz, Neoliberalism, and the Lincoln Center." Popular Music and Society 37 (5): 538-56. https://doi.org/10.1080/03007766.2013.863640.

Lena, Jennifer C., and Richard A. Peterson. 2008. "Classification as Culture: Types and Trajectories of Music Genres." American Sociological Review 73 (5): 697-718.

Lewis, Eric. 2019. Intents and Purposes: Philosophy and the Aesthetics of Improvisation. Ann Arbor, MI: University of Michigan Press. https://doi.org/10.3998/mpub.10075702.

Lewis, George E. 2002a. "Experimental Music in Black and White: The AACM in New York, 1970-1985." https://doi.org/10.7916/D80R9N37.

_. 2002b. "Improvised Music after 1950: Afrological and Eurological Perspectives." Black Music Research Journal 22: 215-46.

_. 2004a. "Afterword to 'Improvised Music after 1950': The Changing Same." In The Other Side of Nowhere: Jazz, Improvisation, and Communities in Dialogue, edited by Daniel Fischlin and Ajay Heble, 1st ed. Music/Culture. Middletown, Conn: Wesleyan University Press.

—. 2004b. "Gittin' to Know Y'all: Improvised Music, Interculturalism and the Racial Imagination." Critical Studies in Improvisation / Études Critiques En Improvisation 1 (1). https://doi.org/10.21083/csieci.v1i1.6.

- 2008. A Power Stronger than Itself: The AACM and American Experimental Music. 2008th ed. Chicago: The University of Chicago Press.

_. 2016. "Foreword: Who Is Jazz?" In Jazz Worlds, World Jazz, edited by Philip Vilas Bohlman and Goffredo Plastino. Chicago Studies in Ethnomusicology. Chicago: The University of Chicago Press.

Lewis, John, Gunther Schuller, and Jim Hall. 1960. Jazz Abstractions. LP. Atlantic. https://en.wikipedia.org/w/index.php?title=Jazz_Abstractions\&oldid=961275825.

Lima, Rafael Piccolotto de. 2017. "Blurred Distinctions: Beyond Third Stream." DMA, Miami, FL: University of Miami.

Lock, Graham. 1988. Forces in Motion: The Music and Thoughts of Anthony Braxton. A Da Capo Paperback. New York, N.Y: Da Capo Press. 
Locks, Damon. 2009. "Nicole Mitchell: Creation, Culture and Community." The Population (blog). July 29, 2009. https://thepopulation.wordpress.com/2009/07/29/nicole-mitchellcreation-culture-and-community/.

MacArthur Foundation. 2017. Composer and Musician Tyshawn Sorey. YouTube Video. 2017 MacArthur Fellow. https://www.macfound.org/videos/562/.

McBride, Christian. 2015. "Wayne Horvitz: The Pianist and the Poet." Jazz Night in America. Washington, DC: NPR. https://www.npr.org/2015/12/03/458327063/wayne-horvitz-thepianist-and-the-poet.

Meehan, Norman Lawrence. 2015. "Creativity in Jazz.” PhD, Victoria University of Wellington.

Milkowski, Bill. 2011. "Tyshawn Sorey: Commentary from a Trans-Idiomatic Drummer Composer." JazzTimes 41 (9): 14-17.

Mingus, Charles. 1972. What Is a Jazz Composer? Liner Notes to Let My Children Hear Music. LP. Vol. KC31039. Columbia. . [1971]2010. Beneath the Underdog. Edinburgh: Canongate.

Mitchell, Nicole. 2013. What Matters to Me and Why. YouTube Video. UCI Open. https://www.youtube.com/watch?v=Zg-qms5teLA.

— . 2017a. "What Was Feared Lost." In Arcana VIII: Musicians on Music., edited by John Zorn, 221-36. New York: Hips Road.

—. 2017b. Mandorla Awakening II: Emerging Worlds. CD. Vol. 12. Chicago: FPE Records.

Monson, Ingrid T. 1996. Saying Something: Jazz Improvisation and Interaction. Chicago Studies in Ethnomusicology. Chicago: University of Chicago Press.

- 2007. Freedom Sounds: Civil Rights Call out to Jazz and Africa. Oxford ; New York: Oxford University Press.

Morris, Butch. 2017. The Art of Conduction: A Conduction Workbook. Edited by Daniela Veronesi. New York: Karma.

Nettl, Bruno. 1974. "Thoughts on Improvisation: A Comparative Approach.” The Musical Quarterly 60 (1): 1-19.

Norman, Liesa Karen. 2002. "The Respective Influence of Jazz and Classical Music on Each Other, The Evolution of Third Stream and Fusion and the Effects Thereof into the 21st Century." DMA, Vancouver, BC: University of British Columbia.

Obrecht, Jason. 2011. "How to Interview Musicians.” Jas Obrecht Music (blog). September 10, 2011. http://jasobrecht.com/interview-musicians/.

Pareles, Jon, Jon Caramanica, and Giovanni Russonello. 2017. "The Best Albums of 2017." New York Times, December 6, 2017, Online edition, sec. Music. https://www.nytimes.com/2017/12/06/arts/music/best-albums-2017.html.

Payton, Nicholas. 2014. "Black American Music and the Jazz Tradition." Nicholas Payton (blog). April 30, 2014. https://nicholaspayton.wordpress.com/2014/04/30/blackamerican-music-and-the-jazz-tradition/. 
"Peggy Lee - Cellist Improviser and Composer." n.d. Peggy Lee - Cellist Improviser Composer. Accessed August 6, 2020. http://www.peggylee.net/.

Pellegrinelli, Lara. 2019. "Composer Portraits: Tyshawn Sorey.” Program Notes. Miller Theater. March 13, 2019. https://www.millertheatre.com/explore/program-notes/composerportraits-tyshawn-sorey.

Porter, Eric. 2002. What Is This Thing Called Jazz?: African American Musicians as Artists, Critics, and Activists. Berkeley, Calif.: University of California Press.

Radano, Ronald M. 1992. “Jazzin' the Classics: The AACM's Challenge to Mainstream Aesthetics." Black Music Research Journal 12 (1): 79-95.

- 2009. New Musical Figurations Anthony Braxton's Cultural Critique.

"Renee Baker - Composer.” n.d. Renee Baker - Composer. Accessed August 6, 2020. http://www.reneebakercomposer.net.

Rentner, Simon. 2017. "Drummer Tyshawn Sorey Reflects on His Spectrum of Imagination." The Checkout. Newark, NJ: WBGO. https://www.wbgo.org/post/checkout-drummertyshawn-sorey-reflects-his-spectrum-imagination\#stream/0.

“Ron Miles.” n.d. Ron Miles. Accessed August 6, 2020. https://www.ronmiles.org.

"Rubin Kodheli." n.d. Rubin Kodheli. Accessed August 6, 2020. http://www.rubinkodheli.com/.

Samson, Jim. 2001. “Genre.” In Grove Music Online. Oxford University Press. https://doi.org/10.1093/gmo/9781561592630.article.40599.

"Sara Schoenbeck - Bassoon." n.d. Sara Schoenbeck - Bassoon. Accessed August 6, 2020. https://saraschoenbeck.weebly.com/.

Scherbenske, Amanda L. 2014. "Multplicity and Belonging among New York City ImproviserComposers, 2000-2011." PhD, Middletown Connecticut: Wesleyan University.

Schuller, Gunther. 1989. Musings: The Musical Worlds of Gunther Schuller. New York: Oxford University Press. . 1989. The Swing Era: The Development of Jazz, 1930-1945. The History of Jazz, v. 2. New York: Oxford University Press.

—. 2000. "Third Stream Flow." JAZZIZ, January 2000.

Schuller, Gunther, and Thomas H. Greenland. 2013. “Third Stream.” In Grove Music Online. Oxford University Press. https://www.oxfordmusiconline.com/grovemusic/view/10.1093/gmo/9781561592630.001 .0001/omo-9781561592630-e-1002252527.

Seidman, I. E. 1991. Interviewing as Qualitative Research: A Guide for Researchers in Education and the Social Sciences. New York, NY, US: Teachers College Press.

Shatz, Adam. 2016. "At Lincoln Center." London Review of Books Blog (blog). September 2, 2016. https://www.lrb.co.uk/blog/2016/september/at-lincoln-center.

Shipton, Alyn. 2001. A New History of Jazz. London, Eng.: Continuum. 
Slobin, Mark. 2007. "Musical Multiplicity: Emerging Thoughts." Yearbook for Traditional Music 39: 108-16.

Small, Christopher. 1987. Music of the Common Tongue: Survival and Celebration in AfroAmerican Music. London: New York: J. Calder ; Riverrun Press.

Solis, Gabriel. 2004. “'A Unique Chunk of Jazz Reality’: Authorship, Musical Work Concepts, and Thelonious Monk's Live Recordings from the Five Spot, 1958." Ethnomusicology 48 (3): 315-47.

Sonderegger, Sean. 2014. “'It's More Personal Than We Think': Conducted Improvisation Systems and Community in NYC." Master of Arts, Middletown, CT: Wesleyan University.

Sorey, Tyshawn. 2009. "Music and Meaning." In Arcana IV: Musicians on Music, edited by John Zorn, 294-98. New York: Hips Road : Distributed to the trade by D.A.P./Distributed Art Publishers.

—. 2014. "Tyshawn Sorey Remembers Butch Morris.” Jazztimes.Com (blog). April 2, 2014. https://jazztimes.com/features/tributes-and-obituaries/tyshawn-sorey-remembersbutch-morris/.

_ 2016a. Liner Notes to The Inner Spectrum of Variables. CD. Vol. 65. Pi.

- 2016b. The Inner Spectrum of Variables. CD. Vol. 65. Pi.

—. 2017a. "Perle Noire: Meditations for Josephine - Aesthetics, Discussion, and Reception." https://doi.org/10.7916/D86W9PJQ.

_ 2017b. Ojai Music Festival 2017: The Inner Spectrum of Variables, Friday. YouTube Video. https://www.youtube.com/watch?v=hphwGTxuGS0.

Tatsu Aoki. n.d. "Home." Tatsu Aoki. Accessed August 6, 2020. https://tatsuaoki.com/.

Taylor, Art. 1993. Notes and Tones: Musician-to-Musician Interviews. Expanded ed., 1st Da Capo Press ed. New York: Da Capo Press.

Teachout, Terry. 2000. "Jazz and Classical Music: To the Third Stream and Beyond." In The Oxford Companion to Jazz, edited by Bill Kirchner, 343-56. Oxford ; New York: Oxford University Press.

The Inner Spectrum of Variables. 2016a. CD. PI65 vols. Pi Recordings.

“___.”2016b. Pi Recordings. June 3, 2016. https://pirecordings.com/albums/the-innerspectrum-of-variables/.

The Modern Jazz Quartet. 1966. Third Stream Music. LP. Vol. SD 1345. Atlantic.

“Tomeka Reid." n.d. Tomeka Reid. Accessed August 6, 2020. https://www.tomekareid.net.

Tomlinson, Gary. 2002. "Cultural Dialogics and Jazz: A White Historian Signifies." Black Music Research Journal 22: 71. https://doi.org/10.2307/1519944.

Toynbee, Jason. 2000. Making Popular Music: Musicians, Creativity and Institutions. London : New York: Arnold; Co-published in the U.S.A. by Oxford University Press. 
Tynan, Liz. 2011. "Print Media and Broadcast Interviews." In Media \& Journalism: New Approaches to Theory and Practice, edited by Jason Bainbridge, Nicolá Goc, and Liz Tynan, Second edition, 72-80. Victoria, Australia: Oxford University Press.

Walls, Seth Colter. 2017. “Jazz Flutist Nicole Mitchell's New Concept Album Asks, 'What Is Progress?"” Bandcamp Daily (blog). May 1, 2017. https://daily.bandcamp.com/features/nicole-mitchell-interview.

Waterman, Ellen. 2008. “'I Dreamed of Other Worlds': An Interview with Nicole Mitchell.” Critical Studies in Improvisation / Études Critiques En Improvisation 4 (1). https://doi.org/10.21083/csieci.v4i1.510.

“Wayne Horvitz.” n.d. Nonesuch Records Official Website. Accessed August 10, 2020. https://www.nonesuch.com/.

Wayne Horvitz Gravitas Quartet. 2006. Liner Notes to Way Out East. CD. Vol. SGL SA 1558-2. Vancouver, BC: Songlines.

- 2006. Way Out East. CD. Vol. SGL SA 1558-2. Vancouver, BC: Songlines. SGL SA1558-2.

Williams, Katherine. 2012. "Improvisation as Composition: Fixity of Form and Collaborative Composition in Duke Ellington's Diminuendo and Crescendo in Blue." Jazz Perspectives 6 (1-2): 223-46. https://doi.org/10.1080/17494060.2012.729712.

Williams, Martin, ed. 1979. Jazz Panorama: From the Pages of the Jazz Review. The Roots of Jazz. New York: Da Capo Press.

Wilson, John S. 1960. "Music: A Third Stream of Sound.” New York Times, May 17, 1960. https://www.nytimes.com/1960/05/17/archives/music-a-third-stream-of-sound-schullerconducts-at-circle-in-the.html.

Wilson, Olly. 1974. "The Significance of the Relationship between Afro-American Music and West African Music." The Black Perspective in Music 2 (1): 3. https://doi.org/10.2307/1214144.

— 1983. "Black Music as an Art Form." Black Music Research Journal 3: 1. https://doi.org/10.2307/779487.

Wooley, Nate. 2016. “Anthony Braxton's Language Music.” Edited by Nate Wooley. Sound American 16 (The Anthony Braxton Issue). http://archive.soundamerican.org/sa_archive/sa16/sa16-language-music.html.

Young, James O., and Carl Matheson. 2000. “The Metaphysics of Jazz.” The Journal of Aesthetics and Art Criticism 58 (2): 125. https://doi.org/10.2307/432091.

Zimmerli, Patrick. 2016. "Jazz and Classical—Musical, Cultural, Listening Differences | NewMusicBox.” Blog. NewMusicBox (blog). December 15, 2016. https://nmbx.newmusicusa.org/jazz-and-classical-musical-cultural-listening-differences/.

Zorn, John, ed. 2000. Arcana: Musicians on Music. 8 vols. Arcana: Musicians on Music. New York: Granary Books : Hips Road. 


\section{APPENDIX A: INTERVIEW WITH TYSHAWN SOREY}

\section{Skype Interview, June 2, 2018}

Jasmine Lovell-Smith: Maybe we can just start the conversation by talking about your journey as a composer, how you got started with writing music. At what point in your creative trajectory did writing music come into your activities?

Tyshawn Sorey: I guess it may have started probably during my first year in college or so. I mean, I've written, like, tunes...short little jazz tunes or whatever in high school that I didn't care much for or anything, I didn't think they were anything special. But I did do that, for a little bit, so I've had some basic experience with composing. Then when I got to college, one of the professors there, Anton Vishio, he was one of the most encouraging people there, and so what I would do is I...I had gotten exposed to the work of Morton Feldman while I was there at William Paterson studying. At that time, I was there as a classical trombonist, and playing in different brass quintets and things like that, and also playing in a concert band, while, at the same time, I was playing drums in these jazz combos or whatever (I hate using genre names, but just for the sake of what we're talking about). Let's see, I would play drums in combos and stuff like that, but also concurrently I was also interested...because by that point I had already been familiar somewhat with a lot of different things with new music and stuff like that, which was also something I appreciated, although I didn't necessarily completely understand what a lot of very important twentieth-century composers were doing, I did have a profound respect for it and an appreciation for it. And so, I came to Anton Vishio, who is a specialist in that field, in post-tonal music and that kind of thing, as well as eighteenth and nineteenth century counterpoint and things like that. So he was basically an encyclopaedia of knowledge about music and its theoretical function and that kind of thing. So, one day I walked into his practice room (there was a practice room that was right across from his office at William Paterson). And when I walked into that practice room it turned out that he was practising Morton Feldman's piece called Piano... which was sort of the first work of Feldman's that really attracted me, listening to that music. And I was interested in how that music was working... what went into the composition of that music and that 
kind of thing, and so I'd ask Professor Vishio these questions. And he then invited me to come to the new music concert where that work would be performed, along with pieces by Hans Werner Henze, Steve Reich, and, you know, all the really great twentieth-century composers whom we celebrate, Charles Wuorinen... a lot of different people. And so, they were presenting a concert of this music the following week or something like that, it was like the following Monday.

And so I went the following Monday to that concert, you know, and I was there, I was just entranced by seeing this music being performed live. That was the first time I've seen contemporary music being performed in a live setting. And it was at that point where I said, okay, this is something that I feel really close to. Because I appreciated it for what it was, and also just seeing how it connects a lot with improvisation and that kind of thing. So I was interested from the get-go to see about composing a kind of music that integrated these different principles in twentieth-century music, because by that point I had already known about jazz harmony, and I've placed out of jazz harmony. And I knew a lot about chords, I knew a lot about progressions, I've done a lot of work in that field, but I felt like it was time for me to kind of get away from that way of writing, and into something else, and into some other way of making music. And so that concert kind of shaped the rest of what my life would become, as a composer. Because, it was from that point when I started actually inquiring Professor Vishio to try to get him to teach me some things related to twentieth-century composition and that kind of thing, and this is something that I've done on the side. He was really generous with his time, and so he would meet with me, even during the summer. I would come in with a sketch or something like that and he'd make some suggestions on things that I could do to make things better, and to make the notation clearer...you know, a lot of different things. He was the person who sort of...taught me the ropes, so to speak - you know, coming up, in composition. And so, that's kind of how that all got started.

JLS: And when you started composing when you were meeting with Professor Vishio, what type of forces were you composing for, or what types of things did you start doing?

TS: Well, you know, I didn't have an ensemble who was...ready for that kind of thing. I mean, I guess when I started composing, I was composing more for myself and whoever wanted to play with me at that moment. So, the first compositions I wrote would be, for example, for trombone and something else, and I would be the trombone player...maybe, you know, I imagined somehow 
Professor Vishio possibly playing some of my pieces with me and that kind of thing (laughs), because I didn't know any other pianist who would be willing to even do that. I mean, a lot of the people, and this is not to talk down to a lot of the people in the jazz program at William Paterson, we all sort of did what we wanted to do, which was great. But at the same time, there were some people in there who basically just wanted to, you know, do jazz ...some people weren't interested in new music and that sort of thing. So, I didn't really know anyone who was that interested in the stuff as much as I was. I mean, Mark Giuliana for example, he was one exception among the few who was very much into contemporary music and new music and that kind of thing and, you know, him and I...I mean, we've known each other forever, so...it was clear from the get-go that at least I had some people...I wasn't necessarily alone in this idea, in this getting involved in other types of mediums. But, that was mainly about it, there were maybe - like, I can count on one hand, several musicians who I felt could potentially play that kind of music. But no-one at the school during my freshman year necessarily wanted to play with me. I mean, first of all, I didn't feel that I was that strong of a musician; and secondly, I felt like there were some things that I wanted to get together first before I started to do this kind of thing. So I didn't really find like-minded musicians until somewhat later, maybe like one or two years later during my time at William Paterson, where I started to find more like-minded people who were interested in contemporary music and that sort of thing. But like I said, I can count on one hand a certain group of people.....and even then, they weren't willing to play with me. So, a lot of what I wrote was stuff for myself.

And then, I tried to start a group there, a quartet that did some contemporary so-called jazz, like things that certain people in that world perform basically at that time. I mean, we're talking about the music of Branford Marsalis, the music of Kenny Garrett, people like that. And so, I was interested in starting a group like that, but where I would also integrate my own compositions into the sets. But when it came time to deal with my own compositions...they just wouldn't get played, for whatever reason. Either they were too hard to execute, or it would require too much time, or there was just something about the fact that those...I mean, I don't understand the reason, I don't quite know how that worked out - like, I can't remember (laughs). But, for some reason, none of my own stuff really got played, and so I stopped writing that kind of music for a while, and then what I did was I started writing music again about a year later, after getting together with Professor Vishio and taking all of the knowledge that I've learned from him, and I started writing and bringing music into the jazz ensembles. Now, when I first did that, when I first came in bringing 
compositions into the jazz ensemble, it was more or less in a jazz sort of thing. You know, it sort of catered to the abilities of the jazz ensemble at that time during my freshman year. But when it got to sophomore year, I just stopped concerning myself with that, and I just started writing whatever it was I wanted to write, and I didn't care how hard it was or what it looked like. Somehow, it was going to get played (laughs). So, what I did was I just ended up bringing it to my jazz ensemble classes or whatever, started bringing in these charts that, you know, to some people they're very difficult to play and they had all of these advanced harmonies, I mean they had a lot of what are called slash chords or whatever, they had a lot of polytonal type stuff. So it was a lot of very tricky music, music that's sort of technically difficult to execute. Some of it that called for free improvisation and that kind of thing. So I kind of forced the issue (laughs), in a way, by bringing it to these jazz ensembles. And ultimately I started to like how the students began to take on the music, like they started to take it bit more seriously. Because, I would just say "Well, this is what it is, we're going to have to rehearse, we're going to have to look at this." So then, by that point I started writing for the students in the jazz ensembles, and then it just sort of expanded from there.

JLS: So this harmony that you were using with the slash chords... was this drawing on your studies of post-tonal theory at that time, or was it coming more from a perspective of an advanced contemporary jazz harmony?

TS: It kind of came from both. It came from both mediums, yeah. Because I was also very much interested in the music of [Béla] Bartók. His music also was polytonal in its own nature. So I borrowed a lot from what Bartók did, but I also borrowed a lot from what [Thelonious] Monk and all of these other people were doing, as well as a lot of the more advanced modern jazz composers or whatever coming up at around that time. I mean, Charles Mingus was another major, major influence at that time when I was studying at William Paterson. And so that's what sort of spurred all of that kind of thing, to the point where, you know....it didn't concern me what style anything was in, and for me, Mingus was kind of like that too. You know, where you have the blues, and you had all of these other types of music that are so embedded in his original work, and you can't really categorize it. And so, that was what was fascinating to me, because I was never interested in making a weird music per say, or I was never really interested in playing so-called jazz and that was it, you know what I mean. There was something about the way that I've listened and the way 
that I grew up that sort of proposed that I learn as much from everything as I could, and putting that in a personal sort of vocabulary that I thought would make sense.

JLS: So, when did you first start performing your compositions?

TS: Well, I first started performing...I guess it started with student ensemble performances, probably in 2002 or so. When I did that for the first time, the percussionist Ray Des Roches at William Paterson (who hosted the New Jersey Percussion Ensemble, which has been in residence for a long time there), he said some very encouraging things to me about my work, because he understood that a lot of what I was writing was very much influenced by the music that they were presenting in these new music concerts and everything. By that point, I don't know how many concerts of theirs that I went to, where Professor Vishio included was one of the performers. But Ray Des Roches, he was sort of the person who said "Yeah, I really dig what you're doing," and in fact he was very much into improvised music too. So I saw in him kind of a kindred spirit as well - even though he didn't necessarily play jazz, he had been celebrated for a long time as one of the foremost percussion players of the contemporary music scene. And by that point he had been experienced in it for over forty years. And so, to take that from somebody who is kind of a veteran in that scene, and who knows all of the ins and outs of all of that music, that was a huge point of encouragement for me, to continue writing the music that I was writing.

And so, from that student concert on in 2002, I began to start writing more music that was kind of similar in that way, and then finally I started taking advantage of William Paterson's composition studios, for credit. So I started to do that, and that's when I started coming up with my book of music for... what you know as the Oblique music, and what ended up coming out of that was forty-one compositions, but when I was in William Paterson I think maybe about nine or ten of those pieces were written for that configuration. And at that time, it was for alto saxophone, guitar, bass, and drums, and so it was for quartet, and this was in 2003, 2004 when I started to...I presented this music in my senior recital and, much to my chagrin, a lot of the music didn't turn out really well, but I went on ahead with it anyway, and then I started to look for opportunities in New York to present this music, and to finally get a chance to present this music outside of New Jersey. And so, I guess it was right after my senior recital, maybe a few months after that, I started 
to present my music at Zebulon Cafe Concert in Brooklyn, in Williamsburg - you might be familiar with that place...

JLS: I went there once, when I was on a visit to New York, in about 2008.

TS: Yeah, so in 2004 I started to perform there, and I guess the people at that place, they really loved...I mean, these were two French owners, or Belgian owners, or something like that, they spoke French and everything, and these two guys, Jef and Guills, I guess they both really dug the music because it was kind of unlike anything they had at that venue. Like, of course people would play free and that kind of thing in there, but they didn't hear a music that sort of had all of these contemporary music principles that were there, allowing for open improvisation, as well as allowing for different types of ensemble interplay, and also playing over chord changes that, you know, that don't sound like chord changes (laughs). I mean, there's all these crazy sonorities and things like that...there was no music like that being played at that venue. So, they had asked me on several occasions to return to that venue and play my music there. And so, I think it was like every three or four weeks, Oblique would be there performing at Zebulon for one night, and we started to kind of gain a following there. And so, the rest kind of went from there.

JLS: And so that music, you recorded...was it in 2011 or so, the Oblique music?

TS: 2011, yeah.

JLS: So, what was the journey that led you from that point to the first album that you made as a leader, which was not the music of Oblique 1?

TS: Right. It's a very convoluted journey, because that music that you heard on Oblique, it's very difficult music, it's very difficult to execute by players. I mean, it's one thing to just play a part by yourself and think that you got it, but then when you get together with the other players, it's a whole different story (laughs). I guess in 2006 after my visit to Japan (I did a very brief visit at a monastery there - it wasn't a Zen retreat or anything, I was just interested in the culture and interested in Zen Buddhism and things like that, which I had heard about through the writings of John Cage and Alan Watts, so I was interested in seeing what that was all about) I suddenly realized that a lot of the music that I was writing up until that point was kind of...you know, at that point I had already written forty-one compositions plus a few others for that Oblique project, finding all 
of these very complex ways of presenting music, but then I realized I felt like the music kind of all sounded the same. You know, like the music started to sound the same to me. It started to get old (laughs). It started to kind of become stale...I was no longer interested in the music that was being complex for complexity's sake. Because at that point, I had already been playing complex music by people like Steve Lehman, Steve Coleman, Dave Douglas. I mean, I've played complex music all the time, like, when am I going to get an opportunity to do something else that's not that. And so, the only way that I was able to get out of that was to create a situation for myself where I can explore different way of playing the drums that I do not get to do in these other groups. And that's not to say that the other groups were bad or anything like that, I'm not saying that at all. But, I am saying I was just looking for another way to express myself. And, the only way that I could do that was creating a situation for myself where I could $d o$ that.

And so, the first piece that came out of that trip to Japan was "Permutations for Solo Piano," which is on That/Not. That piece came about just through my visiting Japan. And it's related to a koan, I believe, that suggests "If something is boring after two minutes, then try it for four, and if it's still boring, try it for eight," etcetera. So, everything just kind of exponentially increases until you find that whatever it is you're doing, it becomes interesting - even if it's the same thing, it's not exactly the same. And it led me to think about this other way of experiencing music where, no matter how hard you try, each moment that you do something that sounds exactly the same is kind of a separate thing. I mean, it goes back to that koan...I'm trying to remember, it goes something like: (and it's on the back cover of my album Koan actually, incidentally) "If you understand it, all things are one; if you do not, they are different and separate. If you don't understand it, all things are one; if you do, they are different and separate" (laughs). It's this interesting sort of paradox, or whatever, that set into motion the idea of writing a different kind of music that really breathed a lot, and kind of would raise some interesting questions that sometimes can not get answered, or sometimes that, you know, you can't really answer musically. So, it kind of led me to that place. And also, I just got tired of performing in so-called "jazz" clubs too. That was the other problem I had. Where I would be limited to playing my music in a jazz venue or something like that because there was a saxophone or something there. I mean, I think the fact that I have written music that kind of does not sound like "jazz," I think that should've been enough right there to suggest, "well, this music doesn't necessarily belong in some kind of jazz venue where everybody's going there to drink and have a good time." And I mean, this was never what my 
music was designed for. And so, I started to feel that there was some kind of limitation there, in terms of where I can present my music, so I got tired of that, too. But my work has been going towards this so-called "new music" or "contemporary music" thing, I mean, it has been going towards that direction for a long time.

JLS: Yeah, it sounds like since your first year of college, right? So that's a really long time.

TS: Yeah, basically, it had been going in that direction anyway. So, it's like, why not pursue that in the best way that I could, but within an ensemble of players who I have collaborated with for a long time... and also some newer players, who may not have the same type of improvisational qualities that you may find in other so-called "jazz" players. Like, at that point I just got tired of the clichés that you would get with jazz improvisation by certain players, and that was the other thing that kind of made me shift direction. That when you hand a piano player some music, and it's got these jazz harmonies and things like that that are written on it, people are going to start resorting...here I am, writing all of this conceptual music and then the first thing they do is they start to play bebop licks or something like that.

JLS: (laughs) Yeah.

TS: Like, it's not only a total cop-out, but it wasn't even what I was aiming for to begin with. And so, I created the music, with Oblique, that had these very specific voicings, to the point where a player can not resort to playing any kind of licks or anything. But then I took that [inaudible] even further after the Permutations, and started writing out things where open improvisation would be called for, to the point where I'm going to force the issue, where no licks can get played, but people really had to play from themselves. So, I wanted to create a music that allowed for that. And [pianist] Cory Smythe, who's an integral part of that, we first started collaborating together right after, around 2005, 2006. At first, he was playing the Oblique book, and then suddenly I started handing him this other music (laughs), that I was thinking about doing. He's not a "jazz" player per say, and I purposely hired him for that reason, because I didn't want a "jazz" pianist in my group. Or I didn't want a "jazz" horn player in my group. I wanted somebody who has some experience with improvisation, but I didn't want anybody in there who would just only play what they know, and that's it. [Trombonist] Ben Gerstein is another person like that. I mean, he can play very well over chord progressions and that kind of thing, but he also wasn't necessarily interested 
in only doing that. And so, having him, it was like having another kindred spirit in the group, so now I've got two people who I collaborate with who are kind of going in the same direction that I'm going with, I mean Ben Gerstein is interested in so many things outside of jazz, I wanted to also have him involved. Thomas Morgan, it was kind of the same thing with him, even though he was playing in a lot of jazz groups at that time, he was also interested in other musics, and was also interested in Zen and Taoism and all of these different things. So, there was a lot of likemindedness going on in 2006, 2007 that led me to compose this music specifically for these people, to the point where it just, sort of, stood apart from anything else I've done before. And I mean, even though most of the music was heading in that direction, this was a completely different kind of music that I think was coming out around 2006, 2007.

And so, that's what started me towards writing more works that I guess you might say lean more towards the concert music area. Music that not only should be played or not only that could be played in a jazz venue (should one hire me to present my work), but also maybe at a more neutral space, like the Stone, for instance. The Stone was kind of a neutral space that allowed for that, even though I didn't get to curate that place until two years later. But I just kind of imagined my work existing in these other spaces that do not necessarily fall under the rubric of jazz. And Roulette was the first venue to allow me to do that, where they've commissioned me to compose a work for that group, for that quartet, I think it was in 2008. And what came out of it was a fourhour long composition that I did specifically for that project entitled "Wu Wei." Some of that music is on Alloy and a couple of other things. But essentially the gig at Roulette was another turning point for me, because finally I started to be recognized for the music that I've been writing, in something that doesn't necessarily...stuff that sounds more like concert music, I think it was going in that direction. It was kind of more in the extreme, you know, it was getting more and more and more away from the whole thing that was going on with Oblique and even with some of the early music that I wrote for That/Not. This music started to go even more towards the transposition of Zen principles, things that I've learned from studying Zen and by reading things on Buddhism and what-have-you. So, 2008 was kind of the other turning point. Since then, I've been interested in composing concert music for different contemporary ensembles, and everything. By that point, I had already known [co-founder of the International Contemporary Ensemble] Claire Chase. But the composition of concert music didn't really happen until I'd say maybe 2009, 
2010, with the International Contemporary Ensemble, where they commissioned me to participate in their ICElab Series, and it sort of went from there to where it is now.

JLS: What was the first piece that you wrote for ICE?

TS: Well, the first piece I wrote for ICE, it was based on a Charles Bukowski poem entitled "Dinosauria, We." So, I used all of his lines from that piece, and then adapted it for four members of ICE, plus myself, plus soprano. And so we presented that work at Wesleyan (this was when I was doing my grad degree there in 2010). And, I didn't like the work at all (laughs). You know, upon further review, I mean we presented it, and it went okay, but I didn't care for it, so I ended up throwing it away. But it led to me applying for their ICElab program, and so I ended up writing a series of four pieces for ICE, they had been to be performed at Roulette the following year, I think it was late 2011 or early 2012 or something like that. But I composed four compositions for ICE by that point and, since then, the relationship has flourished.

JLS: So in your first composition for ICE, did that include improvisation?

TS: Yes it did, it included improvisation.

JLS: And did you get the members of ICE to improvise?

TS: I did.

JLS: What types of strategies were you using for that, at that time?

TS: At that time I would have some kind of traditionally notated music, and then what I would do is I would put a box above that music and say "Ok, improvise using this material here, and only use this material, don't deviate from it or don't do other things." There would always be some kind of rule, whatever I would put in the box, in terms of how to handle any material that's below it. But I would never leave it completely open, because I felt that there's got to be some kind of structure to what the improvisation was going to set up. Like, I don't like to write things where everything is wide open, because then it's like, as the composer, you don't necessarily get everything that you want out of it. And so there would always be some kind of rule, there would always be some kind of instructions, with how to handle the material. 
JLS: And were there things about writing for ICE (as opposed to writing for your quartet) when you were first doing that which were uncomfortable, or difficult to figure out?

TS: Yeah, well, one of the things that was a little tricky for me at first was asking them to improvise (laughs). You know, that's something I've never done before. I believed in the idea of getting them to improvise, but I was afraid that they wouldn't want to do it, and that was the thing that was a little bit tricky for me. But then, of course they were open to doing it, and so it led to some interesting music-making at that point. And then, in fact, one of the first things I said to Claire Chase, upon meeting her at ICElab, was: "Listen, some of my music has improvisation in it, but I'm not concerned with the idea of improvisation versus composition, or jazz versus new music, or jazz versus classical - I'm not interested in any of that. I just want to make a singular music that involves all of us responding together, through improvisation or through playing written music, or whatever, because none of these things are separate to me, you know, composition and improvisation, I mean, they're never separate things. It's all composition, really, for me.” And so, I explained this to her upon one of my first ICElab meetings, and I guess she thought to herself "Okay, well I don't know how we're going to do that, but we're going to do it, and it's going to be great," so we sort of went ahead and did that. So that was one of the first things, just sort of gaining the confidence to get them also involved in improvisation and that kind of thing, even if they're not as experienced as I am. I mean, to me, what was more important - I found that, the more experienced the improviser, the more likely they are to resort to doing something that they already know, and I wasn't interested in that at all, at that time. And I'm still not interested in it in certain ways (laughs). But definitely at that time I wanted somebody who would kind of be fresh about their approach, with improvising and that kind of thing, so I felt that was the perfect opportunity to really pursue that.

JLS: It's interesting what you're saying about saying "I'm not interested in jazz versus classical music, I'm not interested in improvisation versus composition, I just want to do something where we're all making a singular music." It seems like in a way, that's making a connection between genre descriptors and barriers to participation or feeling empowered to create, or something, I don't know if that's true, for you? 
TS: Yeah, I think that's something to do with that.

JLS: Yeah, that's an interesting approach. And you've continued to work in pieces that involve improvisation with ICE, over time?

TS: Yes.

JLS: And has the relationship evolved, in terms of trust?

TS: Oh, it certainly has, yeah. I mean, the network of players with whom I collaborate with ICE has definitely grown, and they're a lot more open now to what I'm doing, too. I mean, it's not like they were never open to my ideas but I think, now, it's like they're okay with whatever I come up with, they're always with me, whatever it is I come up with. And they're never afraid to, like, really go for it, because I encourage them that, whenever there is some type of improvisation involved, there are rules there. It gives them a sense of confidence too, whenever I create a parameter for them of how to deal with the material; because, like I say, I don't want to just hand them an empty page and just say "alright, do whatever you want," I didn't want to do that. I mean, I'm not interested in that. But, I did want to give them something that they can be confident in trying, even if they may not have the experience to do it, I want them to gain the confidence to really try something that they haven't done before. And so, I think that they're very open to the ideas and, as a result, a lot of what they come up with ends up sounding - you know, I end up making suggestions if I have to, but, I mean, generally they just go for it without feeling like "okay, well what am I supposed to do?" or "what am I supposed to play?" or anything like that. I don't want to put players in that position. You know, even if they're experienced improvisers...because sometimes I even find that experienced improvisers often tend to make some of the same mistakes (laugh), you know what I mean, they often tend to make some...interesting mistakes that I don't care for that much. And inexperienced improvisers also tend to make different kinds of mistakes. And so, I try to make a situation where that can all be avoided, and to give them a sense of comfort... and a willingness to really explore beyond something they already know.

JLS: So, maybe we can pivot here to talking about The Inner Spectrum of Variables and the ensemble that you have on that album, specifically the string trio. How did you find this trio, or how did you conceptualize writing a work for this instrumentation? 
TS: Well, I've always been attracted to different kinds of string trios, listening to a lot of that kind of music was something that has always attracted me, and I wanted to put that in tandem with my piano trio. And, you know, I guess this would mark one of the first times that I began writing music for strings. It was important for me to really explore that world, because I've always wanted to write a string quartet, but I was never commissioned yet to do it, and I was never commissioned to write anything for a string trio. So, I was in one of those situations again where I just kind of made a situation for myself where, alright, I'm going to put this ensemble together and I'm going to write for it. And so, that's how that came about. And the string players who I found, some were old friends, some were people who I discussed the idea of collaborating with. [Fung] Chern Hwei was a person in the Sirius Quartet who I had been in touch with, you know, we would joke around, over Facebook and that kind of thing. We shared a lot of similar interests, in terms of what music was really cool to him and what was cool to me. But we never had worked together. But he was the person who I kind of called by chance. I mean, I'd never even heard him before, but I knew the music that he played, and who he collaborated with, and that sort of thing. So, I contacted him based on that. Rubin Kodheli, I worked with him during my tenure with Dave Douglas in late 2004 early 2005, and I had known that he had studied extensively with Fred Sherry, who is a great contemporary cellist (he's up there in age now), and he was also interested in all kinds of different music, just like I was. So, he was kind of the first-call cellist who I had in mind to participate in this project. And [violist] Kyle Armbrust was, at that time, a member of ICE. He was another person who was constantly saying "Man, I want you to write a piece for me," and of course that never materialized, and so then I finally said, “Alright, well since you didn't ask me to write a piece for you, I'm going to do it on my own accord, I'm going to involve you in this in some kind of way." And so that's how that came about, so now I've got my three string players. And by that time, Cory Smythe and Chris Tordini had already known about the direction where my work was going, where there would be a lot of notated music, and they'd have to find ways of dealing with the music that are challenging, and they're up for any challenge. And, seeing that they're up for pretty much any challenge, it was never really a problem for me to come up with anything for those guys, and so I had the perfect group, I thought. So that's how that group formed.

JLS: So, would you say that The Inner Spectrum of Variables is a continuation in certain ways of the approach that you were using with the trio on Alloy, in terms of the larger scale of compositional material? 
TS: Yeah, it's definitely related to that, at some level. And at some levels it kind of departed from it, too.

JLS: How so? Tell me about that, that sounds interesting.

TS: Well, the material was more vast, I mean, there was so much written material for The Inner Spectrum of Variables, there was a lot of notated music. With Alloy, there was a lot of notated music also, except that there were...well, how would I put this? I guess you could say that it's a continuation, I think it is a continuation after all. Because, I mean, even with Alloy you've got all of these different kinds of musical experiences converging in one another, and you've got a lot of different musical things that are happening within Alloy that you can't categorize. So, Inner Spectrum of Variables, it was even more the case where you can't categorize it. I guess you would say it was a development from Alloy, basically. Not necessarily a departure.

JLS: And on The Inner Spectrum of Variables, was that the first time in your recordings that you were using Conduction?

TS: That was the first time I started doing it in recording, but before that, I started integrating some of that into the piano trio concerts that I did, where I would give certain directions to the musicians at certain points.

JLS: Were you doing that with the Alloy material, in those trio concerts?

TS: Yeah. And even before that, I was teaching classes in Conduction and conducted improvisation in Norway, and in Denmark, and in Germany and a number of other places. But it was only on The Inner Spectrum of Variables that I kind of decided to just go public with it and just do it. Kind of develop my own system and, you know, do something like that.

[At this point Sorey realized that he had almost run out of power on his device, so we agreed to stop the interview and resume the conversation at a later time].

JLS: This is a great start, so thank you very much.

TS: Thank you.

END OF INTERVIEW 


\section{APPENDIX B: INTERVIEW WITH WAYNE HORVITZ}

\section{Skype Interview, September 12, 2018}

Jasmine Lovell-Smith: You compose music for a really wide variety of contexts, in terms of ensembles and instrumentations. Do you think that was always something that you wanted to do with music, from the beginning, or how did you get from your initial musical activities to this really diverse output that you have now?

Wayne Horvitz: That's a good question. No, I don't think it was particularly conscious on my part. I think partly it was motivated by just sheer ignorance, and I'll try to explain to you what I mean by that. I started fairly late. Do you know who Jamie Saft is, a great pianist? (If you look him up, you'll see that he's played with lots of people). I remember walking down the street with him in New York, and saying "Well Jamie, I'm not like you, I didn't start playing when I was seven" and he looked at me and without pause he just said "three" (laughs).

But I started when I was 14 and I didn't get serious until I was 18, and I played in blues bands and stuff like that a little bit. And then, when I started getting serious (and I know this is circuitous but I am actually going to get to the heart of your question), I really was just starting to learn how to play, and I was interested in Cecil Taylor and the Art Ensemble of Chicago and all that kind of music. But I also was listening to the [Béla] Bartók string quartets a lot. And I don't think I knew enough to know that I couldn't just write a string quartet, do you know what I'm saying? And it took me a long time to get there.

One of the reasons I've been able to expand my palette is because I had this project in the 80s called the New York Composers Orchestra, and that was the first time I'd written for a big band. And, I mean, I was just awful, and my first score was just awful, and I just had enough...I've always said that everybody in my band has always been more advanced musically than I am, and so I get the benefit of learning from them. You know, I had great people like Art Baron (who played with Duke Ellington and Aretha Franklin), and Marty Ehrlich, and Doug Wieselman, and Bobby Previte, all saying to me "You know, Wayne, you've got to fix this," you know what I 
mean. And I did, and by the second or third piece, I think that people were excited about my music because it didn't fit their normal expectations.

So that was my introduction to large ensemble music. And of course I wrote for trombones and saxophones, because those were what my friends played. But very soon, partly through the scene that we were in in New York (since it wasn't strictly a jazz scene), through if I was working with myself, or with Elliott Sharp, or with [John] Zorn, or with Bobby Previte, or with Butch [Morris], we met violinists, and we met bassoon players, and we met oboe players, and we started to play with people who came from classical new music but were interested in improvisation.

Even in Santa Cruz, Chris Brown (who taught at Mills for many, many years) was a really good friend of mine. You know, he played traditional classical music, then he started getting interested in twentieth-century music, then he got interested in improvisation. I played in blues bands, I got interested in Jimmy Hendrix and the Grateful Dead, which led me to Stravinsky, which lead me to the Art Ensemble [of Chicago], and I got interested in improvised music. So, the trajectory is completely the opposite, and we arrived at exactly the same place. But he probably, having grown up with Beethoven, would never occur to him to write a symphony. And I was too stupid to know any better, in a way. So, I just always dug into... whatever it seemed would teach me something, I would then do next.

JLS: Did you study music at University, or in a traditional way? Or was not doing that maybe part of why you had this mentality?

WH: I did and I didn't. I went to the University of California at Santa Cruz. Which didn't have an incredible music department. Ironically Cabrillo College, which also [has] the Cabrillo music festival, which does a lot of contemporary music - Cabrillo is a junior college, a two-year college, and they were just down the road - they had an incredible music program for both classical and jazz, with a lot of.... Like, Kenny Wolleson, who plays with Bill Frisell and Zorn a lot, he went to Cabrillo, so then he was the drummer in the new klezmer trio with Ben Goldberg. But UC Santa Cruz didn't have that great a music department. But I wasn't qualified to get into it anyway, because my reading wasn't good enough, and so I designed my own major. But I designed my own major with three interesting professors, one of whose name I forget, it was kind of like the new music guy. One was an ethnomusicologist, who just was a fan of mine and was helpful. And 
one of them was Gordon Mumma, who, I don't know if you know that name, but he had worked with John Cage and Merce Cunningham for years.

So Gordon arrived at UC Santa Cruz pretty much the same day I did, but I arrived as a student and he decided he was tired of touring with Merce Cunningham after all these years and wanted to stay home once in a while. So, he got a job at UC Santa Cruz. So he brought this incredible wealth of new music that was very much coming out of...not the rigorous, academic new music, but more in the spirit of Cage and Merce, and that was going on. And so, a lot of us sort of improvised music people....You know, it was the seventies, so if I'd been an improvised music person at Harvard, the new music person would've just shunned me in 1972. But Gordon was a guy who went to hear Coltrane all the time, and so he was super open minded. So that created a great, weird confluence at Santa Cruz at that time. So he was one of my advisors, and that was very helpful. But I did design my own major, and I didn't have to learn German, I didn't have to give a recital where I played traditional literature. The recital I gave was just all my own music, and...it was California in the seventies, it was pretty loose (laughs).

JLS: (laughs) So you were already well into composing when you were in college?

WH: Yeah, I was. I always like to say I would've been a much better pianist if every time I'd practised, I'd just kept practising, but always I would end up practising for fifteen minutes and taking out a pencil and starting to write something. I mean, I was inclined in that direction from the very beginning, even though I didn't have a lot of resources at first. So yes, the answer is yes. And I started arranging too, I remember doing a concert of the music of Thelonious Monk and Duke Ellington, and I wrote the arrangements for three horns. I mean, I had never taken an arranging class, and I had certainly never studied arranging. But, you start small and go from there.

JLS: And were you always improvising, from your early days of music activity?

WH: Yeah, if the truth be known, improvising is the only thing I can do. That's kind of not true, I mean, I was working on a Scott Joplin rag this morning. But my classical chops are pretty miserable, and even my jazz chops, I really came to improvising from...I'm cautious about calling it "free improvising" because I don't like that term, but I would call it kind of "new music" improvising, before I got into playing on jazz. I had played some blues, as I mentioned, and I had 
a little bit of language that way, but then I sort of jumped straight to Cecil Taylor. And learning to play like Red Garland or Bud Powell or something - my attempts to do that came later, actually. You know, I sort of moved backwards, I really did. So, the Cecil thing was a huge influence for the first couple of years that I was in college. And I didn't sit around trying to play what I heard on his records, but I just kind of got some sense of, like, what that might be like, and tried to develop my own language at the piano. And it was so long ago, I don't really remember how I did that, to be honest.

JLS: So, when did you first write I guess what you would call chamber music?

WH: Well, I actually remember distinctly, because I had a girlfriend who played the violin, and she didn't improvise. And it was funny, her name was Lydia Kapell and her uncle was William Kapell, who was probably the most famous pianist of his day. And so, she came from this very musical family, and she was a good violinist. She ended up not going to conservatory and not pursuing it professionally but, you know, she'd grown up with this very musical family, her father actually was a good pianist too, but her uncle was a famous, famous classical pianist who died on a plane flight from Australia to San Francisco. And twenty miles from the airport it crashed. And if you look up his name, you'll find out - I mean, she told me he was famous, and I was sort of "yeah, yeah, whatever" and then years later I looked him up. I mean, he was maybe the most famous classical pianist at that time.

So, I'm embarrassed when I think back that I handed her this piece of music that I wrote. And I remember how difficult it was for me to actually write out the piano part, you know, it wasn't improvised, it wasn't changes. I completely wrote out the piano part, and I wrote out the violin part. The notational embarrassments, now when I think back on it, must have just been sort of legion. And it was very Bartók, it was a Bartók rip off in a lot of ways, because that was kind of my reference for written music, for non-jazz music, for modern music. I had not only listened to the string quartets a lot, but I had played through the Mikrokosmos and that kind of stuff, and was influenced by that kind of polytonal sensibility. And I realized I heard that in Cecil Taylor too. There's so much, kind of, modes against modes in Cecil's playing. I mean, I think that the harm that Cecil Taylor did to music was it gave all these pianists the liberty to sort of play clusters 
and think they were making great music. And Cecil's harmonic imagination is actually so incredibly deep, you know, rich. And I heard those kinds of things that I heard in Bartók.

So, yeah, I tried to write something for violin and piano. But for example, for my senior recital. I remember that - this is very funny, I forget his name, but the one guy who was the classical contemporary music guy of my three advisors; this friend of mine and I, a flute player, she and I did an improvised duet. And his comments at the end of my recital was that that piece was the most structurally responsible of all the pieces (laughs), and it was improvised! And he was probably correct that some of my more composed stuff wasn't really that advanced, but it was ironic that it was the completely $100 \%$ improvised piece that he thought that here I had really nailed it, you know. And I actually learned something from that, because the structure of the improvised music was in some ways less beholden to traditional... at least jazz constructs of form, you know. I think he may have had a point, whether he meant to or not (laughs). So, I didn't really get around to writing anything that I would call chamber music seriously again for quite some time.

JLS: You mention in the liner notes to Way Out East that you had been focusing on writing through-composed chamber music for the last five years before that.

WH: Yeah, when did I write that? 2005.

JLS: So, around the year 2000?

WH: It was actually a really simple thing happened to me. I had written - I mean, I want to clarify one thing, because I had written music for the New York Composers Orchestra in the early 80s, so that was large ensemble pieces, and some of my pieces behaved more like jazz (what I would call "rhythm section oriented"). And some of them didn't. There was a piece called "The House that Brings a Smile," and even though there is percussion in it - and Bobby Previte was great, I didn't have to write out a percussion part for him to play the drums as if he was playing percussion as opposed to as if he was playing jazz. I mean, I realized later how much another drummer might not have been able to do that, and really how gifted he was, and he sort of gave that to me, you know, I didn't realize how lucky I was at the time. 
But in $1999 . .$. Oh, I know, one thing I was going to say was that even though I didn't write any chamber music for a while, I always joke that I had a loud band and a quiet band, and my quiet band was a trio with Butch Morris and Bobby Previte, and then later I had this band in Seattle called the 4+1 Ensemble. And that was with Reggie Watts, and Eyvind Kang, and Julian Priester, and Tucker Martine, who did processing. So that was trombone, two keyboards, and viola, and electronics. So, both of those groups were chamber groups, but I wasn't writing chamber music in the sense that it was through-composed. They both had some kind of indication of my sensibility, if that makes sense.

So in 1999 , to answer your question more directly, the Seattle Chamber Players - three of them were members of the Seattle Symphony (still are), and one of them was not a member of the Seattle Symphony but was very prominent on the chamber music scene here. They were fans of my music, and they liked other things that I was associated [with], most of them knew [John] Zorn's music and knew [Bill] Frisell's music. But they came to me and said they'd like to commission me to write a piece, and they're not improvisers. So, this didn't freak me out, I mean I wrote music all the time. But it was the first time in a while that I was going to sit down and write something very through-composed, and then I wrote this piece called "Otis Spann." And an important part of that to me was that Otis Spann, I don't know if you know who Otis Spann was, but he was a great, great blues pianist, kind of the reason I started playing the piano. He played in the Muddy Waters band, which was obviously an incredibly important Chicago blues band. He was a half-brother, I believe, of Muddy Waters. He also did this beautiful solo piano stuff. You should check him out.

\section{JLS: I will.}

WH: Try to find some records where he's playing solo piano. They're just the best, and really informed my sensibility. But I made a really conscious effort not to try to make a piece for flute, clarinet, cello and violin that was trying to be bluesy, I thought that would be an extremely heinous idea. And so, I didn't write anything that sounded like Otis Spann's music. And what I was trying to convey is something I felt strongly about all along. You know, you can love Jimi Hendrix's music, but playing it with a string quartet may not be the best idea. But that doesn't mean that the spirit that Jimi Hendrix gives you about how it makes you feel about music can't be an inspiration. 
But it doesn't mean you have to use Jimi Hendrix's language to reflect that inspiration. Now, I might reference Jimi Hendrix's music if I've got electric bass and drums and electric guitar and, you know, things that fit. But I'm not going to try to recreate that in chamber music, and I think a lot of the attempts to rock chamber music have really been... unsatisfactory is the polite way for me to put it (laughs). So, I had no intention of doing that.

So, I wrote that piece, and that got me back into it. Actually, with one exception, the Kronos String Quartet actually did commission me to write a string quartet, that I had written about ten years earlier. So, I had done that. And then, shortly thereafter I had a really great opportunity, and this was a huge, huge chance for me... Oh, there was one other thing, there was a Harold Pinter play called "Mountain Language, that was the last piece that Pinter ever wrote, and it was not particularly well known. And she asked me to write for that, and I wrote some string quartet music for that, which I later expanded. So I had done a few things in the eighties, but 1999 was when I sort of got back on it, and really I've been on it ever since. And it was the Seattle Chamber Players.

And shortly thereafter - did you ever know of this band, Briggan Kraus made a record called 300? It was with Kenny Wolleson, it's on the Knitting Factory label. It's an improvised trio. So, Briggan Kraus, Kenny Wolleson and myself, mostly playing electronics. This was really seminal, and I'll actually send you the tape I got of it. I'll send you one movement that I'm particularly happy with.

They said, "We want you to play for three nights with your group 300 at the Vienna jazz festival. And each night the trio will play, and each night, the other set will be one of you leading a group of local musicians." So Briggan asked for, like, four or five really nerdy improvisers, laptop guys and stuff like that. Kenny just said "Get me a bass player and a guitar player and a sax player and a trumpet player," and they just played some tunes of his. And I said, completely joking, I said "Could I get a...strings, chamber strings." Which isn't full orchestra, but it's still asking for 25-30 musicians. And they emailed me back, or I don't know, this might have been before email, they faxed me back, and said "Sure, no problem" and I was like "Oh fuck!" I couldn't believe it! (laughs)

So I wrote this piece basically for two vibraphones, some drums, and string orchestra... and Briggan is the improviser, and I played some electronics. And I learned so much! Like, I hadn't 
even marked my scores, I'd put some dynamics in but I hadn't slurred the strings. There was this woman there who, later her string quartet recorded my string quartets (she was Australian actually, but she lived in Austria). And really, I should go find her and kiss her right now, because of the way she respectfully treated the fact that I really didn't dot my Is and cross my Ts, but instead said "Hey, let's hang out afterwards and fix this" (or not fix it but, you know, get it better). She slurred it for me, and she liked the music, again I just got really lucky. And I've never presented anyone with an un-slurred score since, but I learned so much from that. So that was a huge, huge experience for me. Also, the conductor, he was into my music, so he cut me a break. I mean, another conductor could've really treated me shabbily in this context, and he was awesome. And so, that gave me a huge amount of confidence. And then I wrote Joe Hill after that, I wrote two string quartets after that, I wrote kind of a chamber opera, you know, on and on, and I've written a ton of music since then. Sorry, that was a little long winded, but there it is.

JLS: No, that's great. So, you've mentioned Cecil Taylor and Bartók, but your personal canon of influences, it sounds like it hasn't been from one tradition?

WH: No, not at all. And Otis Spann was another person...I mean, Otis Spann is really the reason I play the piano, and if you listen to Otis Spann as a blues pianist, and you listen to the way I touch the piano, I've only thought about this in recent years, but I realize how much I owe to him. Because so many other blues pianists are real hitters, you know. And they're great, I love that. But Otis Spann, everything he did was sort of understated, and if there's one thing I...if someone was to come up to me and complement me, one of the nicest things they could say is that my music is understated and it's not obvious. I mean, I don't know if anyone's ever said that to me, but that's something I like to think. And so, I think I owe a lot to him for that. And the Art Ensemble of Chicago were a huge influence on me. The Chicago school was an influence on me, but as much as I love Anthony [Braxton], and I know him personally, and I adore him, and I like his music, and as much as I love George Lewis, and as much as I love other people out of the Chicago scene and even Roscoe [Mitchell's] own music, or even Lester [Bowie's] own music, which I also love - none of them influenced me anywhere as much as the Art Ensemble. And the Art Ensemble freed me from the Cecil Taylor thing, not that I wanted to leave it. But it freed me from the density thing that was always involved in that kind of free music. And the thing about the Art Ensemble that was just so important was that. And if you listen to Otis Spann, you'll hear the same thing...that 
there's a lot of space in his playing. And also, the Art Ensemble were masters of not saying what they were saying. They kind of had this way of implying things without stating it. And so, even their themes, their written themes were always sort of like....there was this ambiguity. It wasn't that they avoided harmonic language, but they always kind of hinted at two harmonies at once. And what is that like? That's like the polytonality you find in Bartók, but it's almost like a conceptual polytonality too, they'll have different ideas going at the same time.

Also, I love groups that are larger than the sum of their parts. Like The Band, you know the group The Band, it's a classic...I mean, those five guys individually, none of them did things particularly that interesting, but together.... mean, you could say the same for the Beatles in a lot of ways, and I think the Art Ensemble were a great example of that. You know, in a jazz world where we always admire the individual, the great thing about the Art Ensemble was they were so much stronger than the sum of their parts. I mean, they were so much greater, they made so much more as a group, and they complimented each other so much. And I think, as someone who's loved rock music and loved bands that felt like bands...I mean, sure, you could say that about Art Blakey and the Jazz Messengers, you could say that about certain periods of the Duke Ellington band, but the Art Ensemble felt like a rock band that way. There was this marriage going on that created something that was really unique.

Stravinsky, obviously when I was young, I remember a classical friend playing the Rite of Spring for me, and I was like "Holy fuck, there's music like this?” (laughs) I mean, I just had no idea. And it had power that reminded me...that was when I was young, so I was listening to Jimmy Hendrix a lot, and the power of some of those movements reminded me of that. I didn't have any other reference, because I didn't have a background in classical music. So, you know, I didn't hear the other obvious influences out of classical music because I wasn't familiar with them.

JLS: So, it almost seems like you were able to exist in a musical world without boundaries and borders between different scenes in New York in the seventies and eighties (I don't know if that's a fair reflection). Did that kind of hit at some point, did people start trying to pin you down? Or when did that happen, that people started talking to you about "are you a jazz musician" and all this kind of thing? 
WH: Well I think, to go back just a little bit, I think in the sixties there were a lot of radio stations that did do - my brother went and heard Miles Davis and Santana on the same bill, you know, there was this sort of moment where that was happening. And you would even do things like the Count Basie band would play at the Fillmore. I heard Willie Dixon, who was the person who wrote much of the classic Chicago Blues, I heard these guys, five middle-aged Black guys in suits, at the electric circus in New York with a light show. I mean, it was so weird, I was thirteen, my older brother took me (laughs). But they must have thought it was weird too, I mean you know, they were like, "What they hell is going on here?" So I always thought, you know, if you go particularly to the so-called "Downtown scene" in the eighties, and we were supposed to be revolutionary because we were mixing genres - I didn't understand that at all, really. I mean, the Grateful Dead didn't say "Oh, we're going to mix genres." It was just sort of what was in the air. The Even Dozen Jug Band, who were obscure, even the Lovin' Spoonfull... and even a band like The Band, or even Dylan, in a way, you know, when he took his acoustic music and mixed it with a certain kind of electric music, but kept that traditional folk music. I mean, this has probably been happening for thousands of years, but all I'm saying is the New York scene, it sort of became known for genre breaking. But I was like "who cares?" I mean, that wasn't what was exciting to me. What was exciting to me in New York was people's individual voice and the music.... and the Art Ensemble too. The Art Ensemble were cross pollinating in every possible kind of way.

As for being pinned down...yeah, that's still a drag. I mean, I just wrote an orchestra piece for the Seattle Symphony, and I don't think there's a note of jazz language in it, but it's like "The jazz musician, writing an orchestra piece." I like to say that everybody calls me a jazz musician except jazz musicians, who say that I can't play jazz. You know, because I'm not someone who can play Cherokee at 240 [bpm] or whatever. And I don't think of myself as [a jazz musician]. I certainly am as influenced by non-jazz traditional American music as I am by jazz. That being said, I grew up listening to jazz as a kid, my dad was a big jazz fan. You know, so...I just don't [think] about it too much. But sure, it makes it hard. I mean, even Bill Frisell, by way of example, is a much more legitimate jazz musician than me, you know. He's played with Paul Motion, played with Lee Konitz, played with all these people. But I don't think you go listen to Bill's music and think it's just out of the jazz tradition. So...it's a tricky business. 
JLS: And in Seattle, do you feel like you operate in multiple scenes or communities, or is there just one scene that encompasses all of the different things that you do? How does that work?

WH: I'd say both. I mean, I think that all the "classical" musicians, and the more "rock" musicians and the more "jazz" musicians that I work with, all themselves...if they don't cross-pollinate themselves, they're super open to it, and they're not surprised if I call them to play together, if that makes sense. I mean, Matt Cameron; I'm doing a gig with Matt Cameron from Soundgarden in a couple of weeks, but it turns out that Matt's like the [inaudible] Elvin Jones freak you ever knew. I mean, who knew that? And that band will be with some people who I would say are jazz musicians, and then the violinist isn't a jazz musician at all, but she's an improviser. I mean, Seattle's pretty awesome that way. And even the classical scene is just very, very open minded. I mean, so much has changed, generationally. Younger classical players just come up not having the same attitudes about improvising and, whether they improvise or not, they have so much more open-mindedness to playing all sorts of types of music. Seattle's pretty deep that way, though, how really beautiful the scene is here, and how open the players are.

JLS: And you're also involved in education, is it right, teaching at Cornish [College of the Arts]?

WH: Yeah, a little bit.

JLS: So, what is your approach to that? If you are teaching composition, what does that look like?

WH: Yeah, that's a good question. I mean, ironically, I think I'm a much better composer than I am a jazz pianist, for example. In fact, that's an understatement, I feel that very strongly as a matter of fact (laughs). But, that being said, I have an easier time teaching jazz piano than [when] I teach composition, because teaching composition is tricky, I think particularly in this day and age. I think, back in the day, particularly in classical music, you didn't even try to study composition unless you were really pretty far along in your music studies. And now, I get a lot of students of a wide range of abilities. And I'm kind of shocked sometimes....you know, I don't need them to have studied counterpoint, or whatever, but I want them to have strong fundamental understanding of Western harmony, no matter what their language is.

I tend to strip people down, a lot of my composition students, I just strip down to basics. I'm like, you know: "Let's get your voice leading together, why are you asking about all of these 
extended harmonies when you can't really run all your triads and inversions in all twelve keys and move from key to key or move from inversion to inversion gracefully and easily, no matter what you do?" I mean, I would use my wife's [Robin Holcomb] music as an example, because she will claim that she doesn't know what she's doing. But when you look at her piano music, the voice leading is astounding. And that's because, she may not be conscious of it, but she played classical piano for seventeen years, it was just in her bones. And I didn't, so I had to learn that through another harmonic - you know, most of my formal harmonic study has probably been through jazz. But you know, if you call it two different words for the same chord, who cares? I mean, as long as you can identify it. And so jazz language tends to be my language for analysis.

And so, when I teach composition, I try to get people to learn to write for all the instruments, learn to arrange, don't worry about being inspired. You know, people come to composition wanting to have their genius moment. I tend to teach much more pragmatically, you know: "Take this Bartók piano piece and put it into a string quartet. Write a theme on a blues. Take these chords and write a new theme to it. Write a melody, next week let's harmonize it four different ways. Take somebody else's tune and arrange it." So that by the time you are writing your own music, you're not hung up by the fact that you're not facile, does that make sense? I mean, one of the things I think that kills inspiration the most is not being able to work quickly. So I teach a lot of very pragmatic stuff, like: "Learn to write fast, learn to write on spec, learn to write because the film composer needs it next week," you know.

I once had a student who I told them to write something and he came back and he said "I wasn't inspired” and I said: “Ok, let's do this: if I give you \$20,000 would you have it for me by tomorrow?" And he said "That's different" and I said "No, it's not different. You're in school to prepare for that happening," you know, "I need it in five hours." So I actually think that 99 percent of composing is perspiration, and I think the whole genius part of it gets really overrated. And I think that if you can write quickly for things that you're not that invested in, when you are invested in something, you're going to have a lot more inspiration, because you can stay writing for longer periods of time. So, to me, I put people through: "Put your iPhone on timer and get up every hour and walk around," you know. Or "Decide when to serve a cup of tea." I mean, I know that sounds silly. But those are the things that I have found over the years that have been really useful for me, is learning how to work, you know. And just learning how to power through. 
JLS: Yeah. What taught you that? Was it just having bigger and bigger projects lined up and just needing to find those skills to get through it?

WH: Yeah, because writing - you know, sometimes when you write a theme for a band, you're just sitting at the piano practising and you get some lick and you write it and you're done. Or you make a sketch, you come back the next day. But if you're writing an orchestra piece, you have to work for eight to ten hours a day for at least a month. I mean, that's what it took me to write a piece that was really only in two movements and was half of a - not even concert length, I mean a quarter of a concert length. And then I still came home, I mean, I went some place to do that, but I still came home and probably put another 100-120 hours into it. But then more piecemeal, you know, a little bit here... But yes, that is what taught me, is that you can't write longer pieces without treating it like an eight-hour day. And that requires that you need to move your body, you need to take breaks, you need to eat. If you're stuck, you need to have techniques out of getting stuck.

I mean, I do ask people to use things like twelve tone rows, or intervallic sequences, but I always say to them: "Use these as tools, not to base..." Well, let me roll backwards to serial techniques. Everybody thinks that if they write a twelve-tone piece, that that makes them a genius. That's just not the case. There's been more bad music written using twelve-tone techniques than probably any other technique ever invented. Which doesn't mean that Schoenberg's music isn't drop-dead gorgeous, because it is drop-dead gorgeous. And I think people forget just how beautiful Schoenberg's music is, not just how fascinating it is.

But you can use those kinds of more "math" approaches to things to get yourself out of trouble when inspiration isn't serving you. You know, try that, but when inspiration comes back - this is just me, and that's because of the kind of background that I come from, which isn't particularly formal - but I use nerdy ideas to compose myself out of corners, but then they can often lead me to something that essentially goes back to the way I used to work when I was first starting, which is sort of: what tickles my ear is what pleases me is what I work with. But when you're writing long pieces, you have to think structurally, and you have to think in more...I don't know, from the neck up, in more intellectual ways, to make things hold together.

JLS: How have you developed ways of thinking structurally, has it been through studying the work of composers you admire, or have you evolved it out of your own processes? 
WH: Yeah, I think so more. I mean, sure, I'll see an idea or I'll hear someone talk about their I'll give you an example, I was reading an interview with Carla Bley years ago, and she said she was trying to write some pieces where the line never repeated itself. And I went back to my pencil and paper, and I said "Ok, I'm going to do that." And I wrote a three-minute line that - it's not that it doesn't reference itself, it's a constant variation - but it's not an eight-bar phrase that repeats itself, it was one through line that never repeated itself exactly. And I ended up giving it to the bass player and making a big band piece out of it, this piece called "Prodigal Son Revisited." And it was all inspired by something I read in a magazine by Carla Bley. I mean, another example is I wrote a piece that's much more formal for solo piano (and I'll send you that because you might find it interesting). So, I wrote it for my friend Cristina Valdés, who's just a complete, amazing contemporary music pianist. This is a piece that I wouldn't play, it's a virtuoso piece - it's like a [György] Ligeti etude or something. And in fact, Ligeti, in the preface to his etudes, he talks about how he started playing piano too late to ever be able to play these, and that's exactly the way I feel. But he knows enough about the piano to write for it! So I took basically two chord shapes, I took an augmented triad with a Major 7th, and a diminished triad with a Major 7th, and based four whole movements on that. And I think you'd be hard pressed to hear it as being really obvious, if you heard the piece, until you started to dig into it. So yeah, I limit myself with constructs all the time. And I like that. And rhythmically too - I mean, I'll take ideas that I read about. Olivier Messiaen's music has been something in my ear, all my life, just those ideas of the modes of limited transposition and those kinds of things... and certain rhythmic ways that he creates. But he's a complete control freak about it, whereas I'll use one of his ideas to just sort of get me started, and then I just go and...you know [inaudible] (laughs).

JLS: Can you think of any examples of pieces that you based on the Messiaen modes of limited transposition?

WH: Oh, lots of things, but I actually wrote a little children's piece called "I'm a Nine Note Scale" that's in a book of pieces. Obviously it just says that, off the bat, you know. It's that great scale he uses that's whole step, half step, half step, whole step, half step, half step. And then once, years ago, I was writing this piece based on this book called The Heart Song of Charging Elk, and that's never been released. It was an opera actually, or a song cycle that I hoped would eventually turn into an opera, and I sort of lost interest in it but it turned into a nice song cycle. And there was a 
piece that was about a bureaucrat in it, it takes place in Paris. And I thought, well, what better place to use a twelve-tone row than a piece about a bureaucrat, you know? (laughs) I mean, in a way, it was like a musical joke for me, but actually I ended up loving the music. But I did stick very strictly to it for this one song, and...it was inspirational.

JLS: Maybe now we can talk a little bit about the Gravitas Quartet, so I don't miss that out. So, you say again in the liner notes [to Way Out East] that you had been searching for an ensemble that could "bridge the gap between the through-composed chamber music" and the "lifelong love of small group improvisation." So, I'm curious if that opened new things up for you compositionally, having those two things together in one room? What was the experience like, of working with that ensemble?

WH: Well, in the first place, you can't ask for three better people to play with. I mean, it's as simple as that, and that of course goes back to, whether you call it "jazz" or not, the thing about the Duke Ellington band: it's for the musicians in the band, as opposed to, obviously, when Beethoven wrote, or, when Wagner wrote. You know, they don't know who is going to play the music, they're not writing for an individual voice. So, I met Sara [Schoenbeck] and Peggy [Lee] pretty much at the same moment. I met them at something called the Time Flies [Improvised Music] Festival in Vancouver, which is a Company - you know the Company style, you know what I mean by that? Derek Bailey, years ago, used to put together "Company," he would call it, and he would just ask eight improvisers to come for a weekend, and then would do things with solos, duos, trios, and that was it completely - so I met Sara and Peggy there with about eight other improvisers, and I just said "Oh my God." I mean, they were both so great to play with, and such great instruments too. I got to know Ron [Miles] very differently, through helping to remix a record of his, and then through Bill Frisell, and we started playing together, and he played in my big band. So Ron's obviously the person who really comes from jazz. But you know, he has a trumpet performance major that was a regular performance major, I mean, he had to do all his classical stuff. So, these are very well-trained musicians, plus me, basically (laughs). And so, you know, it was embarrassing in that band sometimes. I'd bring in this music, and I'd have been practising for weeks, and I'd show it to them, and they'd play it down, sight-reading, and I was still messing it up. And it didn’t have a rhythm section obviously, so that was an important decision. 
So, one thing I realized later, that I don't even think I was that conscious of, was that it was a stroke of genius on my own part, to have the bassoon and the cello. But really, I had those instruments because I loved Sara's playing and I loved Peggy's playing. But later, you know, it gave a lot of...because those are two unusual instruments in that they can cover the bass and the inner voices, and the melodies all. And that's not true for trumpet, and that's not true for bass, and that's not true for clarinet. And so, Peggy and Sara, between the bottom half of the piano and those two, I had a lot to work with in the bass. And all of us were able to play a melody, so that was great. So, I think on the second record particularly I became more ambitious about some of the pieces being more like contemporary music. Some of the first record, the pieces were maybe - not all of them but some of them - more harmonic, in a traditional sense. But I also didn't do a lot of arranging for the band. I would bring things in and we would figure out how the arrangement would go - not always, but sometimes. And so, they were all obviously quite capable in that regard.

And you know, after a while you start to know what's going to work for whom. I mean, Ron was perfectly capable of making all sorts of interesting noises, as were Sara and Peggy. And Peggy and Sara were perfectly capable of taking very beautiful, melodic type solos, but Ron was always going to be the king when it came to a certain kind of changes. I mean he was the one, particularly if there was anything that hinted at jazz or swing, he was just going to kill it. And you know, both Sara and Peggy were just so gorgeous, in the more inside stuff. Sara's a master of sound, but Peggy's sonic language is just...particularly mind-blowing. And her ability to mix up something that was very traditional with something that was very sonic, kind of all in the same breath. I think the cello also lends itself to that, but she had a particular...so, I couldn't have picked a better band. So, I don't know if that really answers your question, but...sure, I brought the music in, but there was a lot of, not only ensemble playing, but ensemble ideas in rehearsals.

JLS: It's really all about the people, right, the specific people, in that case? I mean, is that the case with a lot of the music that you write, it's just all to do with your community and the resources you have at your disposal? Or more with some things than others, perhaps?

WH: Yes, more with some things than others. For example, I probably think that the very best thing I do is improvise, completely freely. And yet, how many records of mine are there with me improvising completely freely? Hardly any. Partly because I keep having projects I want to do, 
you know (laughs). I feel like it's a waste of a record or something. But, there are a very small amount of people that I really want to do that with. I mean, I have all sorts of bands with all sorts of people, and yet I don't really want to get together with most of those people and...I might put a band together where we play very freely within some constructs. Like this trio that I just put a record out with bass and piano, they're local musicians, and I love how they play, I love playing with them. But I wouldn't say "Let's just go onstage and play free for 45 minutes" with them, they're not the people I would pick for that. Peggy I would pick for that, Sara I would pick for that. Briggan Kraus, who I have played with a lot, particularly if I was playing electronics. Like, I love playing freely with piano with Peggy or Sara. Electronics I love playing with Briggan, there's something that he brings to that...So, there's very few people I feel are ... so much real free playing just goes into some zone I'm not interested in. But, outside of that, I would say that a lot of my musicians, I could say, I'm going to go to San Francisco and I'm going to put together a band and I'd be just fine, I could put together something in lots of places. I could call you up and say "I'm coming to New Zealand and I want to play these tunes of mine" and you probably could find me a good group of folks.

JLS: Anytime (laughs), that'd be great!

WH: And I think that's more true than it used to be.

JLS: Yeah. I'm curious, going back to the Gravitas Quartet, is this type of ensemble for you something that works best in a concert setting? Do you tailor the performance contexts very specifically to different ensembles? Or how do you find the home for the different types of music that you do?

WH: You know, that's a great question, because I don't. And, um.... I should. I remember...do you know the British composer Jonathan Harvey? Have you ever heard of him?

JLS: No, never.

WH: Yeah, he just passed pretty recently, I think within the last year or so. And I met him because George Lewis and Jonathan Harvey and I were in Italy on a panel together for an artist residency, and we were choosing artists. And that was interesting in two ways. One has to do with Butch Morris, who I wouldn't mind talking about a little bit. But the first thing was that Jonathan came 
up to me and said "Wayne, George tells me that you use electronics in a lot of your music. So, how many days do you try and get into the concert hall ahead of time, to tweak the electronics?" and I was like "You know, usually I get out of the van or the train, and I walk into the club and I set the stuff up, and we're playing 45 minutes later." And he was coming from a very different world, which was spending three years writing the piece for orchestra plus MaxMSP patch, and getting in a week before and working it all out, I just had to laugh. I wish I could [do that]. Gravitas played in concert calls and in clubs. But it worked better in concert halls, there's no question about it. And then, certainly, I have bands that play with drums, or that play loud, where a concert hall is kind of tough just acoustically. I don't think I have any projects at the moment that I wouldn't bring into a concert hall. I do have projects I wouldn't bring into a club. Or, again it sort of depends on the club, I mean you have clubs in New York or even in Seattle that are used to - essentially, even though they are a bar, art music is not uncommon there, and then it makes a difference.

I'll tell you the greatest regret I have about the Gravitas Quartet, is that we played in Texas at the....it was actually in the rehearsal room of a famous concert hall that was named after Van Cliburn, the famous classical pianist. Who happens to have been from Dallas, Texas (which most people don't know), and the Van Cliburn competition happens every year. And downstairs they have a room with two massively beautiful Steinway D pianos that aren't even on the stage, they're just for the pianists to warm up on. But they have concerts there sometimes. And the Gravitas Quartet played, I think, the two best concerts I've ever played in my life, down there, two nights in a row. We didn't record them, and I will forever regret that. But part of the reason was because the acoustics were so amazing and the piano was so amazing; and it makes a huge difference, there's no question about it. But I've been probably far less picky than I should be about that kind of stuff, and I tend to be game to play in all sorts of contexts. You know, at the same time, I do think that certainly that, certainly, that band was very well served...to have to use monitors and microphones and stuff is not the way that music is best experienced.

Oh, the other thing about Butch was that Jonathan Harvey was on this panel, and Butch Morris had submitted to the panel. And George and I both were very honest, we said "Listen, you know he's a friend of ours," just for letting everybody know that we were going to be prejudiced in his favour. But Jonathan Harvey, on the last day - so this is an old school, very, very modern composer, but, you know, already in his sixties, very much coming out of contemporary music in 
a mid-twentieth-century way - and the person who ran the thing said "Listen, if anybody wants to keep any of the CDs, you're welcome to keep them, we're not sending them back, they're just work samples." And Jonathan Harvey said "No, that's okay - except for this fellow Butch Morris, I have to find out how he puts his music together." And of course, it was $100 \%$ improvised, except that there was Conduction [Butch Morris's conducted improvisation system] involved. But it wasn't $100 \%$ improvised in that sense, but in terms of the pitches and the rhythms and all those things, it was 100 percent improvised. And he found it, structurally, really intriguing. And I thought that was very telling.

JLS: Yeah, definitely. And Conduction is something you have worked with also, in some of your ensembles, is that right? Have you brought it into small group playing at all, or is it something that you tend to do just in a large ensemble context?

WH: Yeah, that's a really excellent question, because the question becomes kind of like...Sometimes I feel like in a small group I wish I could just put my hand up to someone and just go, you know "Could you loop that" or "Could you stop playing" (laughs) or "Could you play more quietly?" And yeah, and it sort of doesn't feel like the politic thing to do, you know.

JLS: Because of the kind of leadership - like, the social contract, of the power - ?

WH: Yeah (laughs). I mean, you're right, it's just sort of this assumption. Also, I've never put a small group together where I've said "Hey, this is what I'm going to do." There is a band, what are they called... Kneebody, have you ever heard of Kneebody?

JLS: Yeah, they have cueing systems, right?

WH: They have hand signals that they use. I've never done that in a small group. I've also never played in a group where I was doing the Conduction and also playing. So when I'm doing the Conduction thing - you know, I don't consider myself a big Conduction person. I mean, I loved doing it with Butch, I feel like its Butch's thing, I didn't want it to become my thing. So, when I used it, I always used it but in the opposite way that he did, I've always used it in the context of written music. I don't mean completely written music. But in fact, I've used it more in my more jazz-based big band thing (I have this band called the Royal Room Collective Music Ensemble) and I love it, but I realized, it's sort of like instant Charles Mingus. You know, I've got some riff 
going, and then I can loop it in these different ways, and get it layered, and it's a great way to achieve that. And I love it because the pianist in the band - I don't have to play and he plays great, and so the whole thing is just fun, I just have to sit up there and wave my arms around. But I've been doing recently this project called Electric Circus. And in it, I take riffs from James Brown and Sly Stone and Los Lobos and the Clash and Devo and Sun Ra and Miles Davis, and I write out just, like, a two-bar phrase, or a four-bar phrase, I don't take the whole tune. And I mix that up. And it's been a blast, because sometimes the music's really pretty heavy, I mean, I think some of the music's really great. But, of course you have audiences because they hear the Sly and the Family Stone tune, or last week we did it and I had a Pointer Sisters song in there and, you know, stuff like that. You know, I didn't do it to suck people in, but it draws a really good crowd of people who never hear improvised music. And sometimes the first fifteen minutes won't refer to a single piece of written music. But they're sort of there for the payoff, I mean it's a terrible thing to say. But what's also interesting, going back to Bartók, is I often will get, like, four pieces of music going at the same time in different keys. I do it in a bar - I mean, this is a band that has to play in a bar, there's no question about it, I wouldn't bring this band into a concert hall - but it's, like, the weirdest bar band you ever heard. And you know, I don't want to spend my life pursuing it but, six or eight times a year, it's just a blast. And it's a great sort of...I loved Butch, and it's my way of honouring how much I adored him and how much he meant to me. I mean, he was so important to me. And so, it's a great way to sort of keep that spirit...just a reminder for me, you know.

JLS: It's interesting what you say about using [Conduction] in the opposite way....and then, instant Charles Mingus being the result...it's cool.

WH: Well I should clarify one thing though, which is that, in the very early days, that's what Butch did. He did it in David Murray's band. And then he wanted to get away from it being used in tunes. And just before he died, he started talking to my wife, Robin Holcomb, and I about a project that he wanted to do where he wanted to start using composed music again, but he wanted to commission people to write pieces that then he would apply the Conduction thing to by breaking them apart. And he got sick. It was going to happen in Italy. I mean I was so, obviously, sad that he died, but I also was sad that project never happened. But, sort of coming around to this idea of using themes and stuff. So, maybe I'm taking off where he was about to go anyway (laughs). 
JLS: Yeah. So, the themes that you apply Conduction to, I think I saw an interview where you talked about that and you said you looked for things that were modular or could be broken up in to chunks. So, you couldn't just use Conduction with any music, you're thinking about which types of musical architecture work in this context?

WH: Well, you know, it's a good question, I think also...I have a lot of fun doing Conduction, but I will say that when I'm done with it, I'm exhausted. Like, I've never felt the pressure to feel like you need to keep coming up with good ideas that I have when I've been doing Conduction, on the spot. Because you've got, like, seventeen people doing something, and they're like 'Ok, we're here now, now what," you know. Of course, you can just point to someone to solo or something, but if you're going to do more interesting things than that...So, it's pretty important to know your materials. And so, I'm lazy enough that, I mean the idea of taking, like, you know...I mean, let's say, just for the sake of argument, that I get a string quartet together and I say - I mean, I would never do this, but - "Let's take Bartók's third string quartet and let's play it but, every once in a while, I'm going to use these hand signals." I just don't feel like I would know the materials well enough for it to be more than just a bogus trick that was kind of clever, you know? I actually feel that with less materials I can do more, because I really know them inside and out. That being said, I don't really study my materials that carefully. If I wanted to have a life of Conduction, I could probably take more complex constructs and work with them. But it's not something that I'm...there's other things I'd rather be doing, but that would be the way to do it. You know, you'd have to spend a year with that Bartók string quartet and then go do it.

JLS: Yeah, that makes sense. So, what are the things that you're working on now, or some of the things that you want to be doing in the future, that you haven't done yet?

WH: Well, the one thing we haven't talked about, which is very prescient because the CD of at least one aspect of this is coming out any minute: I wrote this orchestra piece with Bill Frisell as the soloist, so it's a concerto. And then I also wrote - I've written a number of pieces where the classical players are playing what they're trained to do, and the improvisers are doing what they do best. My friend Beth is a clarinettist I work with here, her last name is Fleenor. She's the improvising soloist on this string quartet I wrote called These Hills of Glory, which hasn't been released yet. And then the orchestra piece is called Those Who Remain. And it's about sixteen 
minutes long, it's in two movements, and Bill is the soloist. The string quartet is the full four movements, it's a little more than a half hour, and Beth is the soloist.

But Beth is the soloist on the version that's coming out on the CD, but Bill has done this string quartet (as well as the orchestra piece Bill has also been a soloist for the string quartet), Ron Miles has done it, Peggy Lee has done it, Sara [Schoenbeck] has done it - people you would know, do you know who Carla Kihlstedt is? Incredible violinist, she's done it. Eyvind Kang, who you might have seen on my records, Eyvind has done it. And then some people you wouldn't know of, who are local people or other people. Carla had a band called the Tin Hat Trio for a long time, she did a lot of stuff with Fred Frith. She's a serious badass classical player, also a great improviser. She was one of my favourite soloists on that. Beth also was one of my favourite soloists, which is why she ended up on the record. That piece I wrote in, like, 2003, I just hadn't put it out yet. It was performed a couple of [times] in different incarnations. In fact, I recorded the string quartet without the soloist, because it's too expensive to record the string quartet and the soloist together, because then if they played the part well but you don't like the solo, you know, then you're just.....So in both cases with Bill and the orchestra - I mean, the orchestra, my God. If I'd had to wait until I had [inaudible] income....I mean, that would've meant $\$ 140,000$ later. I mean, it cost me $\$ 24,000$ to have a three-hour session. I mean, it took me two years to raise the money. So I recorded the orchestra, edited it, mixed it - I mean, I had someone do that - and then I overdubbed Bill on it, and then we mixed that in and spent a lot of time. And I edited his tracks, too.

So, this is different than the Gravitas Quartet, where we have written music and improvised music, and it's different than the chamber pieces I wrote where it's all through-composed. This is a very specific idea I had, which I think is very...honestly, I think it's a very conservative idea. I mean, we have a lot of "Getting classical players to improvise more," or we have a lot of "Improvisers playing very hard new music things that maybe some of them are qualified to do (very qualified), but some of them aren't." I think, with the improvisers and classical musicians, I think that's fine, and I encourage other composers to do it, but I'm not that interested in it. My feeling is that I've got these people who've spent their whole life learning to interpret notation I'm going to take full advantage of that, you know what I mean? And so, these pieces are conservative in the sense that they're not really breaking any boundaries, it's just that the concerto aspect of it is improvised. Instead of writing what the soloist is doing, it's improvised. 
And so, I have those two pieces. There is a piece, a string quartet, called Whispers, Hymns and a Murmur that Eyvind Kang is on, that he's the improviser on. And I've done a couple of other pieces like this, which is like - you know, I sort of have this new idea, or at least in the least ten years, I've sort of thought: "I don't want to call them classical musicians, I want to call them conservatory trained musicians." I mean, in other words, I'm going to work towards their skill set. And even that I got from Butch too, because one of the things that I noticed when I heard a lot of what I considered to be contemporary music that was influenced by improvised music (a lot of extended techniques and that kind of thing) is that the players were playing what the composer wanted, and it often wasn't in their comfort zone. And I remember going to see Mark Dresser play an improvised solo bass thing, and thinking "This sounds amazing," and two weeks later, I heard this contemporary music piece written for bass, that was a solo bass piece, and the bass player just looked miserable the whole time, you know... Whereas Mark spent thirty years developing his improvising language, which had just as many extended techniques, and was just as contorted in some ways, for the bass, but he was a master of it. And I thought about this years ago when I recorded with Frisell, I produced a record in Nashville (it was called Nashville, it's a nice record of his). And I thought, "You know, these guys who are playing in this recording session, they can't do all these other things that other people can do - but boy, do they do this really well," you know what I mean? And I started thinking about the idea of comfort zone.

And then I started thinking about Butch, that when Butch would do these Conductions with a lot of jazz musicians, a lot of times, he was unhappy. Because they would bring their jazz language to their assumptions about what's improvised. But he'd go to Europe and work with these young orchestras, or young chamber ensembles, and the music would be amazing. And I thought, "Well, sure." If they had been a very conservative orchestra, it probably would have been like pulling teeth. But these are all young men and women who have been playing Ligeti, who have been playing Schoenberg, who've been playing Stockhausen. And so, to them, as long as they're told that they're supposed to play, and when they are supposed to play, and these ideas that he would do with his hand signals, they had all this language. And yet, they were never told to jump to the certain place on the string, like they might've been told on a score, that was, like, really hard to do. Instead, they played what was in their comfort zone, even if it was very modern. And there was a reason that the music had such vibe and had such flow: because they weren't being asked to do anything that made them miserable - unless they hated the idea of improvising, but that's a 
different subject; I mean technically miserable, you know what I'm saying? And that extended technique thing can work both ways, you know, it can be brilliant, and it can totally come to bite you in the ass, as a composer. Because if the player hates what you're asking them to do, they're just not going to play your piece well. So anyway, back to what I've been trying to do, is if I have the Seattle Symphony, I'm just going to give them what they love to do. It's still going to be my music, I'm going to ask them to play my rhythms and my harmonic concept, but I'm not going to ask them to do stuff that they aren't thoroughly comfortable doing, and then I can leave the improvising to the improvisers. So, that's been something that's, you know, it's been on my plate for a little while, but this record's coming out with these two pieces, so it's very [similar] what's happening in both of them, you know.

JLS: Cool, so that's coming out soon?

WH: Any minute, I mean, a couple of weeks. It's on National Sawdust. National Sawdust is this performance space in Brooklyn, that does a lot of contemporary music, and they now have a label and they put out some things, and this guy Jeffrey Zeigler, who - I think he was in Kronos, I think pretty briefly actually, cellist. And he now runs the cello department at Mannes, and helps run the string department. And you know, he's a new music guy, and he's running this label, and he's real excited about it. So it's coming out, and I have a trio record that just came out, that's sort of they're coming out together. And that's completely the opposite: bass, drums, a lot of amplified piano, a lot of processed piano, and samples and stuff. So, two very different records.

JLS: Both on the same label?

WH: No, one came out right here on Songlines. And it came out - I mean, I got my copies like a week ago. The other one I haven't got copies of, but they're both being released officially in October.

JLS: Yeah. Great, well I look forward to checking those out - that's good timing for me, with the orchestra stuff.

WH: Do you write for large ensemble? 
JLS: Not that much, I've been writing for a ten-piece band (which I'd say is not super large) recently. And a few years back I've written big band works. But I'm going to be writing an orchestra piece - like, a short orchestra piece - probably later this year. So, yeah, it's something I'm working towards doing more of.

WH: And who's going to play it?

JLS: Well, we'll see (laughs). Probably the University orchestra will read it. And I'm going to see if I can submit it...there's a readings that you can submit to for the New Zealand Symphony Orchestra that you have to apply for, so I'll go for that. They're a very good orchestra, so we'll see. But that's definitely the hard thing, right? Like, you don't want to just write an orchestra piece and then not have anything happen with it ever.

WH: No, absolutely, no, it's tricky. My wife has just gotten two really good opportunities to write for orchestra that sort of came out of the blue, and so that's really exciting (she had written one smaller piece for orchestra). But it's also very daunting. My advice, particularly if a University Orchestra is going to read it, is that, you know, in the first place: don't put all your good ideas into one piece, you know, stick to one or two good ideas. And just dot your I's and cross your T's, because you'd just be amazed at how the stupidest question can take up five minutes of a rehearsal, and you just don't want that to happen, because you have so little rehearsal. So, you know, proofread, proofread, proofread - I mean, so much more than any other thing I've ever done. And I was proud, I was so proud when Ludovic Morlot, who's leaving the Seattle Symphony but he's been the conductor for the last eight or ten years, wrote me back and he basically said "I have three questions. In the oboe in measure 47, shouldn't that rhythm be written out the same way as the strings?" and two other things, you know. I mean, I was like "Yes!" The irony was that the first two or three weeks of writing that piece, my goal was to write a beautiful piece of music, but by the end, my only goal was to have no smart ass saying something stupid, you know (laughs). Classical musicians love to prove that you're incompetent. And I didn't get that - I mean, they just love it, they go, "What do you mean here?" you know, blah blah, blah. So just don't give them spend most of your energies in just not giving them that opportunity, you know? (laughs). It's a [huge] struggle. 
JLS: (laughs). Yeah, I'm learning more and more about the importance of the specificity of notation from my composition teacher, which is a real cultural difference between jazz and the classical scene.

WH: Yeah, so that goes back to when I did those big band pieces and Art Baron would say to me, "Do you want it like this or like this?" and I would say "I don't know, play it," you know? But because I had that opportunity then, I learned what those things meant and started to be able to do them. And by the way, I'll give you another piece of advice about that, which is that: do not be shy asking - I really learned this, boy did this help - You know, I told you the story about the woman who helped me with the slurring of that piece. But now, I still go to my friends whenever I have strings involved. I go to one friend of mine who's played a lot of my music. And she comes over, and she's a violist and a violin player and we slur it together. And I found out that Brahms had a violinist friend who slurred all his music for him. I mean, I don't mean just handed it to him, I mean they worked it out, you know. And she'll bring her instruments, and she'll say "Well, you know, Wayne, you could slur it both these ways." I mean, I'm good enough now that I could slur it without her, but I still wouldn't do it, because I want the best possible. I sent my first trumpet part to the first trumpet player in the Seattle Symphony. I emailed him, and I said to him "Can you please read through this part, I'll pay you as if I'm taking a lesson with you (I don't play trumpet, so there'd be no reason to take a lesson with you). Instead, let me pay you for what would be the equivalent of a trumpet lesson, for looking at this part." And you know what he did? He wrote back to me, and he not only said "You don't need to pay me," but he said, "You have no idea how few composers even bother to ask us." And instead of being insulted, that I should know, instead he was flattered. And also, he felt engaged. So, I would suggest showing every single part that you do to someone.

Man, I'm telling you, I've learned - I mean, I'm 63 - I've learned the hard way. Even ten years ago, I wouldn't have been qualified to do this. Even my Joe Hill piece - I mean, that was in pretty good shape, but I made a lot of mistakes. I'll tell you a brilliant thing I learned, you know, we were talking about polytonality. I had this really very beautiful moment towards the end of the piece where the strings are playing very simple, in a pentatonic scale. But the other instruments are doing things that don't relate to that tonality, at least in an obvious way. So, I had been using Logic you know the program Logic, the software program? - and I had been using it for notation too, 
which was really stupid. But, more importantly, I didn't check my enharmonics, which was a huge mistake. And, we're at the end of this recording session, I've raised all this money to do it, and we're down to just the strings, luckily. I had a nine-hour session, I had to add a tenth hour, which was going to cost me another $\$ 6000$, if it had been the whole orchestra, it would have cost me another $\$ 14000$, you know? I thought "I'll figure out how to get $\$ 6000$, we've got to finish this piece!" And so we're doing it, and it just isn't coming together. And the first violinists are playing this modal thing, and everybody else is playing this other kind of harmony. And finally, Misha, who's a friend of mine, said “Guys, it's all an E flat pentatonic scale, what we're doing. Don't worry about what they're doing." But I had written it out, and there would be E flats, but there would be $\mathrm{G}$ sharps instead of A flats. If I had written it out all the way it should've been written out, if I had had my enharmonics together, they would've known that immediately. And it's because the enharmonics were wrong, so even in this very polytonal context, if that Eb minor-ness wasn't in tune, even against this non Eb thing, it didn't speak, right? And I was like 'Never again am I not going to check my enharmonics backwards and forwards.” And it's huge. I mean, I still give E flat parts to big bands where there's a C double sharp because I didn't proofread it, but that's because I'm working fast. You know, and we're going to rehearse, and they're friends of mine. But if you're dealing with an orchestra, they're not your friends (laughs).

JLS: (laughs) Yeah. That's good advice. I will keep it in mind.

WH: Well, good luck with it all. That's exciting.

JLS: Yeah, well thanks so much for speaking with me.

WH: Thanks a lot, have a great day. 


\section{APPENDIX C: $1^{\text {ST }}$ INTERVIEW WITH NICOLE MITCHELL}

\section{Skype Interview, September 28, 2018}

Jasmine Lovell-Smith: Could you tell me a little bit about how you got started with composing music?

Nicole Mitchell: Sure. Composing didn't seem, necessarily, an obvious thing that I would do. It's not that I wrote a bunch of music as a child, or that I talked about wanting to compose, or that I was making up songs when I was playing my instrument. It's kind of weird - like, I didn't really do any of those things. I started composing really when I was a student at Oberlin, and I didn't start through taking a composition class or anything, I just started creating music and writing it down when I started the jazz major there and performing it with jazz students at the time. But it wasn't something, originally, that I thought of that I wanted to do. It was more something that I was just suddenly compelled to do, but I didn't necessarily have a warning leading up to it like "Oh yeah, this is what you're going to do." I think I definitely had the desire to have an outlet to express my full self, and so improvisation really invited that. And then when I started improvising, I started realizing that the formats that I was being given to improvise on were not the environments that I wanted to create in, so in order to have the environments I wanted to create in, I had to create new environments, through composing. So that's really how I came about composing. It was to satisfy the desire to be free as an improviser, to really express what I was trying to express.

JLS: Okay, that makes a lot of sense. And had your practice of improvisation developed much earlier than that, or was it also at Oberlin that you got really into improvisation?

NM: Well, first of all, I don't want you to make the assumption that I went to Oberlin and got a degree from Oberlin, because I didn't. I ended up leaving Oberlin. But improvisation really started when I was in San Diego as a student at UC San Diego before I transferred to Oberlin. I took a jazz class with Jimmy Cheatham, and that was really the beginning of me improvising, after trying to learn how to master my instrument. And then it was like starting over, now trying to improvise, you know. So, that happened a few years before going to Oberlin, and mostly I was playing on the street as an improviser, and then I had some experiences in the first ensemble that I was in, which 
was an Afrobeat band. But really my first experience improvising was in California, before going to Oberlin. I was very new at improvising when I transferred.

JLS: I noticed when I was reading about your biography that you studied in a few institutions, and you kind of moved around and ended up in Chicago, and you did a Master's degree, is that right? In Chicago.

NM: That's right.

JLS: So, how did all of the things that you studied lead you to where you were - or maybe they didn't lead in a linear way, or you were looking for something you didn't find -

NM: It definitely wasn't linear. I knew when I left California that music was supposed to be my life. I didn't know how it was going to work. I knew that the flute was central to my voice. I didn't know how that was going to work. And so, basically, I ended up leaving Oberlin and living in Chicago, and not going to school for a really long time, because I decided that school wasn't the place for me to grow as a musician. It was more that I needed to be a part of a community in order to grow the way I needed to grow. And school couldn't provide that. So that's why I had such a strange (laughs) kind of navigation, where I don't feel that what I learned as an improviser I learned at school. At all. But I think things have changed. I think that the way people teach now is very different from the way they were teaching when I was a student, and the things that I needed just didn't really exist back then in the University setting.

JLS: So was it through your association with the AACM in Chicago that you found that community that you needed to develop what you were doing as an improviser?

NM: Definitely, through the AACM, and also just a broader, very strong African American arts community in Chicago. I had lots of friends that were my age that I was running around with, that were writers and visual artists and filmmakers. They were people that had a vision and were really looking at this idea of what I, at that time, was calling "visionary work" - kind of embracing the past but looking towards the future. Now people would define that as Afrofuturism. At the time we didn't use that term. But I was very thankful and grateful to find a community. And also, the broader arts community in Chicago is a very strong infrastructure that supports the arts. Like, the Jazz Institute of Chicago is a really great organization, you know, and other organizations that I 
was a part of, that were related to the Black Arts Movement, outside of just the AACM. Like Third World Press (for example), where I worked for thirteen years. So, I really found a sense of connectedness with community, and also inspiration with other young artists to connect with. And so, that's really what I needed in order to develop as an artist, and I really couldn't, at that time you're talking about the late 80 s (laughs) early 90 s - I couldn't really find that in school, or in the schools that I was going to, you know.

JLS: Okay, and you started your own ensemble, the Black Earth Ensemble, twenty years ago?

NM: Yeah, in 1998.

JLS: So how was being a bandleader and bringing together your own ensemble important for your development of your compositional voice?

NM: Well, that was the thing. I was starting to perform with a lot of other groups, as a side person. But whenever I brought music to those groups, to say "Can you play one of my songs?" they were like, "No, why don't you start your own band?" And I kept getting that over and over again. And I especially got it from Hamid Drake, the drummer, who I was working with, and [saxophonist] David Boykin. A group that was really instrumental to me starting out, was the David Boykin Expanse. He (David) was like "Start your own group," and I was like "I guess if I'm going to hear this music, I'm going to have to start a band.” But I really was hesitant about taking on leadership at that time. I mean, I think it's been a gradual development. My development as a leader has been very gradual, and it wasn't this desire to be a bandleader, it was, like "I need to hear this music," which forced me to have to take leadership and put myself in that position to tell people what to do, which I really wasn't comfortable with, and it took a lot of courage and time to get that going, you know. But before starting my own group I was a part of Samana, which was an all-women's music collective, and that was for seven years that I was in that group. I didn't do anything else in music but that (Samana) for seven years. And so that was kind of the gestation period to develop my confidence in order to move forward and then start my own group.

JLS: Okay, so maybe we can talk a little about your [2009] Black Earth Strings album, Renegades. What was the impetus behind forming the Black Earth Strings, in terms of what possibilities did 
you see in that instrumentation, or those people, that were different from other things you had been doing, that you wanted to explore?

NM: Well, if you look at my very first recording, Vision Quest [2001], which was the first Black Earth Ensemble recording, the instrumentation is mostly strings. And what happened was that was this first CD I put it out, people didn't really know how to respond to it, because there weren't any "jazz" instruments. There was no piano. There was no trumpet. There was no saxophone. And so, people were like "Ok, this is kind of cool, but is this jazz? What is it?" And at that time, people, the way they responded to it, had a strange reaction at that time and I said "You know what? Let me change up this group and start adding some of these "jazz" instruments," and that's when I made Afrika Rising [2002]. And when I made Afrika Rising, I still missed that sound of the strings, so then I started Black Earth Strings so that I could continue writing music for that format. So, it wasn't that Black Earth Strings really came after, it was that Black Earth Strings was kind of the original concept of Black Earth Ensemble. But my seed idea of Black Earth Ensemble was that it be flexible, and that the instrumentation change and personnel change depending on the project. So with BEE at that time, I was, you know, looking at the traditional jazz instrumentation, and what could I do with that, because I really like challenging myself as a composer, so I wanted to be able to write for all these different types of formats. So then, Black Earth Strings started so that I could continue to write for that. And I love the idea of not having to play with a microphone, not have to be amplified - to have a more intimate sound where everything is exposed. And blending with the flute and strings is really a beautiful sound. And I really love, from my experience playing in orchestra - I still love that sound of playing with strings. So, you know, I thought I can bring these string instruments together and make them swing real hard - but not in the way other people have done it, you know, not in the sense of Uptown String Quartet or what some other people have done, but do it in my own way - so I wanted to use the strings to do that.

JLS: You mentioned playing in orchestra. So, were you playing in orchestra when you were growing up on the West Coast, or had you been still participating in those types of Western Art Music contexts in the intervening years?

NM: Yeah, well when I first started playing the flute, that was the only context that I knew the flute in, and so before I was introduced to improvisation, I thought that's what I was going to do, 
be an orchestral player. And I was very much encouraged to do that, when I was a student at UC San Diego. I was a part of the San Diego Youth Symphony, and I was also in the orchestra at UC San Diego, the community orchestra that UC San Diego still sponsors. And then, when I got turned on to improvisation I was like "What, why didn't anybody tell me I could do this?" So, then I kind of stepped away from that for a while. But then I came back to classical music. While I was living in Chicago, I was a member of Coleridge-Taylor Perkinson's New Black Repertory Ensemble, and for five years, I was a flutist in the Chicago Sinfonietta founded by Paul Freeman, which at that time was the second orchestra under the Chicago Symphony. And I also was a flutist in the Joffrey Ballet Orchestra. So, doing all of that repertoire was a lot of fun, especially the Ballet Orchestra, because I was piccolo player and doing Rite of Spring, and Cinderella and, you know, all of those classic composers. It was a lot of fun, doing that work.

JLS: It's interesting what you said about the acoustic, playing with Black Earth Strings and enjoying playing without a microphone, and things like that. So, did that ensemble perform in different types of contexts, where you really could perform fully acoustically?

NM: Oh yeah, all the time. And sometimes I would add drums - you notice on the recording I decided to add percussion. But most of the concerts we did were without drums. Sometimes I'd have drums, sometimes I wouldn't. That group hasn't really continued as much since I moved to California. Black Earth Ensemble has continued. Black Earth Strings has done a few concerts, but not as many.

JLS: Is that mostly for logistical reasons, to do with just being somewhere else, or just because your interests have gone in a different direction?

NM: Yeah, I think my interests are always changing (laughs).

JLS: And you've just made another album with a drummerless chamber quartet. I guess I'm interested in the ways you categorize your music. So, would you consider that there's a relationship between the music for Black Earth Strings and the music for Maroon Cloud, because they both have a kind of chamber-like instrumentation, or are they exploring very different things?

NM: I think they're exploring different things. When you are in the AACM you learn how to approach having different unusual configurations of instrumentation and how you can make music 
with any situation. And especially coming up in Chicago, there were many times that, you know, I would have a gig at the Velvet Lounge and maybe the bass player - maybe his bridge would break, or maybe the drummer wouldn't show up, or maybe something would happen, where the people that were supposed to show up, maybe they wouldn't be there. And I had to be prepared no matter what happened, even if I was the only person onstage, to be able to do the show. And that's a really encouraging kind of skill to attain, once you feel comfortable with whatever happens and the unpredictable, because that's how life is. And it helps you to be able to adjust. I like creating challenges for myself. I have another group that plays without drums here in California. We haven't recorded, but it has Billy Childs on piano, Mark Dresser on bass, and Dwight Trible on vocals, and myself. And we've done some concerts and that group is totally different from what Maroon Cloud did. So even not having drums doesn't mean it's going to have the same kind of sound, you know. In that particular project with Maroon Cloud, I was really focusing on that text, based on my writing for Arcana VIII, "What was Feared Lost” (2017). And this concept, you know, that I spoke of on the album. And how do I draw out this concept of, you know, honouring the mystery in life, and where our creativity comes from. That's a quiet place, so that sound was what I wanted. You know, I wanted a dark and quiet sound.

JLS: It seem that a lot of your projects have a conceptual basis or they are based on a text or a collaboration. Have you always incorporated influences from other art forms or interdisciplinarity in your work?

NM: Yeah, actually I would say that, from the beginning, there's always a narrative underlying every piece of music that I write. And I've been writing poetry probably longer than I've been making music. And so narrative, story, poetry, is directly related to the music, and in other situations it might be visual art or, like with the Octavia Butler work, someone else's fiction. Or a philosophy or a concept, like with Mandorla Awakening. I don't think that there's ever a time that I'm making music, that it's just about the sound. So, the audience may not know the other parts of it, but those sounds that they are hearing wouldn't have been able to be created without the other elements that are part of the composition process. 
JLS: So, it seems like the community that you were in in Chicago...I guess being part of a community of all different kinds of artists is a really necessary context for you to be able to do your work?

NM: I think it was necessary for my development - I think now, I think once you get going, you can be more independent and be anywhere. And of course, like, I draw inspiration from different locations and different communities that I'm involved in, definitely. But I think that when you're really developing your voice, it's really important to have those elements, whatever those things are for you, and for me, community was really important. Now, living in California, I don't have the same kind of community here, but I've still developed a practice in which I can create wherever I am. And I still also spend a lot of time in Chicago, and a lot of my premieres are in Chicago, or in New York. So, I feel more part of a global community now, but I also know where I come from, you know what I mean, I think that's important.

JLS: Who do you consider to be some of your important musical influences?

NM: Well James Newton is definitely a really important influence. He was the first person I heard improvising live, and he's a flutist. And he was someone in the room with me, that I could actually talk to, and it had a tremendous impact on me, those few minutes that I met him and heard him play. But, of course, there's recording artists, you know, that you listen to, that you've never met, that also have an impact on you. Like, for me, Eric Dolphy, I thought was the most awesome flutist ever. I've never met Hubert Laws, even though he's in L.A., but his music has definitely had an impact, because he's a great flutist. He's a great improviser. But then there's composers, like Muhal Richard Abrams, and then to be able to meet him, and be able to hear his music, and the same with George Lewis. Anthony Braxton, having the opportunity to have played some of his music, and played with him, and got to know him, and read his words - I mean, it's really incredibly impactful, you know. Wadada Leo Smith, the same thing. Like, when I look at Wadada's work, the idea that - to be so committed to create your own musical language, that's written down - wow. I mean, I feel I have my own improvisational language, but in terms of how my music is written down - you know, Wadada's really on another level of something completely individualized, and effective, and original. And that's a lot to come after, you know what I'm saying. Those are some big shoes to walk in. And the same with Roscoe Mitchell, because he never 
stops creating. Like, he's always, always working on something, and trying new things. So, how could I ever be discouraged, seeing these people do the work that they do?

But then there's also artists like Amina Claudine Myers, who I feel doesn't get the recognition she deserves. Geri Allen was a huge influence on me as a woman artist that I really idolized when I was younger, and then had the opportunity to meet, and then had a few times that I got to play with her, who really left us too soon. And then there's all the people that other people don't even know who they are, you know what I'm saying? (laughs) Like the other women who founded Samana Maia and Shanta Nurullah - who are still around, still creating music, and they don't necessarily get the kind of recognition, you know, for their work. And maybe they don't have the opportunities to do their work on a larger scale, but they're still out there doing it - and where would I be without those influences, you know? I mean, it's a big question.

JLS: Yeah, definitely. And when you think about how your music is disseminated into the world and finding a listening public, how do you feel about your relationship to the label of jazz? Do you feel like that's a useful term to describe your music, or not? Or maybe you have a more complicated set of emotions?

NM: I completely understand the struggle that people have had with embracing the identity of being a jazz musician, because if you look at a lot of our elder musicians and what they had to go through, and how they were being limited in what their possibilities are, just for being labelled as a jazz musician, and the lack of respect and opportunities that were presented to them for being labelled as a jazz musician, then, I mean, that's something that we have to always keep in mind. And yet, there's an amazing legacy that goes along with that word that I want to be connected to, that I feel that I am connected to. I mean, I don't want to disconnect from Sarah Vaughan and Ella Fitzgerald, and Charlie Parker. I mean, there's a direct relationship there with, you know, Duke Ellington, and Archie Shepp, and all these great musicians that have been put within that framework of being a jazz musician, like [Charles] Mingus and [Thelonious] Monk, you know. So, while a lot of people may not want to take on that identity, and they may take on the label of being a creative musician or they might say "I just play music," some people say "I play Black Music," you know, I identify with the word jazz, I don't squirm away from it. I think for people, for audiences, it's easier for them to navigate my music understanding that I'm a creative musician, 
because then they're not going to have expectations of a certain kind of thing; whereas if you say you're a jazz musician there's all these expectations that may not be fulfilled (laughs). So, that's, I guess, the complex way that I'm addressing that. It's not easy, straightforward for me to answer that question. But I'm definitely not, like, anti-jazz in terms of my identity. And then for some people, it was like, when my album Mandorla Awakening was given the rank of the number one jazz album [of 2017, by the] New York Times, that was a real ironic moment, because a lot of people would be like "This isn't jazz. How are you going to say this is the number one jazz album, and it's not even jazz," you know. So, that's kind of a perfect example of what I'm trying to explain.

JLS: So I know you've also written orchestra music, including your piece Flight for Freedom for Harriet Tubman?

NM: Yeah, and I also have another piece called Stealing Freedom in Broad Daylight, which was the first orchestra piece.

JLS: How did you approach writing for an orchestra, as compared to how you would approach writing for your own projects?

NM: Well, it's hard when you don't know the players, for me, because I like being able to hear the individuals that are playing. So, when writing for orchestra, that was the hardest thing, not knowing who these players are going to be, and not knowing what their gifts are, individually. But, other than that, I think I took a similar approach. I had narrative that I worked off of, to create the different sections, and when I listen to it, I can see that narrative playing out, even though I may not give it to the audience.

JLS: And what about just the amount of specificity required in terms of manipulating that number of people, and notation, and things like that. Was that something that was a big leap, or did you feel like you had done projects of a similar magnitude before?

NM: Yeah, I feel like even though it was a larger group, that it wasn't that much different, because I had written for fifteen musicians of all kinds of odd instrumentation in, you know, a lot of different ways. So, it wasn't that different. I mean, obviously it's an adjustment, especially looking at timbre. But also, from playing in the orchestra, that gave me the ability to hear what the orchestra 
sounds like, just from having the experience playing in the orchestra. I mean, in the flute section you're in the middle of the whole orchestra. You hear it all around you. So, when I'm writing music, I'm hearing it in my mind from my experience playing in it.

JLS: So, what are you interested in at the moment? What motivates you to do projects that bring together people from different musical communities and traditions?

NM: Well yeah, I've really been interested in collaboration, I feel that collaboration is how we can celebrate coexistence and celebrate difference. And the conversation of different languages in music is really exciting to me (which is what I did with the Mandorla Awakening project). But one thing I'm really interested in right now is playing around with some electronics, I've been doing some projects collaborating with other electronic artists and doing electronics myself, and that's been really exciting, recently. And I also have a lot of work that my mother has done. She passed in 1983, and so I would like to really finish the work that I wanted to do, celebrating her poetry and her visual art through my music, so I'm hoping to do that. And also continue with collaborations, like I have collaborations with musicians in Bamako, in Mali. I'm also working with musicians in Morocco. I'd like to continue those kinds of relationships. And, you know, just keep exploring.

JLS: And in your work as a teacher, what are some of the things you convey to students about creating their own music?

NM: Well, it's really important for me that I support their own voice, and their original ideas, and not push them outside of what's important to them. Because I think that was what was hard for me as a student, was that nobody was interested in actually supporting my own vision. I had a vision of what I wanted to do, and they were like "No, this is the cookie cutter, you're supposed to go through here," and I was like "No, I'm not doing that, bye." (laughs) So, I think now there's a lot more flexibility. There's programs [where] people actually can develop their own ideas, and I think that's really important for the future of the music, I think it's the most important thing. Because I think imagination is our greatest human resource.

JLS: How do you see the relationship between composition and improvisation for you, in your music? 
NM: I think they're definitely directly linked, but you're going to have different results. Like, if you are improvising, a lot of times, you can have discoveries that might get lost if you don't record them, or they might just be in that one moment, but with composition you have the opportunity to take some of those revelations and develop them, on a slower pace, and really kind of look at them and have a deeper understanding of what they are. And so, it's more reflective, you know, to do the composition. And also, with composition, you can think about all the possibilities of how human beings respond to sound, and you can really think about your intent of what you're trying to create. Whereas when you're improvising, you can have an intent, but you're also very much in the moment, in the environment, and that moment will have a lot to do with what's created.

JLS: Do you feel like you can be equally yourself in a context where everything is notated, like the orchestra - or actually, I don't know whether there was improvisation incorporated into your piece, Flight For Freedom? Was that a fully notated piece, or did it have an improvised aspect?

NM: It was mostly notated, but there was a cadenza, and there were spaces where I could improvise. I wrote it so that if someone wanted to be the solo flutist and they didn't improvise, they had enough to play that was written. But I had space for improvisation.

JLS: But the rest of the orchestra was playing fully notated material?

NM: Yes. I think it's a different experience for players, definitely, if you have improvisation or if you don't. But you can also create something that sounds improvised, that's not, for those that aren't comfortable improvising, which sometimes I have fun doing that. I mean, I think it's a positive experience for everyone to learn how to improvise and to have the experience.

JLS: Well, thank you so much for speaking with me! I really appreciate your time.

NM: Good luck!

END OF INTERVIEW 


\section{APPENDIX D: $2^{\mathrm{ND}}$ INTERVIEW WITH NICOLE MITCHELL}

\section{In-person Interview, New Smyrna Beach, FL July 10, 2019}

Jasmine Lovell-Smith: So, I just want to start by asking you a general question about genre in your music. Can you tell me a little bit about how genre relates to the range of projects that you do, ranging from Black Earth Ensemble, Black Earth Strings, to orchestral and chamber works?

Nicole Mitchell: Sure. I don't really think about genre, in terms of creating music. But I do maintain an awareness of it, because I know that different circles might ask me to make music and have certain expectations. The most confusing thing for me is if a classical organization asks me to write something, but they're assuming it's going to be jazz, that's probably the most confusing thing to me. Because I do write through-composed music, and I do have a lot of aesthetics that I explore. And so, when they make assumptions that it's going to have drum set, or it's going to be a certain kind of way, like some other things that maybe I've recorded, it can get a little confusing.

So, the genre thing, I think, is dissolving more than it has in the past, because of the online way that we experience music, the fact that you can access music from all over the world, and from all different kinds of scenes and cultures, like, really easily. And so, I embrace a lot of genres, that's the way I deal with it. I look at, say (for example) new music, or "classical music," I definitely have had a lot of experience in that realm - you know, I played in two orchestras for five years in Chicago, like the Joffrey Ballet Orchestra, the Chicago Sinfonietta, and then playing the traditional rep most of the time, in those situations. And then, also, composing, I'm always trying new things, and trying to see how much I can get people to stretch their comfort zones in the classical realm, which can be fun, but also challenging for everybody (laughs).

And then I would say that most of my identity has centred within the jazz realm. I mean, I think when people know me or know of my work, they're going to be thinking about me playing as an improviser in jazz, on the flute. But they'll also think about me being a bandleader in what is normally classified as jazz music...but is also classified as creative music...it is also just classified as improvised music, depending on who's classifying (laughs). I don't have a problem with being identified as a jazz musician. I mean, I connect and enjoy that connection to the legacy 
of great musicians that I feel that I'm continuing their journey in my own work. But I also like the term creative music because it opens audiences up to not have expectation of something to sound a certain way, and more to have the expectation of surprise. And then again, I like collaborating with musicians that play what would be called "world music." So, I also collaborate and improvise in contexts that might be, like, Malian, or in some cases Afrobeat, or playing with Taiko drums or, you know, you could find me pretty much anywhere (laughs). And I enjoy the inspiration and the challenge of doing that. So, I don't know if I really directly answered your question, but I tried.

JLS: (laughs) Yeah, there was a lot in there. So, you mentioned when writing that sometimes people have an expectation in one circle that you would do something from another sphere, like your example of the new music ensemble that commissioned you and thought you were going to write jazz. And then you said that you have a lot of aesthetics that you draw from. So, what is the relationship between your work and the western classical tradition, or "new music"? Are there specific composers in that tradition that you feel have been a big influence for you?

NM: Definitely. I mean, I think one of my favourite composers that's living is Kaija Saariaho. And I've never met her, but everything she's written, I like (laughs). And I don't think people would necessarily listen to my music and hear that influence, but I've listened to her music a lot, and I've thought about it a lot. And I feel that it's very organic, and it connects to her experience, and her interest in nature, and ....yeah, like I said, even though people might not hear that influence, I think that's a big influence on my work. There's a lot of AACM composers that have written for new music, like George Lewis and Roscoe Mitchell, Muhal Richard Abrams, Leroy Jenkins, and they've definitely had an influence as well, seeing how they translate improvisational concepts into through-composition, what their approaches are, and how they successfully manifest that, that's really been influential to me, also.

There's always new influences that would influence my new music writing that might not be new music, you know what I mean. Like, listening to Oumou Sangaré, or I'm really interested in Sudan Archives, which is this really young producer, I guess, that's in Los Angeles now. So, there's all these other influences too. And then, sometimes I just try to look at what I'm doing with improvisers and see, is there another way that I could write this, that it would have, like, a parallel sonic world or effect for through-composition? Like, you know, we've been talking a lot [during 
this residency at ACA] about this idea of colliding or, like, repeating or rotating ideas in these pods that collide against each other, and, you know, I think I really started developing that when I did the Xenogenesis [Suite]. But I've tried to do that with classical musicians, which can be confusing, because when they see the score, it's not all measure by measure. And so, for someone to try to look at the score and try to get it to work, it can be....different, because one group of musicians is in one time, and the other group of musicians is in another, and they have to decide when to come in and, you know, it can be... (laughs) You kind of have to be there, to help them figure that out. But I'm definitely not finished with trying to do that, and seeing what other possibilities there are. I'm also interested in writing for, like, smaller...just piano solo or two instruments, so that they can kind of just do it on their own.

JLS: I saw a video of a piece you did for International Contemporary Ensemble...

NM: That was like that.

JLS: That's what I was wondering - like, what was going on in that piece?

NM: That's called "Inescapable Spiral," and that piece is actually about 25 or 30 short pieces that could be played independently, they're like, between 30 seconds and two minutes long, each piece. And with flexible instrumentation. But it's designed to be....like, the group can decide on what the order of these pieces is. And then, they're supposed to collide against each other, that's the whole point is that there'll be a time where you only hear that one piece, but there'll be other times where they're overlapping with other things. So, this idea of overlapping is something I'm really interested in. I'm interested in it philosophically, like when I talk about Mandorla Awakening and this idea of why don't we find, like, the greatest wisdom from each culture and bring those together and overlap them in order to recreate a better reality, versus this idea that only European culture is the best and let's not listen to anybody else. Like, it's not getting us anywhere doing that (laughs). Obviously, every single society has strengths and weaknesses, why don't we draw on the strengths of everyone and come up with some new ideas? You know, so this idea of overlapping different languages and concepts, literally colliding them is something that I'm interested in it playing out in a lot of different ways, not just musically. But it's something that I would like to see people try in a lot of different ways. 
JLS: Yeah, that's really interesting, because it's kind of clear conceptually but also musically that you're exploring that. What are the practical realities that you have to confront when you explore that? Like, I've read that you'll use musicians in your ensemble who have never improvised before and get them to improvise, or you'll make ensembles with people from totally different communities who have never played together before. I guess, what are the challenges, but then also what's the benefit?

NM: I think we've experienced some of the challenges here [at ACA] where I don't feel we totally succeeded with the improvisation, where people didn't bring their whole self. I guess a lot of it has to do with the environment encouraging and maybe even pushing you past your comfort zone, where, in your own head, you've segregated these different things that you do, and you're like "that's not the time and place for this," and you're, like, policing yourself. (laughs) We do it to ourselves, like "well, this wouldn't be appropriate in this situation, so let me do what's appropriate." That's not really interesting to me. Like, I think it's more interesting to have someone do something that completely is another world, and everyone else kind of has to navigate what that is and find a way to make meaningful interaction with that, you know what I mean. And that's how we can learn. But if people don't bring it, then everybody loses out. The person loses out if they don't bring it, because they're not being their whole self, and then the other people lose out because they didn't get the opportunity to be challenged and to learn more about themselves in navigating this thing that they're not used to, you know what I mean. And, to me, that's a great metaphor for diversity, and how I feel that we should approach diversity... and to not expect people to, you know, get into this uniformity thing. I think the whole uniformity thing, it's definitely been a way for a historical.....if we look at how societies have developed, there's been a lot of that. You know, and this idea of one idea being better than another one, and really holding onto that. In some cases, something might be more effective. Like, drinking filtered water versus drinking tap water: It's going to be more healthy to drink filtered water. But, there's other things that...it's okay, there's no better or worse. Like, if somebody likes strawberry and somebody likes chocolate, it's like, okay well, what's wrong with that, why do we got to fight over it, you know what I mean? (laughs)

JLS: Yeah. That's kind of revolutionary though, in my brain, in terms of thinking about doing one musical thing in a totally different musical context...it's exciting. I'm just thinking about how I 
police my writing in the context of the University composition doctorate, and trying to think "what do they want me to do?"

NM: Yeah, and that's actually a very important point, because that's exactly what I try to get students to not do, in my program. Like, when I was at UC Irvine, which I just literally departed, I really was rigorous in trying to get students to not do that to themselves, because each one of them has their own principles that are inherent to their expression. And they may be completely different from the principles of the faculty and their musical aesthetics, or whatever. That doesn't make it wrong or bad. And the whole point of that program, of ICIT, is about creating original music that is breaking grounds and doing new things, so why squelch that, you know what I'm saying? Of course, there's plenty of other programs that are very traditional and have these expectations that are set up aesthetically. Like, some programs focus on this particular type of composition. And if you come there, it's because you want to do that particular type of composition. Which is fine, it's just that I wouldn't want to teach in that program (laughs). But for someone else it could be great. It's just not how I'm put together - it's not my role, my role is more to instigate (laughs).

JLS: So, when you bring these different people together, or you bring people to these different ways of making music, are there flow-on consequences from that? Are there things that come out of that that generate more things, maybe even beyond you, that they go on to do?

NM: You know, that's a good thing, because sometimes I'll make individual musicians in my compositions, I'll make them approach their instrument in a way that maybe they haven't done. And then I see them continuing that in their own practice, because now it's another part of their language that they can utilize, and I love it when that happens! And sometimes it does take someone else to push you in another direction. You're going to have your own comfort zone and your own interests, but that's not your whole potential. You know, you might get stretched by someone else - I was thinking about, like, Louis Armstrong, he was in Chicago and he was doing great with King Oliver, but then he went to New York to work with Fletcher Henderson, and that's where he learned how to read - like, they were kicking his ass. And he had to really step up his technique and his reading skills, and then when he came back to Chicago later in life, he became the famous Louis Armstrong, but it took other people pushing him. Like "Yeah, you're super 
talented, but, like...this is sloppy" and whatever, you know what I mean. And so, I think that's what programs try to do, or what they think they're doing, but it's a fine line between pushing someone to reach towards their greatest potential, and putting them in a box, you know. So, you have to kind of know what the difference is (laughs).

JLS: Yeah, for sure. So, I guess I'm thinking about one of the ideas that I've come across at University, which maybe is a bit outdated at the moment, but is this idea of art music, versus folk music or popular music -

NM: High and low art? (laughs).

JLS: Yeah, high and low art. How do you think your work interacts with those sorts of ideas (or doesn't)?

NM: I think it embraces all of it (laughs). I mean, I think that when I do my improvisations, like, solo, that there's a lot of folk in that, you know. Just, like, simple melodies, and all the time I spent playing on the street, just creating melodies, and this idea of writing songs that are singable, and things like that. To me, that's like getting at the core of being human - like, why throw that away, you know what I mean? But then, also, I love this idea of challenging myself, and challenging other people, and doing things like this idea of going to the moon, like Star Trek, to go where no person has gone before. You know, to find what those boundaries are, to try to push against them - that's exciting too. Like, I was thinking about the Art Ensemble...the trumpet player, Lester Bowie, wearing a lab coat. You know what I mean, like, he's a scientist. Using music, like "Well, what other sounds can we make, and [how] other ways can we impact people with sound?" Like, taking that attitude, and at the same time taking the "for the people attitude," you know what I mean, and just going in both directions as far as you can go. I think that it gets messed up when people....I mean, the whole idea of high/low is hierarchy and high being more respected, and it literately translates into more money. Like, I think that with a lot of the publishing societies, that if you put that your song was classical versus putting that it was jazz you're actually going to make less royalties if you say jazz. So it's literally, there is a hierarchy that's been created. Just like this whole racial hierarchy, it's really an illusion, it's like this whole thing of different races, it's not real. But it was fabricated and it goes into action, and it affects people's lives, you know. And it's the same thing with this whole high and low art thing, it's like - all art is, you know....I think 
when you look at different cultures you can't say that the art of this culture is lower than the art of this culture. You know, they are both serving the culture and the society that they are created in, and for, and how are you going to judge like, what level of how deserving it is. You know, it's just wrong. But our universities perpetuate those ideas, in a lot of ways, you know. I mean, what's being taught? Like, in music, classical music is number one, a lot of times we do now have jazz programs, but they are taught in a very narrow way - like, only this idea of, you know, up to 1950, in a lot of situations. And not taught...we're not really learning about the music in the philosophical ways. Like, the musicians were always thinking about different ideas. They weren't just thinking about techniques, or this is how you make a pattern to fit into this chord, you know. It's like, all musicians are thinking about ideas, and about having an impact in some kind of way on their audience, whoever the audience is. But we don't talk about that enough, I don't think.

JLS: Something I like about your music is that it's really about things, and you say what it's about, and it's kind of different from, sometimes, music in contemporary jazz or contemporary classical contexts...

NM: Yeah, "I wrote this tune..." (laughs)

JLS: (laughs) Yeah, you give it an obscure name...

NM: Yeah, "Sunday afternoon..."

JLS: What you are talking about, about musician's aesthetics, is that something that you came in touch with at a particular point in your development? Like, when you were working with musicians and finding out the underpinnings of their music? Or was that always there for you, like you intuitively made music about things?

NM: I mean, that's a good question. I know that all my titles have always been pretty colourful, even if they weren't about "social justice" or something like that, it could've been like....You know, like I played that song "February," or, you know (laughs) "Sun Cycle," or "the Creator has Other Plans for me" (I'm thinking of titles)... Vision Quest...I mean, that was my first album, Vision Quest, so I guess...I was writing poetry before I was playing music, I think that they're very intertwined, the idea of narrative and music, and a lot of times I have a story for each song, even if I don't really share it with the audience. You know, like I have a song called "Cause and 
Effect," but my dad, like, he was super into Spock (laughs). And he would always be saying that all the time. Like, if something went wrong, or if something happened, he' $\mathrm{d}$ be like "cause and effect, cause and effect," you know. And so, it was really me kind of... remembering him and ruminating on him, in a funny way, but nobody would know that, from the song. And it's not like the song sounds like cause and effect. But it's still kind of....the narrative is informing what I write. And sometimes I will write intuitively and make a title later. But it's definitely very connected for me. I know that's not necessarily the case for other people.

JLS: And with artists that you've worked with in the AACM, or in your wider Chicago arts communities, were you taking about all those kinds of ideas a lot, about aesthetics and philosophical -

NM: Yeah, I mean, the thing with the AACM that I always try to help people understand that are not in the AACM is that it's not a specific aesthetic. People make the assumption that "Oh, it's free jazz" or "Oh, it's all about this weird stuff inspired by Stockhausen (laughs) or John Cage or something." You know, people try to put it in this box, but I always try to bring home the point, it's like actually, no, it's just about making original music. I mean, Edward Wilkerson Jr., for example, sounds like Ellington reincarnated. Or, like, Ernest Dawkins...his music has that R\&B, soulful kind of sound, you know. And some people would think of it as more, like, traditional straight-ahead. Every AACM member and every album that an AACM member makes, it's really its own thing. I mean, Fred Anderson, you know, is like this saxophonist that mostly would get on stage with free improvisation with a trio, with bass and drums. Actually, his biggest inspiration was Charlie Parker, and he was trying to play his own Charlie Parker-esque kind of language, but improvised, more in an Ornette kind of fashion, and then people called it free jazz, you know, so everybody's different. And aesthetically, that's something that I understood and I saw with all the AACM members, this idea that you can just do your own thing, and that's really what it's about. But it also is about knowing the tradition, being able to play the changes, having a strong foundation, and also exploring, so I think that's part that people take for granted with the AACM, because I see other younger musicians now that just play free, and they don't necessarily have any link or understanding of the history, or how to navigate in those contexts. But that's not really how AACM musicians developed. They really were interested in understanding....it's like the Art 
Ensemble's motto "ancient to future." Like, to have a way to express the history and go into breaking boundaries. So that's something I think people don't talk about so much.

JLS: Yeah. Another thing I wanted to ask you about is about performance contexts for your work. So, how have you navigated figuring out where and how your music is best presented?

NM: Performance contexts - well, that's something that you're always working on as a musician, I don't think you ever stop. Like, for example, when I was starting out, playing at the Velvet Lounge every month was my home base. And that performance context was very community based, and also very economically difficult (laughs). You know what I mean, it was a door gig, and we don't know how many people are going to show up, and you make what you make, and you've got to pay the band. So, that was a performance context that had its pluses and its minuses, and I think every performance context has that, even if it's, like, Carnegie Hall or the Kennedy Center. Because, when you get into those performance contexts that are super great and beautiful, and great acoustics, and the people treat you right, and all that, then it's like: who gets to actually come to the concert? (laughs). You know, they've got to pay a bunch of money to come see you. So I like to be flexible...like, to actually play in different contexts and not just have the goal of this specific one or a specific kind of environment to play in. Because I like being accessible, I don't like the idea of not being accessible. What I've been more concerned about is educational contexts. Like, how accessible am I to anyone to wants to learn from me. The fact that I was at UC Irvine and, [in] the time that I was there, there was not one Black student in the program that I taught in for, like, seven years. And the fact that the school itself only had 2.7 percent Black students in the university - there's something wrong with that, I mean, the population of California is 8-10 percent Black. So, when you have diversity of everyone else, like, every other population of people of colour, except for Black students, it's kind of weird. And also because of my schedule performing and traveling, and then, this being in Orange County, [there's] not a lot of possibility for trying to expand your accessibility in the community. So, that's part of the reason why I'm very excited about going to the University of Pittsburgh, because at least the actual community that the University is seated in is very diverse. So I can make myself accessible. If things aren't as open in the university, at least I am there in a community where I can connect with a very diverse population of students or young people, or whoever wants to work with me, and I think that's important. 
JLS: Yeah. Thinking about being a performer and composer, and specifically being an improviser, how does your practice as an improviser impact your composing? Are they both equally important to you as part of your musical identity? How do they interact?

NM: Definitely. They're definitely both hand in hand, I think. When I compose, I'm creating environments that are fun to improvise in. I mean, that was what motivated me to compose, because when I discovered improvisation, I didn't really like a lot of the songs that I had to do a solo in, it just felt awkward or not really what I wanted to do, the way things were set up. Which, sometimes, it's not just the song and the melody of the song, and not even just the changes, but the way those changes are to be played, and, rhythmically, or the way the whole thing is set up, the design of the foundation that you're supposed to improvise on. So the idea of writing your own songs, writing your own composition, you can create anything you want. And so if you're hearing something that you want to improvise, or that expanded to hearing other instruments and wanting to hear them do different things that maybe I wasn't hearing in other contexts. And so, it's like being a playwright and being an actress, and there's certain things you want to do in your acting, but all these plays you're being offered are nothing close to what you want to do on stage. So, write your own play! Or nobody's hiring you, that's another thing. Because, as a flute player, when I was starting out in Chicago, people didn't call me! (laughs) Who needs a flute player, you know what I mean? They need a saxophone, they need a trumpet. And it'd always be like "do you play sax too?" and I'm like "no," and then it's like "well, do you sing?" and I'm like "no, not really." So, I mean, it wasn't that many opportunities for me to play, so I had to create them. But then, that makes you stronger, when you have to do for yourself. So that was the motivation for composing. And then to realize that I'm composing, but then my improvisations are pretty different from my compositions. What would it sound like to bring in the way that I improvise more into the compositions that I'm making? You know, so there's just so many things to play with. To me, it's just a big playground, I mean, there's just so many things to try. The relationship between those two things is really...they feed each other.

JLS: Yeah. I know you compose - well we talked about that piece for the International Contemporary Ensemble, so you sometimes compose for contexts where you are not the performer. And was that strange when you first started doing that, writing music not for yourself? 
NM: Yeah. I think the first experience that was really scary was when I did a reading for the American Composers Orchestra. It was a reading for jazz composers and I was, like, sitting there listening to them. And I felt like...they were playing the right notes, but they weren't...the fact that I couldn't fix it, because it's on the stage happening and there's nothing I can do...and the kind of detail that you have to write to get.... and even when you do the detail, to get the way of approaching the phrasing, and even the time, is so hard, you know what I mean. And this idea of working with an improvised ensemble, and the kind of connection you have with them, and the gesturing and the communication and, like, stuff that really the written music can't fully do. And the thing is with classical music it's the same thing, it's just that we already have this huge tradition of knowing what to do with what we're looking at. It's not that it explains everything either, it's not like the written classical music has the end all, be all of how to play it, it's just that we already are trained to hear it a certain way when we're looking at it, you know. And, when you're doing something new, there's no reference point (laughs). So that can make it challenging. And the other part is the performance practice of new music ensembles really not being as invested in rehearsal as improvising groups, because of the hierarchical structure of money, and how much it costs, per minute (laughs), for rehearsal. So, how do you actually have the time to make a breakthrough if people don't have time to actually learn something new, it's like you have to give them something they're already familiar with in order to do it well, but then how do you break anything? You know what I mean, so that's the challenge.

JLS: That's interesting, because I can relate to some of that in some of the experiences I've had, and it seems like, is there a way that the ways of learning music could also cross pollinate more?

NM: Exactly, I think that's the challenge. I guess it would have to work with younger musicians that are willing to put the time in and have a transformative experience, and then they would be the ones to transform the music, because then they could be equipped to be the new wave of new music people that embrace improvisation. And we're seen some of that, and I think that's really the only way it really works. So I think that chamber ensembles, smaller groups, tend to have a lot more potential than, like, a big orchestra, which is like a machine, you know. I love the orchestra, and I'm really happy I had the experience I had playing in the middle of it, as a piccolo player. It's just a very complex thing to set up... Not that I wouldn't want to write more for orchestra, but it's 
definitely more of a rare experience, and maybe I'm not - maybe I'm better suited for working with chamber ensembles.

JLS: With that piece you mentioned for International Contemporary Ensemble, did you have to be there in person to work with them on that?

NM: We had a few rehearsals together, which was nice, you know. We had two rehearsals together. And then they played it several times without me, which was nice. And sometimes they even did it with student ensembles, like a mixture of them and students, because I tried to make it flexible. So, yeah, it was positive.

JLS: Cool, well I guess we're out of time (laughs).

NM: Oh yeah? (laughs)

JLS: That was really great, thanks for doing it.

NM: I'm glad we got to actually meet, and I'm so glad you were here.

JLS: Me too.

END OF INTERVIEW 